\title{
Assessment of Energy Production Potential from Ocean Currents along the United States Coastline
}

\author{
Final Project Report \\ September 15, 2013
}

Georgia Tech Research Corporation Award Number: DE-EE0002661 


\section{Project Title: Assessment of Energy Production Potential from Ocean Currents along the United States Coastline}

\section{Recipient: Georgia Tech Research Corporation Award Number: DE-EE0002661}

\section{Working Partners:}

PI: Dr. Kevin A. Haas - Georgia Institute of Technology, School of Civil and Environmental Engineering, khaas@gatech.edu

Co-PI: Dr. Hermann M. Fritz - Georgia Institute of Technology, School of Civil and Environmental Engineering,fritz@gatech.edu

Co-PI: Dr. Steven P. French - Georgia Institute of Technology, Center for Geographic Information Systems, steven.french@coa.gatech.edu

Co-PI: Dr. Vincent S. Neary - Oak Ridge National Laboratory, Environmental Sciences Division, nearyvs@ornl.gov

\section{Acknowledgments:}

Georgia Tech's contributions to this report were funded by the Wind \& Water Power Program, Office of Energy Efficiency and Renewable Energy of the U.S. Department of Energy under Contract No. DEEE0002661. The authors are solely responsible for any omissions or errors contained herein.

This report was prepared as an account of work sponsored by an agency of the United States government. Neither the United States government nor any agency thereof, nor any of their employees, makes any warranty, express or implied, or assumes any legal liability or responsibility for the accuracy, completeness, or usefulness of any information, apparatus, product, or process disclosed, or represents that its use would not infringe privately owned rights. Reference herein to any specific commercial product, process, or service by trade name, trademark, manufacturer, or otherwise does not necessarily constitute or imply its endorsement, recommendation, or favoring by the United States government or any agency thereof. The views and opinions of authors expressed herein do not necessarily state or reflect those of the United States government or any agency thereof. 


\section{Table of Contents}

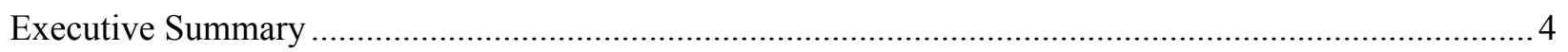

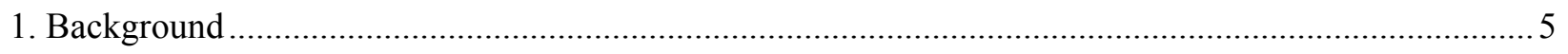

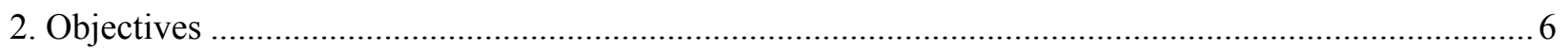

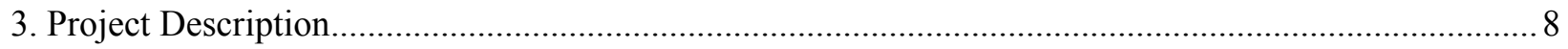

3.1. Ocean Current Energy Resource Database ……………………………………………………. 8

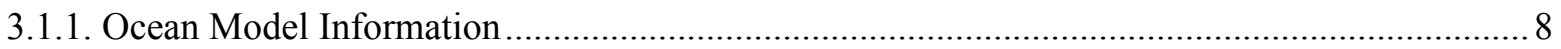

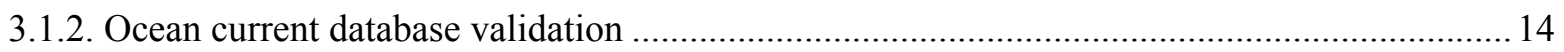

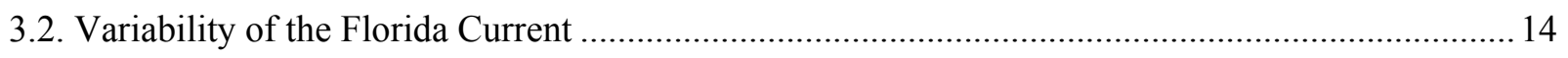

3.2.1. Spatial and temporal variability in the Florida Current ………………………………..... 15

3.2.2. Variation of kinetic energy flux in the Florida Current ………………………………...... 16

3.2.3. Estimating 30 years of kinetic energy flux …………...................................................... 18

3.3. Total Extractable Power from the Gulf Stream System..............................................................22

3.3.1. Analytical estimate of power potential from the Gulf Stream system .....................................22

3.3.1.1. Simplified ocean circulation model .........................................................................22

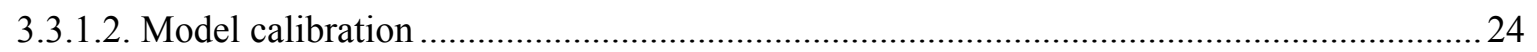

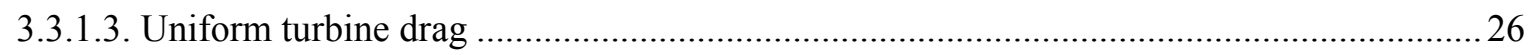

3.3.1.4. Localized turbine drag ................................................................................. 30

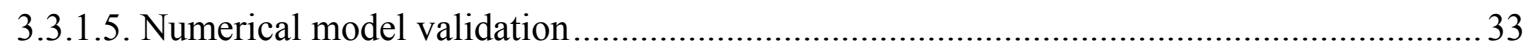

3.3.1.6. Total energy dissipation by localized turbines................................................................ 34

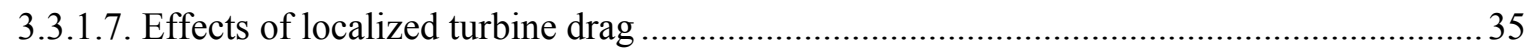

3.3.2. Total available power from undisturbed power density ......................................................... 41

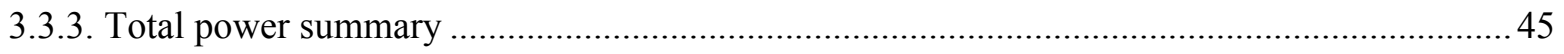

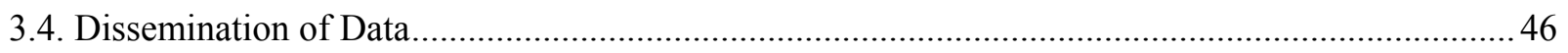

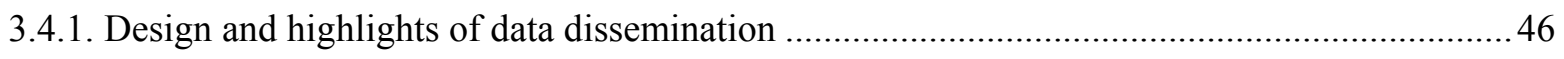

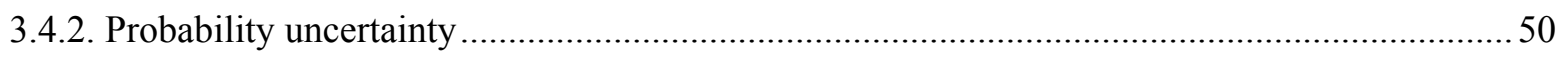

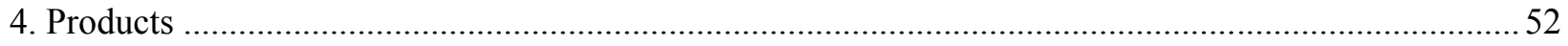

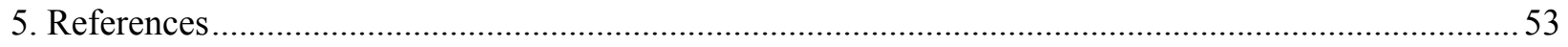

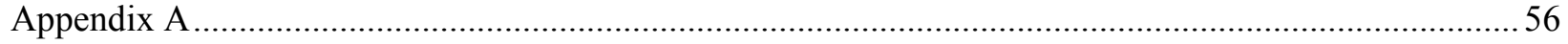




\section{Executive Summary}

Increasing energy consumption and depleting reserves of fossil fuels have resulted in growing interest in alternative renewable energy from the ocean. Ocean currents are an alternative source of clean energy due to their inherent reliability, persistence and sustainability. General ocean circulations exist in the form of large rotating ocean gyres, and feature extremely rapid current flow in the western boundaries due to the Coriolis Effect. The Gulf Stream system is formed by the western boundary current of the North Atlantic Ocean that flows along the east coastline of the United States, and therefore is of particular interest as a potential energy resource for the United States.

This project created a national database of ocean current energy resources to help advance awareness and market penetration in ocean current energy resource assessment. The database, consisting of joint velocity magnitude and direction probability histograms, was created from data created by seven years of numerical model simulations. The accuracy of the database was evaluated by ORNL's independent validation effort documented in a separate report.

Estimates of the total theoretical power resource contained in the ocean currents were calculated utilizing two separate approaches. Firstly, the theoretical energy balance in the Gulf Stream system was examined using the two-dimensional ocean circulation equations based on the assumptions of the Stommel model for subtropical gyres with the quasi-geostrophic balance between pressure gradient, Coriolis force, wind stress and friction driving the circulation. Parameters including water depth, natural dissipation rate and wind stress are calibrated in the model so that the model can reproduce reasonable flow properties including volume flux and energy flux. To represent flow dissipation due to turbines additional turbine drag coefficient is formulated and included in the model. Secondly, to determine the reasonableness of the total power estimates from the Stommel model and to help determine the size and capacity of arrays necessary to extract the maximum theoretical power, further estimates of the available power based on the distribution of the kinetic power density in the undisturbed flow was completed. This used estimates of the device spacing and scaling to sum up the total power that the devices would produce.

The analysis has shown that considering extraction over a region comprised of the Florida Current portion of the Gulf Stream system, the average power dissipated ranges between 4-6 GW with a mean around 5.1 GW. This corresponds to an average of approximately $45 \mathrm{TWh} / \mathrm{yr}$. However, if the extraction area comprises the entire portion of the Gulf Stream within 200 miles of the US coastline from Florida to North Carolina, the average power dissipated becomes $18.6 \mathrm{GW}$ or $163 \mathrm{TWh} / \mathrm{yr}$.

A web based GIS interface, http://www.oceancurrentpower.gatech.edu/, was developed for dissemination of the data. The website includes GIS layers of monthly and yearly mean ocean current velocity and power density for ocean currents along the entire coastline of the United States, as well as joint and marginal probability histograms for current velocities at a horizontal resolution of 4-7 km with 10-25 bins over depth. Various tools are provided for viewing, identifying, filtering and downloading the data. 


\section{Background}

Ocean currents are the continuous flow of ocean water in certain directions. However, ocean currents can vary greatly in terms of their dominating driving forces, spatial locations, and temporal and spatial scales. The major driving forces for large scale currents $(\mathrm{O}(1000 \mathrm{~km})$ length-scale) include Earth's rotation (or Coriolis), gravity, wind stress, temperature and salinity differences (or density differences, to be exact). Besides these, meso-scale $(\mathrm{O}(100 \mathrm{~km})$ length-scale) ocean currents can also be driven by tides, river discharge, pressure gradients (generated by sea surface slope setup by coastal long waves, for example), and bottom friction. Among these forcings, excluding Coriolis and gravity (which are constant in time), only astronomical tidal forcing is deterministic, and thus allows for accurate forecasting. However, since the project is designed for non-tidally driven ocean currents, we only consider the non-deterministic forcings, among which the most important are wind and density differences. Therefore, this project takes a probabilistic approach to defining the ocean currents.

Surface ocean currents are generally wind driven and develop their typical clockwise spirals in the northern hemisphere and counter-clockwise rotation in the southern hemisphere because of the imposed wind stresses. The Gulf Stream system is an example of wind driven currents in northern hemisphere, which is intensified at the western boundary of the Atlantic Ocean. Beginning in the Caribbean and ending in the northern North Atlantic, the Gulf Stream System is one of the world's most intensely studied current systems. On average, the Gulf Stream is $90 \mathrm{~km}$ wide and $800 \mathrm{~m}$ to $1,200 \mathrm{~m}$ deep. The current velocity is fastest near the surface, with the maximum speed typically about $2.5 \mathrm{~m} / \mathrm{s}$ (Stommel 1965; Richardson, 1985; Fratantoni 2001). The variability of the Gulf Stream occurs on multiple time scales, from seasonal, stronger in the Fall and weaker in the Spring (Kelly and Gille 1990; Zlotnicki 1991), to weeks, shedding of gyres (Hogg and Johns 1995). Fortunately, stronger meandering occurs primarily downstream of Cape Hatteras, where the Gulf Stream is located further offshore.

An ocean current energy converter extracts and converts the mechanical energy in the current into a transmittable energy form. A variety of conversion devices are currently being proposed or are under active development, from a water turbine similar to a scaled wind turbine, driving a generator via a gearbox, to an oscillating hydrofoil which drives a hydraulic motor. The available in-stream power per unit area, or power density, is calculated using the equation

$$
P_{\text {stream }}=\frac{1}{2} \cdot \rho \cdot V^{3}
$$

where $\rho$ is the density of water and $\mathrm{V}$ is the magnitude of the velocity. This represents the power available at the individual device level. In order to estimate the total power available for extraction from the entire current system, the feedback from extraction onto the flow must be incorporated. 


\section{Objectives}

The specific project objectives are as follows:

1. Host an ocean currents workshop to assess and revise the project methodology.

2. Develop the ocean current energy resource potential database.

- Use data to determine which model worked best for different regions.

- Create joint velocity and direction probability distributions.

3. Develop a web based interface and GIS tools for dissemination of the data.

- Display GIS layers of the velocity and power.

- Provide probability distributions for the velocity and direction.

4. Perform an independent validation of the database.

5. Compute the total theoretical available power.

\section{Task 1.0 Ocean Current Workshop and End User Feedback}

A workshop of leading experts on ocean currents was convened. The intent of the workshop was to review and revise the proposed methodology for assessing the ocean currents to ensure the quality of the ocean current database meets the highest state-of-the-art standards. In particular the workshop facilitated discussions about the best sources of data and archived data assimilation model results, the method for estimating the errors associated with each type of data and the most efficient method for applying blending the data.

\section{Task 2.0 Develop the ocean current energy resource potential database}

The original plan was to use different sources of ocean current data, such as in-situ measurements, satellite observations, high frequency (HF) radar and data assimilation models. The data would be combined using a data blending method such as Optimal Interpolation in order to produce a single time series at each location. Based on the workshop discussions, there is no significant benefit to blending the measurements with the model data, because the models are already including measurements through the data assimilation. Therefore, multiple options for models, including HYCOM, NCOM and ROMS were evaluated in order to determine the best data set.

\section{Subtask 2.1 Use data to determine which model worked best for different regions}

The revised method uses surface drifter data to determine which model performs best in different regions of the country. The drifter data from Global Drifter Program (GDP) (http://www.aoml.noaa.gov/phod/dac/index.php) is used to evaluate the performance of the different models. An overlapped area from two models is chosen to conduct the comparison. Drifter data within that area is extracted, and numerical data from two models is interpolated to the locations of corresponding drifter locations at corresponding times. The model data has a fixed uniform grid, and one snapshot of data is taken for each day. The drifter data are being collected by hundreds of drifter buoys, and one measurement is taken every 6 hours by an individual drifter which results in 4 available data recordings per day for each drifter. To make the model data and drifter data comparable, drifter data of different hours within a day are compared to the snapshot of the model data from the same day, and current velocities of model data are spatially interpolated to the location of the drifter data. Statistics of 
the velocity magnitude and direction comparisons include mean differences, RMS differences, relative standard deviation differences and correlations.

\section{Subtask 2.2 Create joint velocity and direction probability distributions}

The joint probability distribution for the velocity magnitude and direction has been computed on a monthly and annual basis. Therefore 13 discretized distributions are stored for each depth layer at each location. For the West coast the bins have a size of $0.05 \mathrm{~m} / \mathrm{s}$ for the velocities and 10 degrees for the direction. For the East coast, particularly in the Gulf Stream, the bin size is increased to $0.1 \mathrm{~m} / \mathrm{s}$ in the regions of larger currents. The upper 10 depth layers corresponding to 200 meters are stored for the West coast. On the East coast we retain all the layers for the Florida Current on the Southeast coast and the top 20 layers for the rest of the East coast.

\section{Task 3.0 Develop a web based interface and GIS tools for dissemination of the data}

An interactive, web-based GIS system was developed to facilitate dissemination of the ocean current data to interested users, including electric power utilities, policy makers, regulators and turbine manufacturers. The GIS tools allow the user to query the ocean current database

\section{Subtask 3.1 Display GIS layers of the velocity and power densities}

The basic web-based display contains bathymetric maps with the option to display various layers of monthly or annual mean velocities, power densities and the annual standard deviation of the currents. The layers are displayed as points on the grid that are color coded based on the velocities or power density. The interface uses the ArcGIS Server Flex Viewer.

\section{Subtask 3.2 Provide probability distributions for the velocity}

The user can select one or more points ( 4-7 km resolution) to acquire the velocity probability distributions. These distributions may be displayed or downloaded by the user.

\section{Task 4.0 Perform an independent validation of the database}

Oak Ridge National Laboratory (ORNL) performed the validation of Georgia Tech's modeled time series of horizontal ocean current magnitude and direction with observed time series of these variables from independent data sources. Independent data sources include high frequency (HF) radar, stationary ADCP measurements, and flow time series derived from magnetic cables off the coast of Florida. The periods of record for comparison between modeled and observed variables are dictated by observations, which are limited to a few months for the ADCP, less than two years for the radar, and decades for the cable data. Statistical comparisons between modeled and observed time series are reported using multiple summary statistics, including slope and y-intercept from scatter plots, root mean square error (RMSE), mean absolute error (MAE), percent bias (B) and the Nash-Sutcliffe efficiency coefficient (NSE).

\section{Task 5.0 Compute the total theoretical available power}

The total power has been calculated with two approaches: Firstly, the theoretical energy balance in the Gulf Stream was examined using a two-dimensional ocean circulation model based on the Stommel model for subtropical gyres with the quasi-geostrophic balance between pressure gradient, Coriolis force, 
wind stress and frictions driving the circulation. Parameters including water depth, natural dissipation rate and wind stress are calibrated in the model so that the model can reproduce reasonable flow properties including volume flux and energy flux. Flow dissipation due to turbines is represented as additional friction (or turbine friction) in the model. Secondly, to determine the reasonableness of the total power estimates from the Stommel model, further estimates of the available power based on the distribution of the kinetic power density in the undisturbed flow was completed. This requires estimates of the device spacing and scaling in order to sum up the total power that the devices would produce. The drawback with this approach is the uncertainty associated with the device spacing and the impacts that energy extraction would have on the flow field.

\section{Project Description}

\subsection{Ocean Current Energy Resource Database}

This section explains what data sources are available in different regions and how specific data set is selected for specific area to build up the database. A detailed description of the dissemination of the data and the GIS interface is provided in a subsequent section.

\subsubsection{Ocean Model Information}

\section{Overview}

Ocean currents vary greatly in terms of their dominating driving forces, spatial locations, and temporal and spatial scales. Due to this vast and complex nature of the ocean, there is presently no deterministic method for observing or predicting the entire range of ocean currents. Therefore, this study relies on numerical model data because of its high resolution both temporally and spatially as well as its statistically significant duration ( 7 years). Measurements consisting of observational drifter data are available all over the ocean with adequate temporal resolution, and therefore are used to validate model data and to select the optimal model for regions where several are available.

\section{Numerical Model Descriptions}

Most operational ocean models use data assimilation methods for improved accuracy of the predictions. Typically they incorporate satellite measurements of sea surface height and temperature as well as in-situ measurements of temperature and salinity profiles over depth. The numerical model data utilized include: Hybrid Coordinate Ocean Model (HYCOM) from National Ocean Partnership Program (NOPP), Navy Coastal Ocean Model (NCOM) from Naval Research Laboratory (NRL) and Regional Ocean Modeling System (ROMS) from Jet Propulsion Laboratory's (JPL) OurOcean Portal. Among them, HYCOM provides two versions of data, one with a global coverage (HYCOM Global) and the other covers the Gulf of Mexico (HYCOM GOM). The spatial coverage of different models is shown in Figure 1 and summarized in Table 1. 


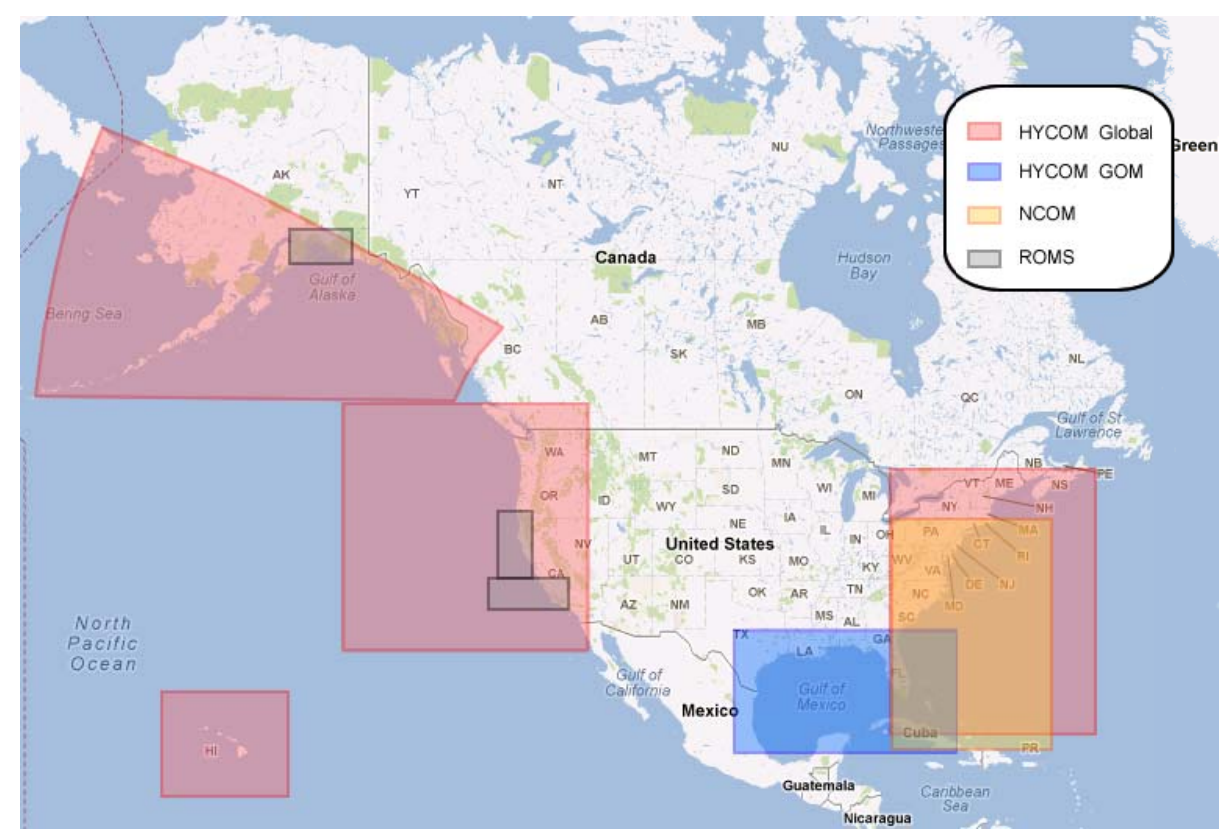

Figure 1: Spatial coverage of the available ocean models.

Table 1: Spatial and temporal coverage and resolutions for the available numerical models.

\begin{tabular}{|c|c|c|c|c|}
\hline Name & Spatial Coverage & Time Period & Spatial Resolution & Time step \\
\hline Global HYCOM & $\begin{array}{c}\text { East, west \& AK } \\
\text { coasts }\end{array}$ & $2004-2010$ & $\sim 7 \mathrm{~km}$ & 1 day \\
\hline GoM HYCOM & Gulf of Mexico & $2004-2010$ & $\sim 4 \mathrm{~km}$ & 1 day \\
\hline NCOM & East coast & $2009-2010$ & $\sim 3 \mathrm{~km}$ & 1 day \\
\hline JPL ROMS & SCB\&WC\&PWS & $2008-2010$ & $\sim 1 \mathrm{~km}$ & 1 day \\
\hline
\end{tabular}

HYCOM is a data-assimilative hybrid isopycnal-sigma-pressure, primitive equation ocean circulation model that evolved from the Miami Isopycnic-Coordinate Ocean Model (MICOM) (Bleck, 2002; Halliwell, 2004). In the HYCOM online data server (http://www.hycom.org), two different sets of realtime modeling data are publicly available. One is HYCOM-NCODA Global Analysis (GLBa), which has a global coverage, and the other is HYCOM-NCODA Gulf of Mexico Analysis (GOMa), which covers the Gulf of Mexico area only, but with a finer resolution. HYCOM-NCODA GLBa is configured on a Mercator grid between $78 \mathrm{~S}$ and $47 \mathrm{~N}$ with a 1/12 degree equatorial resolution. In the vertical, it has 32 layers. HYCOM-NCODA GLBa data are available from 2004 to present. HYCOM-NCODA GOMa's spatial coverage extends from $18 \mathrm{~N}$ to $32 \mathrm{~N}$ in latitude and from $98 \mathrm{~W}$ to $76 \mathrm{~W}$ in longitude with a $1 / 25$ degree equatorial resolution. In the vertical, it has 40 layers. HYCOM-NCODA GOMa data are available from 2003 to 2010 . 
NCOM is primarily based on Princeton Ocean Model (POM) and the Sigma/Z-level Model (SZM). NCOM has free-surface and is based on primitive equations and the hydrostatic, Boussinesq, and incompressible approximations (Barron, 2006). The Mellor Yamada Level 2 (MYL2) and MYL2.5 turbulence models are provided for the parameterization of vertical mixing (Rhodes, 2002). The Global NCOM nowcast data have 1/8 degree resolution, and a global coverage. The NCOM model data are not publicly available; however the NCOM data covering the East Coast for 2009-2011 has been obtained from the Navy Research Lab through personal communication.

ROMS is a three-dimensional, free surface, terrrain-following numerical model that solves 3-D Reynoldsaveraged Navier-Stokes equations (RANS) using hydrostatic and Boussinesq assumptions (Haidvogel, 2008). ROMS uses finite-difference approximations on a horizontal curvilinear Arakawa C grid (Duran, 1999) and vertical stretched terrain-following coordinates. JPL's OurOcean Portal (http://ourocean.jpl.nasa.gov/) provides real-time ROMS ocean forecasting for the Southern California Bight (SCB), Monterey Bay (MB), and Prince William Sound (PWS) at resolution from 1 to $1.6 \mathrm{~km}$.

\section{Model Selection}

The model selection process utilized the drifter data that is publicly available from the Global Drifter Program (GDP) (http://www.aoml.noaa.gov/phod/dac/index.php). The drifters consist of a surface buoy and a subsurface drogue approximately $15 \mathrm{~m}$ beneath the sea surface attached by a long tether. The satellite-tracked ocean drifters have been found to be one of the most economical means to provide near real-time current measurements (Venkatesh, 1990). Drifter data are available from 1987 to the present.

Different model data covering the same region were compared in terms of their statistical agreement with the drifter data. Several statistical metrics were calculated and a score number was formulated to assess the overall performance of each model. The statistical metrics of the velocity comparison include mean difference

$$
M D=\frac{1}{N} \sum_{k=1}^{N}\left(U_{\text {model }}^{k}-U_{\text {drifter }}^{k}\right)
$$

RMS difference

$$
R M S D=\sqrt{\frac{1}{N} \sum_{k=1}^{N}\left(U_{\text {model }}^{k}-U_{\text {drifter }}^{k}\right)^{2}}
$$

Relative standard deviation differences

$$
R D S T D=\frac{S T D\left(U_{\text {drifter }}\right)-S T D\left(U_{\text {model }}\right)}{S T D\left(U_{\text {drifter }}\right)} \times 100
$$

Correlation

$$
C O R=\frac{\operatorname{COV}\left(U_{\text {drifter }}, U_{\text {model }}\right)}{\operatorname{STD}\left(U_{\text {drifter }}\right) \operatorname{STD}\left(U_{\text {model }}\right)}
$$

where $U_{\text {model }}$ is the current speed from models and $U_{\text {drifter }}$ is the current speed from drifter measurement, STD is the standard deviation and COV is the covariance. MD and RMSD are typical statistical metrics. RDSTD characterizes the difference of variability around the mean between the model 
and the measurement data, and COR characterizes the tendency in the linear relationship between the model data and the measurement. A metric named SKILL is directly related to RMSD and is given as

$$
S K I L L=1-\frac{R M S D}{\sqrt{\frac{1}{N} \sum_{k=1}^{N} U_{d r i f t e r}^{k}}}
$$

Since $0<1+\mathrm{COR}<2,1+\mathrm{SKILL}<2$, and $1+\left|\frac{R D S T D}{100}\right|>1$, a convenient SCORE (ranges between 0 and 10) that characterizes the agreement between the model data and the measurement data by combining the different statistics is used:

$$
S C O R E=\frac{(1+C O R) \times(1+S K I L L)}{1+\left|\frac{R D S T D}{100}\right|} \times 2.5
$$

The greater the SCORE number, the better the model data is in predicting the measurement.

The U.S. coast was broken up into individual regions and based on the evaluation of the statistics for each region the best performing model for that region was selected. On the west and Alaska coasts, regions with more than one model data available include Southern California Bight (SCB), Monterey Bay (MB), and Prince William Sound (PWS). The statistical comparison for these 3 regions shows that HYCOM data has a better statistical agreement with measurements and therefore is selected for all 3 regions (Table 2).

Table 2: Statistical comparison results for the west and Alaska coasts.

\begin{tabular}{|c|c|c|c|c|c|c|c|}
\hline Name & Model & MD & RMSD & RDSTD & COR & SKILL & SCORE \\
\hline & & $\mathrm{m} / \mathrm{s}$ & $\mathrm{m} / \mathrm{s}$ & & & & \\
\hline SCB & HYCOM & 0.03 & 0.12 & 23.46 & 0.19 & 0.38 & $\mathbf{3 . 3 1}$ \\
\hline & ROMS & -0.06 & 0.17 & -26.84 & 0.09 & 0.07 & 2.32 \\
\hline MB & HYCOM & -0.05 & 0.14 & -43.13 & 0.22 & 0.13 & $\mathbf{2 . 4 1}$ \\
\hline & ROMS & -0.04 & 0.15 & -86.95 & 0.31 & 0.03 & 1.80 \\
\hline PWS & HYCOM & 0.25 & 0.29 & 39.87 & 0.60 & 0.34 & $\mathbf{3 . 8 3}$ \\
\hline & ROMS & 0.20 & 0.27 & 32.77 & 0.36 & 0.38 & 3.54 \\
\hline
\end{tabular}


The east coast is broken down into 9 subregions shown in Figure 2 (E1-E9). For the region of the Florida Current (E1-E3), three sets of model data (Global HYCOM, HYCOM GoM and NCOM) are available and statistically compared among each other. The statistical comparison results are summarized in Table 3 and the direct comparison plots for each sub-region are shown in Appendix A. For the Florida Current region, HYCOM GoM data has a better statistical agreement with the measurement and also a higher resolution than the other two dataset. Therefore HYCOM GoM is selected for the Florida Current region (E1-E3). For a portion of the East coast (E4-E9), both HYCOM-Global and NCOM were selected.

Because NCOM only contained 2 years of data, 5 additional years from the HYCOM were included. The selection of different model data for different regions of the coastline is summarized in Table 4.

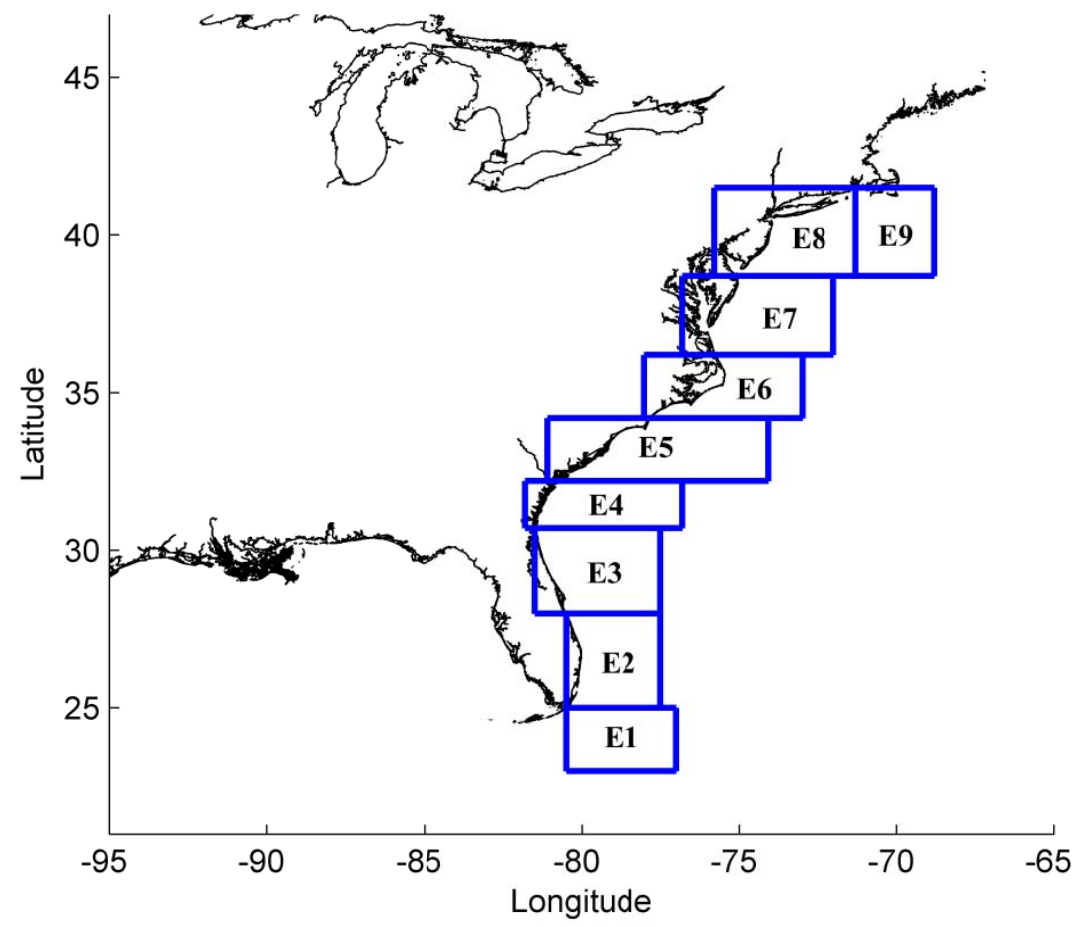

Figure 2: U.S. Atlantic coast divided into 9 subregions. 
Table 3: Statistical comparison results for each sub-region on the east coast.

\begin{tabular}{|c|c|c|c|c|c|c|c|}
\hline Name & Model & MD & RMSD & RDSTD & COR & SKILL & SCORE \\
\hline & & $\mathrm{m} / \mathrm{s}$ & $\mathrm{m} / \mathrm{s}$ & & & & \\
\hline \multirow{3}{*}{ E1 } & $\begin{array}{c}\text { HYCOM } \\
\text { Global }\end{array}$ & 0.10 & 0.31 & 24.25 & 0.76 & 0.52 & 5.38 \\
\hline & $\begin{array}{c}\text { HYCOM } \\
\text { GoM }\end{array}$ & 0.02 & 0.23 & 11.76 & 0.77 & 0.50 & 5.94 \\
\hline & $\mathrm{NCOM}$ & 0.06 & 0.30 & 28.30 & 0.80 & 0.60 & 5.61 \\
\hline \multirow{3}{*}{ E2 } & $\begin{array}{c}\text { HYCOM } \\
\text { Global }\end{array}$ & 0.15 & 0.33 & 22.77 & 0.83 & 0.58 & 5.87 \\
\hline & $\begin{array}{c}\text { HYCOM } \\
\text { GoM }\end{array}$ & 0.07 & 0.28 & 19.08 & 0.85 & 0.63 & 6.35 \\
\hline & NCOM & 0.07 & 0.34 & 16.90 & 0.79 & 0.57 & 5.99 \\
\hline \multirow{3}{*}{ E3 } & $\begin{array}{c}\text { HYCOM } \\
\text { Global }\end{array}$ & -0.02 & 0.46 & 29.33 & 0.34 & 0.27 & 3.30 \\
\hline & $\begin{array}{c}\text { HYCOM } \\
\text { GoM }\end{array}$ & 0.03 & 0.32 & 30.51 & 0.70 & 0.49 & 4.83 \\
\hline & NCOM & 0.03 & 0.37 & 33.55 & 0.58 & 0.41 & 4.14 \\
\hline \multirow[t]{2}{*}{ E4 } & $\begin{array}{c}\text { HYCOM } \\
\text { Global }\end{array}$ & 0.10 & 0.45 & 32.60 & 0.58 & 0.43 & 4.26 \\
\hline & NCOM & 0.08 & 0.45 & 29.45 & 0.57 & 0.43 & 4.33 \\
\hline \multirow[t]{2}{*}{ E5 } & $\begin{array}{c}\text { HYCOM } \\
\text { Global }\end{array}$ & 0.06 & 0.44 & 25.79 & 0.41 & 0.41 & 3.95 \\
\hline & NCOM & 0.03 & 0.40 & 19.99 & 0.53 & 0.46 & 4.67 \\
\hline \multirow[t]{2}{*}{ E6 } & $\begin{array}{c}\text { HYCOM } \\
\text { Global }\end{array}$ & 0.02 & 0.56 & 32.53 & 0.38 & 0.42 & 3.68 \\
\hline & NCOM & -0.05 & 0.45 & 33.12 & 0.65 & 0.53 & 4.73 \\
\hline \multirow[t]{2}{*}{ E7 } & $\begin{array}{c}\text { HYCOM } \\
\text { Global }\end{array}$ & 0.12 & 0.55 & 37.68 & 0.59 & 0.45 & 4.18 \\
\hline & NCOM & 0.09 & 0.50 & 26.46 & 0.69 & 0.50 & 5.01 \\
\hline \multirow[t]{2}{*}{ E8 } & $\begin{array}{c}\text { HYCOM } \\
\text { Global }\end{array}$ & 0.04 & 0.15 & -46.26 & 0.37 & 0.55 & 3.63 \\
\hline & NCOM & 0.11 & 0.15 & 13.26 & 0.46 & 0.57 & 5.06 \\
\hline \multirow[t]{2}{*}{ E9 } & $\begin{array}{c}\text { HYCOM } \\
\text { Global }\end{array}$ & 0.23 & 0.44 & 77.79 & 0.09 & 0.32 & 2.03 \\
\hline & NCOM & 0.00 & 0.20 & -12.64 & 0.88 & 0.69 & 7.04 \\
\hline
\end{tabular}

Table 4: Ocean model data selected for different areas of United States coast.

\begin{tabular}{|c|c|}
\hline Location & Selected Model \\
\hline East coast & HYCOM Global (5yrs) \& NCOM (2yrs) \\
\hline Florida Strait & HYCOM GoM (7yrs) \\
\hline Gulf of Mexico & HYCOM GoM (7yrs) \\
\hline West and Alaska coasts & HYCOM Global (7yrs) \\
\hline Hawaii coast & HYCOM Global (7yrs) \\
\hline
\end{tabular}




\subsubsection{Ocean current database validation}

ORNL has performed an independent verification of the ocean current energy resource database with emphasis on the high power density region in the Florida Strait. Their aim was to examine the deviation of HYCOM-GOM outputs from the HYCOM-GLOBAL model, and those based on three independent observation sources: NOAA's submarine cable transport data, Florida Atlantic University's (FAU) ADCP data at a high power density location, and the Southeast Coastal Ocean Observing Regional Association's (SECOORA) HF radar data in the high power density region of the Florida Strait. Comparisons with these three independent observation sets, and HYCOM-GLOBAL outputs, indicate discrepancies with HYCOM model outputs, but overall that the HYCOM-GOM model can provide a best-practical assessment of the ocean current hydrokinetic resource in high power density regions like the Florida Strait, but that there may be ways to improve predictions through improved data assimilation and model forcing for periods when predictions of temporal variation of transport are less accurate than other periods, and by inclusion of additional independent observational data sources, e.g. ADCP measurements. This independent validation is detailed in a separate ORNL report (Neary et al., 2012).

\subsection{Variability of the Florida Current}

The GIS map of mean surface current speed and power density already shows that the Florida Current has the highest power density $\left(>2500 \mathrm{~W} / \mathrm{m}^{2}\right)$ along the United States coast (Figure 3 ). The proximity of the Florida Current to the southeastern Florida metropolitan area $(<200 \mathrm{~km})$ makes extracting renewable energy from ocean currents in this region particularly attractive for local needs for electricity. Therefore, this subsection presents an analysis of the variability of ocean currents in the Florida Current.

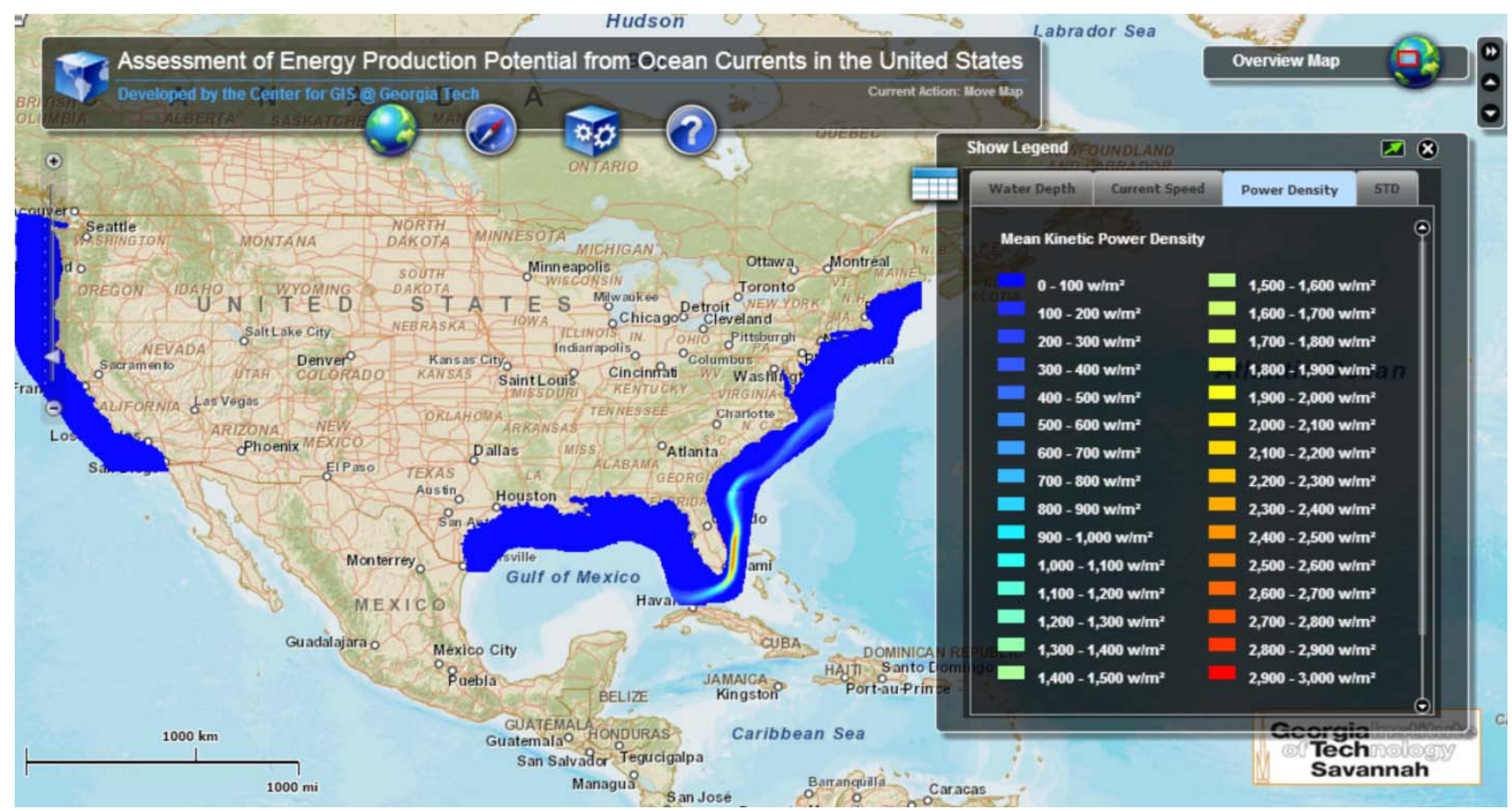

Figure 3: GIS map showing the mean surface current power density for the U.S. coast. 


\subsubsection{Spatial and temporal variability in the Florida Current}

The spatial variation of the Florida Current is investigated by examining the distributions of the mean and standard deviation (STD) of the current speed on the ocean surface as well as in a vertical cross-section plane. The mean current speed is a proxy for the average kinetic power density since kinetic power is proportional to cubed current speed while STD represents the temporal variation of the power potential. For stable and sustainable extraction of kinetic energy from ocean currents, a high level of kinetic power coupled with a low level of temporal variation is desired. In the Florida Strait, the Gulf Stream (i.e. Florida Current) is predominantly flowing northward. The core of the current where the flow is the strongest is concentrated within about $100 \mathrm{~m}$ of the surface layer and spans about half of the width of the channel. The core of the Florida Current is slightly offset to west of the channel centerline (Figure 4a and 5a) reducing the potential cost of transmitting extracted power to shore assuming extraction devices are to be deployed in the core of the current flow. Figure $4 \mathrm{~b}$ and $5 \mathrm{~b}$ show the Florida Current has the greatest temporal variation close to the Florida shoreline on the edge of the core of the strongest current. Comparing daily and monthly snapshots of the current speed distribution shows the high variation near the edge as a direct result of the meandering and seasonal broadening of the core of the current flow. The coefficient of variation, which is the ratio of standard deviation to the mean, shows a low level of variability inside the core of the current and relative high variability outside the core (Figure $4 \mathrm{c}$ and $5 \mathrm{c}$ ). As the current flows downstream past the Florida Strait, its variability increases, partly due to the decrease of geographical constraint from the bathymetry.

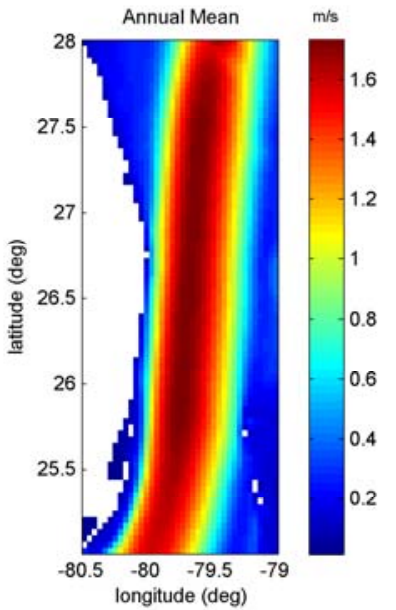

(a)

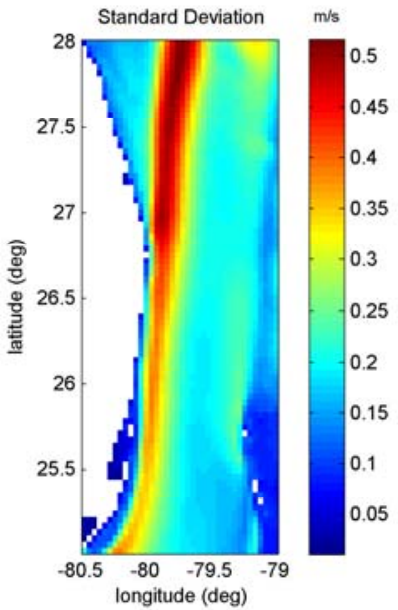

(b)

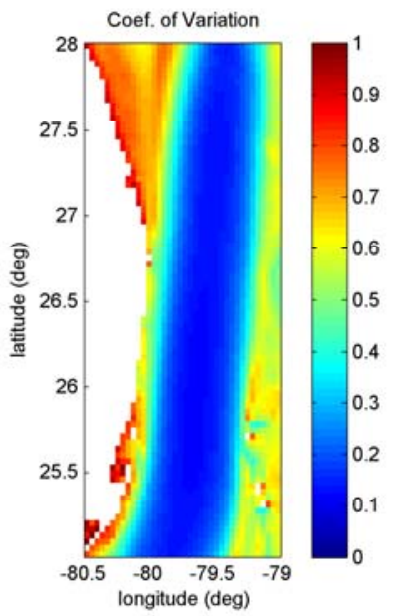

(c)

Figure 4: Distributions of (a) annual mean surface current speed, (b) standard deviation, and (c) the coefficient of variation in the Florida Current. 


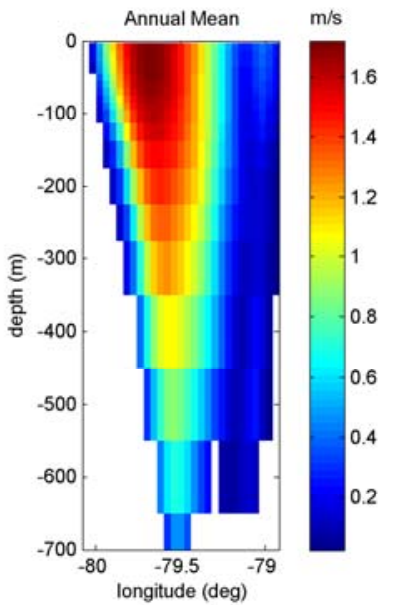

(a)

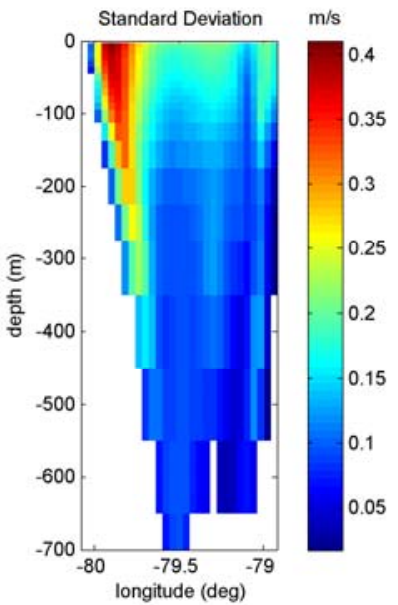

(b)

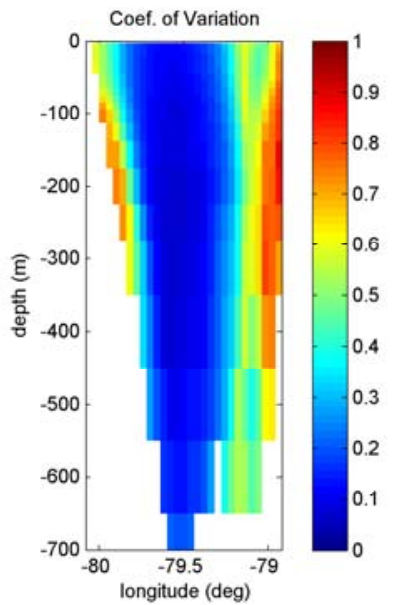

(c)

Figure 5: Cross-sectional distributions of (a) annual mean current speed, (b) standard deviation, and (c) the coefficient of variation in Florida Current at the latitude of 26.6264N.

\subsubsection{Variation of kinetic energy flux in the Florida Current}

Kinetic energy flux is a primary indicator of undisturbed kinetic energy reserve in ocean currents.. The kinetic energy flux $E_{f}$ in the Florida Current can also be integrated from HYCOM data as

$$
E_{f}=\frac{1}{2} \rho \int|\vec{V}|^{2} \vec{V} \cdot d \vec{A}
$$

where $\rho$ is the water density, $\vec{V}$ is the velocity vector and $d \vec{A}$ is the differential vertical area. Figure 6 shows the time series of calculated kinetic energy flux in the Florida Current from 2004 to 2010. The mean level of energy flux in the Florida Current is approximately $22.6 \mathrm{GW}$ with apparent variability at multiple different time scales from weeks to years.

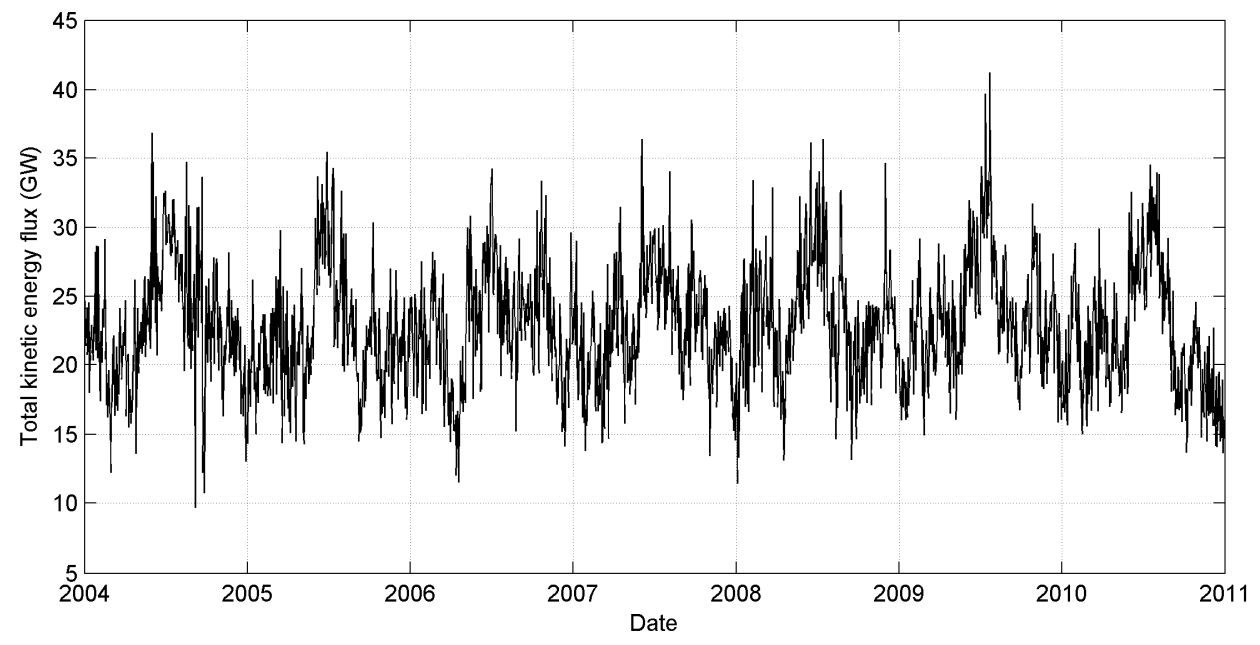

Figure 6: Time series of total kinetic energy flux in the Florida Current. 
Figure 7 shows the annual mean kinetic energy flux for years from 2004 to 2010. It is observed that the annual mean kinetic energy flux is fairly constant over the years. Within each year, the standard deviation varies slightly and the mean standard deviation is approximately $4.3 \mathrm{GW}$.

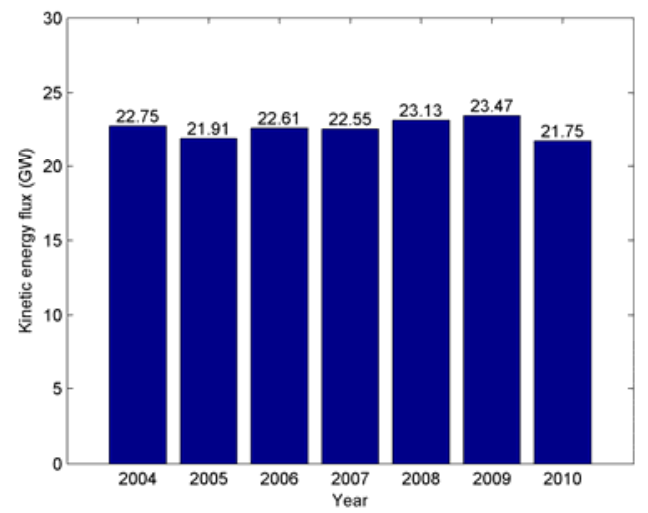

(a)

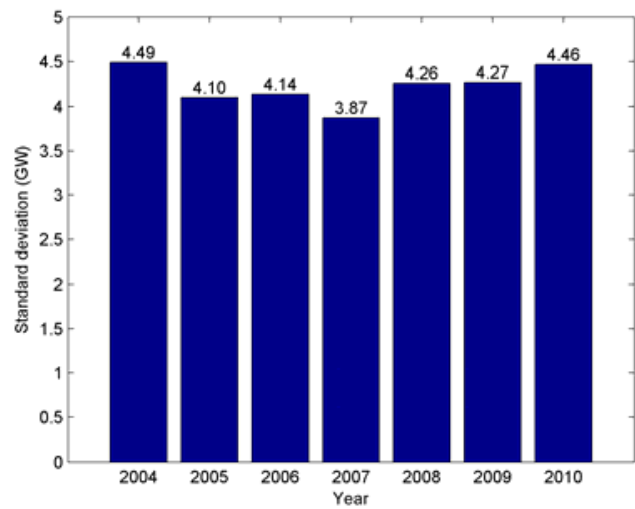

(b)

Figure 7: Yearly variation of (a) mean kinetic energy flux and (b) standard deviation in the Florida Current from 2004 to 2010.

The variation throughout the year is evident from the monthly averages and STD of kinetic energy flux as shown in Figure 8. The months of June and July (or summer season) feature the highest energy flux of the year, greater than $27 \mathrm{GW}$. Energy fluxes in other months are much lower and are mostly in the range between 20 and $23 \mathrm{GW}$. However the standard deviations for different months have a more random pattern with no observable regularity, and are all in the range between 3 and $4 \mathrm{GW}$. This indicates that the total available kinetic power can vary greatly on a monthly basis.

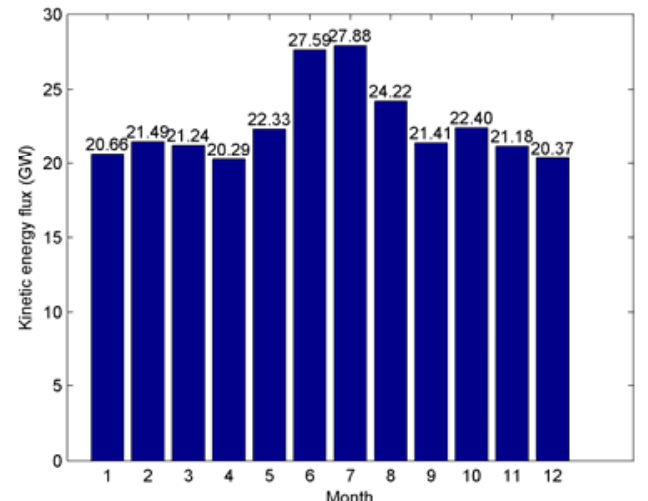

(a)

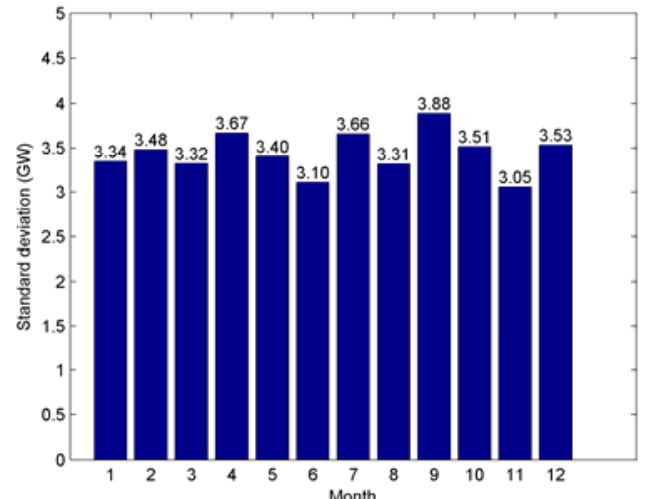

(b)

Figure 8: Monthly variation of (a) mean kinetic energy flux and (b) standard deviation in the Florida Current.

To quantify the change of kinetic energy flux with depth, it is helpful to examine the change of energy flux at different depths by integrating only across the channel but not over depth. Figure 9 shows the kinetic energy flux density $(\mathrm{GW} / \mathrm{m})$ as a function of the depth for 4 different months and the annual mean. The general shape of the curves is similar to the vertical profile of current speed with the highest value near the surface and lowest near the bottom. But these profiles are quantitatively different from vertical velocity profiles. It is clear that more than half of the total energy flux is concentrated in the upper $200 \mathrm{~m}$ of the water column. Stronger monthly variability is prevalent in the upper $100 \mathrm{~m}$ of water column. The 
month of July features the highest level of energy flux while November has the lowest. February and May have flux levels that are relatively close to the annual mean. Below $100 \mathrm{~m}$ monthly variability becomes negligible. It implies the monthly variability mostly results from surface forcing, most likely the seasonal variation in surface wind stress.

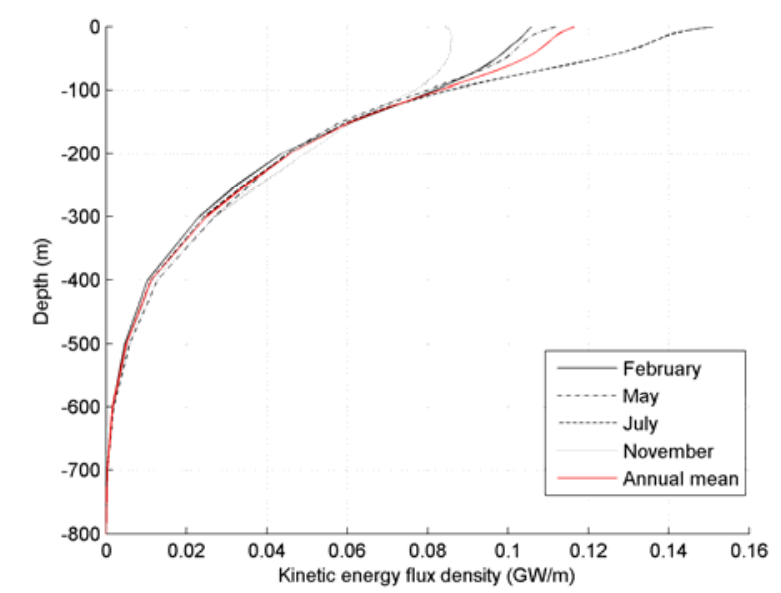

Figure 9: Vertical kinetic energy flux density in the Florida Current for selected months (Feb., May, Jul., and Nov.) and annual mean.

\subsubsection{Estimating 30 years of kinetic energy flux}

The telecommunication cables that run almost perpendicularly through the Florida Strait from West Palm Beach, FL to Eight Mile Rock, Grand Bahamas Island is used to measure the volume transport through the current channel. This measurement is based on the working principle that the flow through the earth's magnetic field can induce a voltage in the cable, which after calibration, can measure the volumetric flow (Larsen and Sanford, 1985). The volume flux from the cable data is a useful data resource which can be explored to determine the possible relations between volume flux and kinetic energy flux in the Gulf Stream. The long cable data measurement record (from 1982 to present) provided by the Atlantic Oceanographic and Meteorological Laboratory of NOAA is extremely valuable.

Figure 10a shows the comparison of volume flux in the Florida Current between HYCOM model data and the submarine cable measurement. The mean volume flux is about $31.6 \mathrm{~Sv}$ from HYCOM and $31.3 \mathrm{SV}$ from the cable measurement. Figure $10 \mathrm{~b}$ shows a 30 -day running average of the two signals, and the correlation coefficient is about 0.77 , which implies a high correlation. A more detailed validation of volume transport between HYCOM model and cable measurement is provided by Neary et al. (2012). 


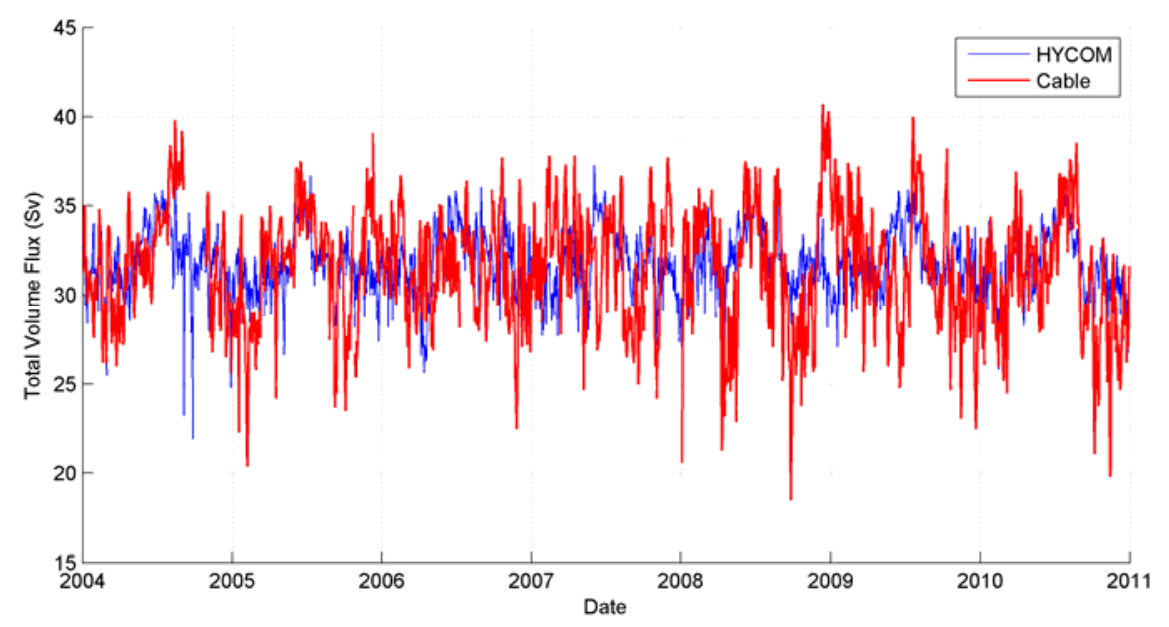

(a)

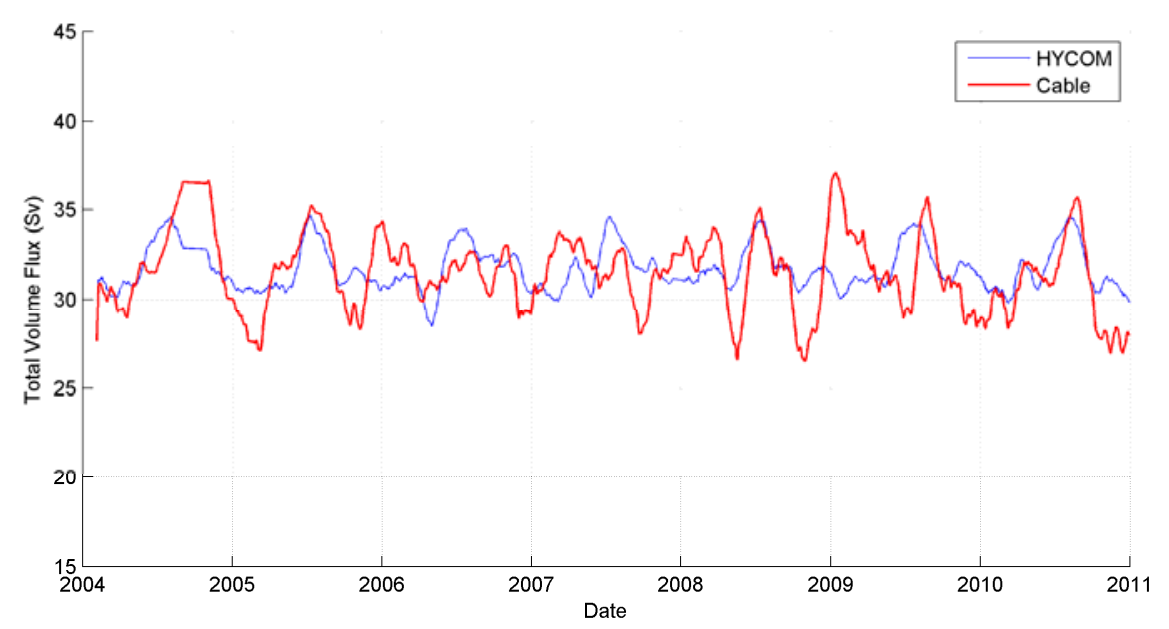

(b)

Figure 10: Comparison of volume flux in the Florida Current from cable measurement and from HYCOM model data: (a) daily time series and (b) 30-day running averaged time series.

The HYCOM model provides 7 year of data that can be used to calculate both volume flux and kinetic energy flux in the Florida Current. Kinetic energy flux is of greater interest to us since the purpose of this study is associated with estimating power potential from ocean currents. Therefore it is desirable to seek a solid relationship between volume flux and kinetic energy flux so that longer record of kinetic energy flux can be projected based on 30 years of historical volume flux data from cable measurement with some level of confidence. First in order to test the robustness of this approach, the 7 years of HYCOM data is divided into two groups. One group extends from 2004 to 2006 and the second group extends from 2007 to 2010. The second group of data is used to establish a statistical relationship between volume flux and energy flux in the Florida Current. The volume and kinetic energy flux of 2007-2010 are plotted in Figure 11a. The statistical relationship is established with a least square fit technique as the following equation

$$
E_{f}=a Q^{n}
$$

with coefficients a and $\mathrm{n}$. The fitted curve is shown in Figure $11 \mathrm{~b}$ where the coefficients are $\mathrm{a}=0.001592$, and $\mathrm{n}=2.766$ with $R^{2}=0.72$. 

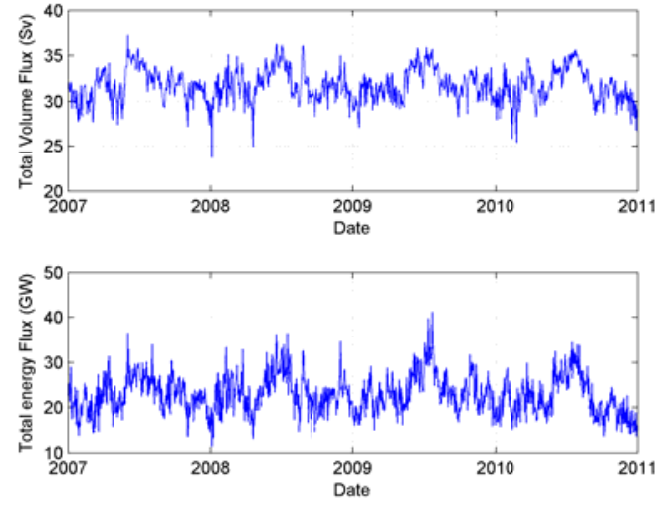

(a)

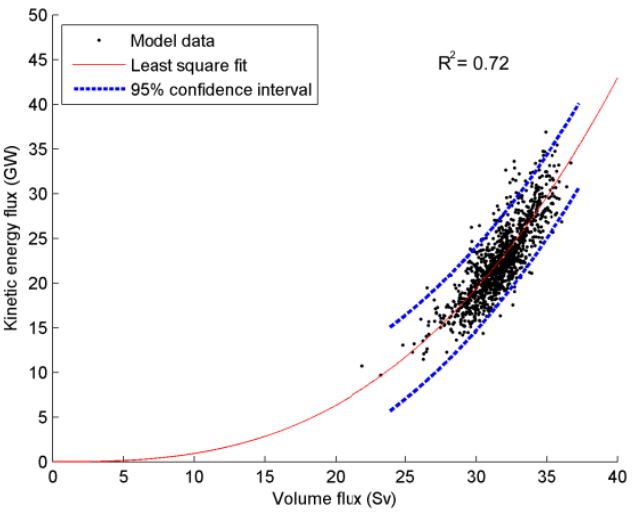

(b)

Figure 11: (a) Time series of volume and kinetic energy flux (2007-2010) from HYCOM model data, and (b) least square fit of the relationship between volume and kinetic energy flux with $95 \%$ confidence interval based on data from 2007 to 2010.

To test the robustness of this statistical relationship, the volume flux data of 2004-2006 from the cable measurement is used as input of the above relationship. A time series of the kinetic energy flux is therefore generated as the output. For comparison, the kinetic energy flux of the same period of time is also calculated from HYCOM model data. Figure 12a shows the time series of kinetic energy flux from both the HYCOM model data and from the prediction by cable data. A low pass filter is applied to both signals and the result is shown in Figure 12b. Some months of cable data are missing, and result in a number of gaps in the red curve. The comparison between the calculated kinetic energy flux from HYCOM (blue) and the projected kinetic energy flux from cable data (red) in Figure 12 features a correlation coefficient close to 0.7 .

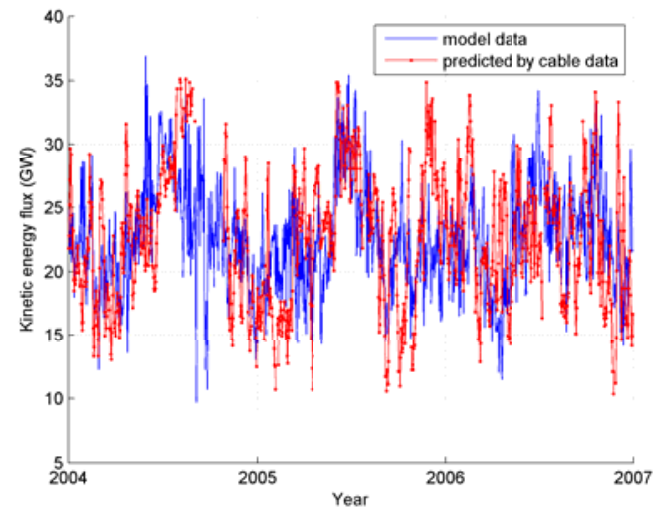

(a)

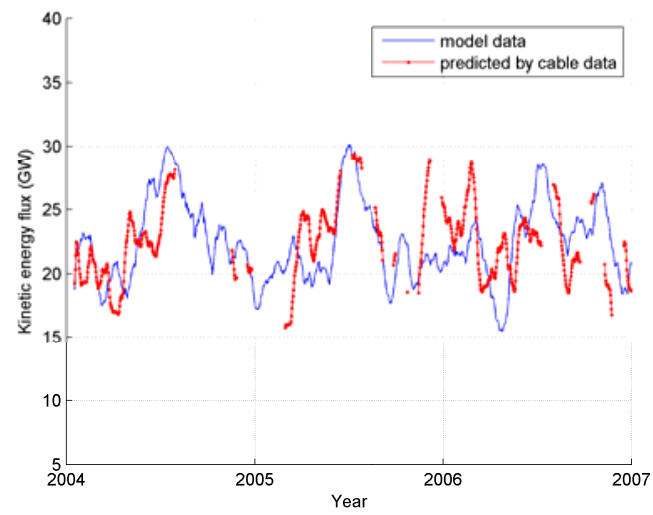

(b)

Figure 12: Predicted kinetic energy flux from 2004 to 2006 from cable data with the energy flux calculated from HYCOM model data: (a) time series of daily data, and (b) 30-day running averaged time series.

This experiment verifies the robustness of the statistical approach of predicting kinetic energy flux from volume flux. Therefore a new and more reliable relationship between volume flux and kinetic energy flux in the Florida Current is computed based on 7 years of HYCOM data with a $R^{2}=0.75$ (Figure 13a):

$$
E_{f}=0.001598 Q^{2.764}(G W)
$$


The 30-year time series of kinetic energy flux with low pass filtering is then calculated and plotted in Figure $13 \mathrm{~b}$ together with $95 \%$ confidence interval. The predicted mean kinetic energy flux from 30 years of cable data is about $22.8 \mathrm{GW}$. The standard deviation is about $5.4 \mathrm{GW}$.

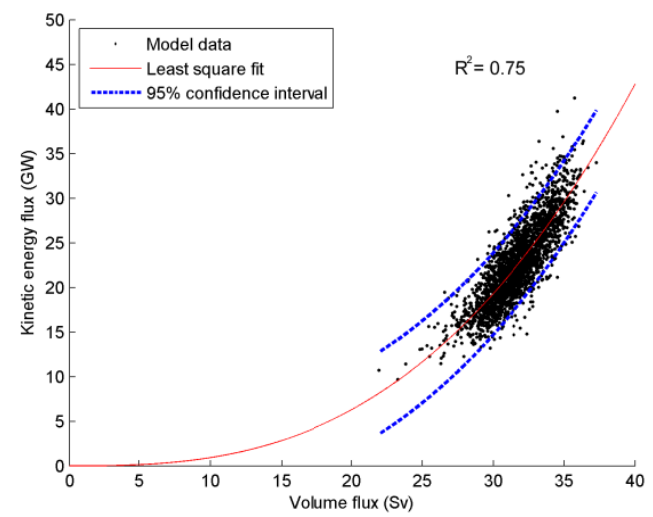

(a)

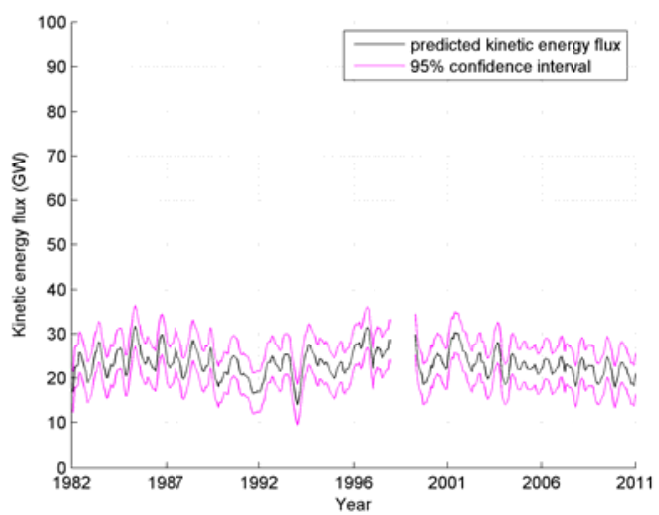

(b)

Figure 13: (a) Least square fit of the relationship between volume and kinetic energy flux with $95 \%$ confidence interval from 2004 to 2010, and (b) projected 30-year low-pass filtered time series of kinetic energy flux based on historical cable data with $95 \%$ confidence interval.

Both monthly and yearly variations of kinetic energy flux mean and STD can also be computed based on 30 years of data, as shown in Figure 14 and 15. It is observed that the mean kinetic energy flux is still the highest in the summer, particularly in July where the peak occurs. The lowest mean energy flux occurs in November, which is in agreement with previous findings. However, this data set suggests that the standard deviation is lowest during the summer months when the average power is the highest. The kinetic energy flux also shows very strong year to year variability. The annual mean power ranges as high as $27 \mathrm{GW}$ in 2002, and as low as $18 \mathrm{GW}$ in 1991.

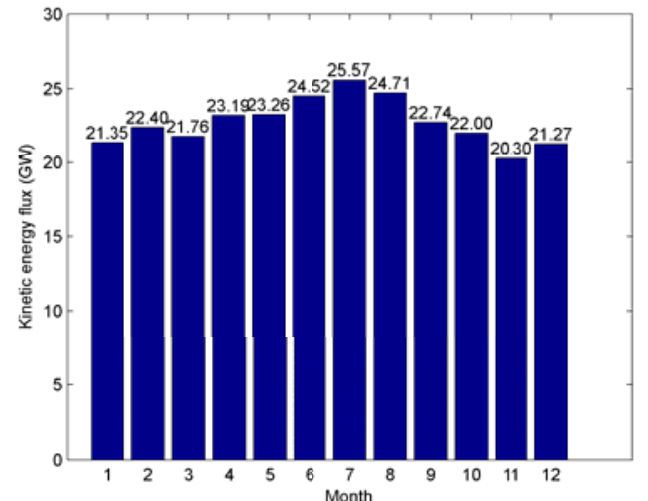

(a)

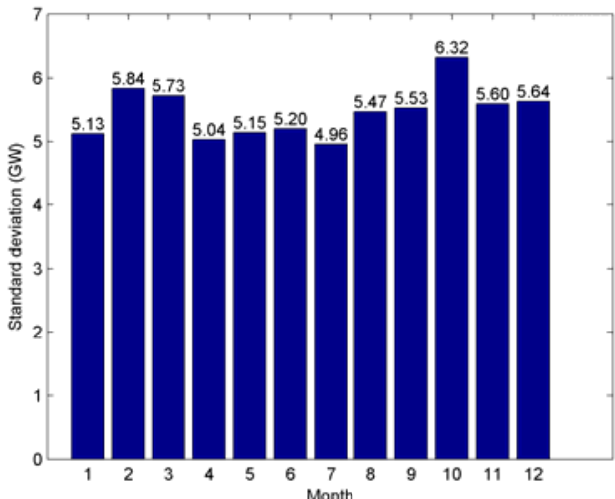

(b)

Figure 14: Monthly variation of (a) mean kinetic energy flux and (b) standard deviation in the Florida Current based on projected 30 years of kinetic energy flux data. 


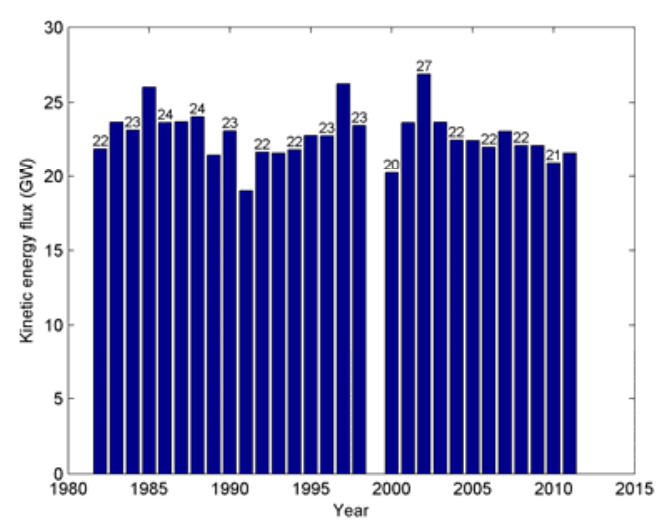

(a)

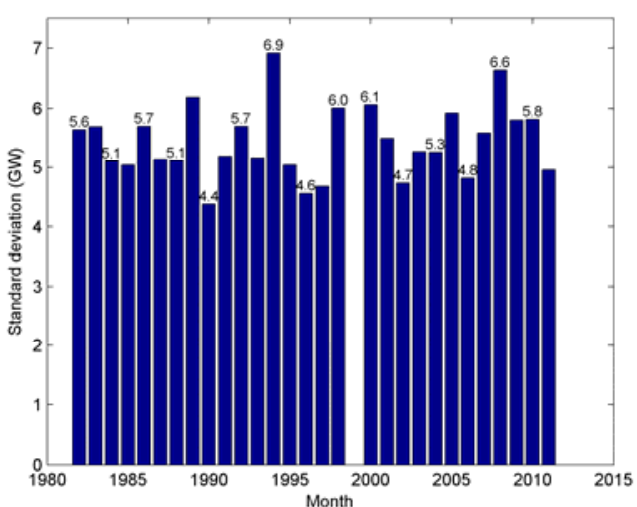

(b)

Figure 15: Yearly variation of (a) mean kinetic energy flux and (b) standard deviation in the Florida Current based on projected 30 years of kinetic energy flux data.

\subsection{Total Extractable Power from the Gulf Stream System}

The map of the power density has shown that the Gulf Stream, particularly the Florida Current, has the highest power density among ocean currents along the United States coastline, making it the ideal region for ocean current energy extraction. Therefore the assessment of the total extractable power for ocean currents for the United States will focus on the Gulf Stream system.

\subsubsection{Analytical estimate of power potential from the Gulf Stream system}

The commonly used approach based on undisturbed power density is useful for identifying high energy regions and preliminary estimates of energy resources. For a single or a small number of devices, as long as there is a negligible change to the existing flow, such an estimate is reasonable. However, power density only characterizes the undisturbed kinetic energy transport by the flow, but not the generation rate of energy by turbines. A large number of devices can block the flow and reduce the current velocity, and hence reduce the generated power from each device. To incorporate the effect of reduced flow velocity due to presence of turbines, it is desirable to study the dynamics of the system in order to estimate theoretically extractable energy. Analytical dynamic models for estimating power potential from tidal streams (Garrett and Cummins, 2005) and atmospheric jet streams (Miller et al., 2011) have been proposed. Similar analytical modeling approaches may be applicable to open ocean currents. Although tidal currents and open ocean currents share obvious similarities, they are fundamentally different regarding their dynamic mechanisms. Tidal stream currents are primarily driven by head difference between the entrance and exit of the channel, while ocean currents are in quasi-geostrophic balance and driven primarily by surface wind stress. This section provides a simplified theoretical estimate of recoverable energy resources from the Gulf Stream system.

\subsubsection{Simplified ocean circulation model}

The analytical model applied to the present study investigates energy dissipation from added turbines, a more realistic measure of extractable energy resources from the Gulf Stream system. It is based on the model proposed by Stommel (1948). The computational domain is a simplified rectangular basin with a flat bottom representing the North Atlantic Basin. The positive $\mathrm{x}$ direction is eastward and the positive $\mathrm{y}$ northward. The horizontal and vertical extensions of the idealized basin are similar to the real dimensions 
of the North Atlantic Basin. Water density is assumed constant and the flow is assumed steady. In the ocean, the advective terms (nonlinear terms) are much smaller than the Coriolis term (i.e. Rossby Number $\ll 1$ ), and therefore can be neglected (Vallis, 2006). The reduced shallow water quasi-geostrophic equations consist of two horizontal momentum equations and the continuity equation:

$$
\begin{aligned}
& -f v=-\frac{1}{\rho} \frac{\partial p}{\partial x}+\frac{\left(F_{x}+W_{x}\right)}{\rho} \\
& f u=-\frac{1}{\rho} \frac{\partial p}{\partial y}+\frac{\left(F_{y}+W_{y}\right)}{\rho} \\
& \frac{\partial u}{\partial x}+\frac{\partial v}{\partial y}=0
\end{aligned}
$$

where $\rho$ is the water density, $p$ is the pressure, $f$ is the Coriolis parameter, $W_{i}$ is the surface wind stress in $i$ direction, $F_{i}$ is the opposing forces associated with natural friction, turbulence, and possibly turbine drag in $i$ direction $(i=x, y) .(x, y)$ are the east-west, north-south axes, and $(u, v)$ are two corresponding horizontal velocity components.

Shallow water approximation and hydrostatic pressure are reasonably assumed since the depth of the ocean (on the order of $1 \mathrm{~km}$ ) is much smaller than its horizontal extensions (on the order of $1000 \mathrm{~km}$ ). Therefore horizontal pressure gradients are simplified to the following:

$$
\nabla_{h} p=\rho g \nabla_{h} \eta
$$

where $\eta$ is the free surface elevation. Under the $\beta$ plane approximation, the Coriolis parameter can be approximated as

$$
f=f_{0}+\beta y
$$

where $f_{0}$ and $\beta$ are constants defined as $f_{0}=2 \Omega \sin \theta_{0}$ and $\beta=\frac{2 \Omega \cos \theta_{0}}{a}$ with $\Omega$ as the rotation rate of the earth, $a$ as the earth radius and $\theta_{0}$ as a reference latitude.

By cross-differentiating the two momentum equations and subtracting, the pressure gradient terms are eliminated, resulting in

$$
f\left(\frac{\partial u}{\partial x}+\frac{\partial v}{\partial y}\right)+\beta v=\frac{1}{\rho}\left(\frac{\partial\left(F_{y}+W_{y}\right)}{\partial x}-\frac{\partial\left(F_{x}+W_{x}\right)}{\partial y}\right)
$$

The first term of above equation is eliminated using the continuity equation. The number of unknowns can be reduced by defining a stream function as

$$
\begin{aligned}
& u=\frac{\partial \Psi}{\partial y^{\prime}} \\
& v=-\frac{\partial \Psi}{\partial x} .
\end{aligned}
$$

Boundary conditions require that both velocity components are zero at the basin boundaries, i.e. no slip and no penetration at the boundaries: 


$$
\begin{aligned}
& u(x, 0)=u(x, b)=u(0, y)=u(a, y)=0, \\
& v(x, 0)=v(x, b)=v(0, y)=v(a, y)=0,
\end{aligned}
$$

where $a$ is the basin length in east-west direction, and $b$ is the basin width in north-south direction.

The circulation in subtropical gyres is almost entirely governed by the forcing of the wind, therefore only wind stress is considered as the driving force in this model. The prevailing wind system on the surface of the North Atlantic ocean include easterly trade winds in the tropics and the westerlies in the middle latitude, exerting a clockwise and negative curl on the ocean surface. A convenient way to represent such wind patterns is to assume a sinusoidal wind profile:

$$
W_{x}(y)=-\frac{\tau_{0}}{H} \cos \left(\frac{\pi}{b} y\right)
$$

where $H$ is the uniform depth of the ocean basin and $\tau_{0}$ is maximum wind stress.

The drag force is commonly assumed to be proportional to current velocity square, although it can also be assumed to be proportional to current velocity to make mathematics simple (i.e. the simplest case in Garrett and Cummins, 2005). This model is kept simple by assuming the drag forces associated with natural friction and turbulence, and possibly turbines are linearly proportional to the current velocity. The undisturbed natural drag (i.e. without presence of turbines) is written as

$$
\vec{F}=-\frac{C_{d} \rho}{H} \vec{V}
$$

where $C_{d}$ is the natural drag coefficient and has the dimensions of velocity in the present setting.

Without the presence of turbines, this model essentially simplifies to the Stommel's model. The derivation of Stommel's model is explained in great detail by Stewart (2008). The solution becomes

$$
\Psi(x, y)=\frac{b^{2}}{\pi^{2}} N\left(\frac{1-e^{m_{2} a}}{e^{m_{1} a}-e^{m_{2} a}} e^{m_{1} x}+\frac{e^{m_{1} a}-1}{e^{m_{1} a}-e^{m_{2} a}} e^{m_{2} x}-1\right) \sin \left(\frac{\pi y}{b}\right),
$$

where $M=\frac{\beta H}{C_{d}}, N=\frac{\tau_{0} \pi}{\rho b C_{d}}, m_{1}=-\frac{\left(M+\sqrt{M^{2}+\frac{4 \pi^{2}}{b^{2}}}\right)}{2}$, and $m_{2}=-\frac{\left(M-\sqrt{M^{2}+\frac{4 \pi^{2}}{b^{2}}}\right)}{2}$.

The two velocity components are then derived to be

$$
\begin{aligned}
& u=\frac{b}{\pi} N\left(\frac{1-e^{m_{2} a}}{e^{m_{1} a}-e^{m_{2} a}} e^{m_{1} x}+\frac{e^{m_{1} a}-1}{e^{m_{1} a}-e^{m_{2} a}} e^{m_{2} x}-1\right) \cos \left(\frac{\pi y}{b}\right), \\
& v=-\frac{b^{2}}{\pi^{2}} N\left(\frac{1-e^{m_{2} a}}{e^{m_{1} a}-e^{m_{2} a}} m_{1} e^{m_{1} x}+\frac{e^{m_{1} a}-1}{e^{m_{1} a_{-}}-e^{m_{2} a}} m_{2} e^{m_{2} x}\right) \sin \left(\frac{\pi y}{b}\right) .
\end{aligned}
$$

\subsubsection{Model calibration}

Before the model can be applied to calculate energy dissipation, it needs to be calibrated to ensure it reproduces reasonable flow properties. Considering the great complexity and variability of the Gulf Stream system, this simple analytical model is only calibrated by time averaged bulk flow properties, ideally volume flux and kinetic energy flux. 
The basin is defined as $a=6000 \mathrm{~km}$ long in x direction, and $b=3142 \mathrm{~km}$ wide in y direction. The Coriolis parameter $\beta$ in the middle latitude is approximately $2 \times 10^{-13} \mathrm{~cm}^{-1} \mathrm{sec}^{-1}$. The "basin depth" $H$ in this model is not the mean physical ocean depth, but the depth of surface layer primarily driven by surface winds (i.e. Ekman layer). Stommel (1948) proposed the basin depth $H=200 \mathrm{~m}$, maximum wind stress $\tau_{0}=10^{-5} \mathrm{~N} / \mathrm{cm}^{2}$, or $1 \mathrm{dyn} / \mathrm{cm}^{2}$, and natural drag coefficient $C_{d}=0.02 \mathrm{~cm} / \mathrm{s}$, however these parameters are further calibrated here.

The calibrated model needs to be able to reproduce most reasonable bulk flow properties including volume flux and energy flux in the selected cross-section on the western boundary (Figure 16) that represents the Gulf Stream. In this study, the seven years of HYCOM data is used to calculate the reference volume and energy fluxes. It's already been demonstrated in previous sections that the HYCOM data is accurate in predicting the bulk flow properties of the Gulf Stream system.
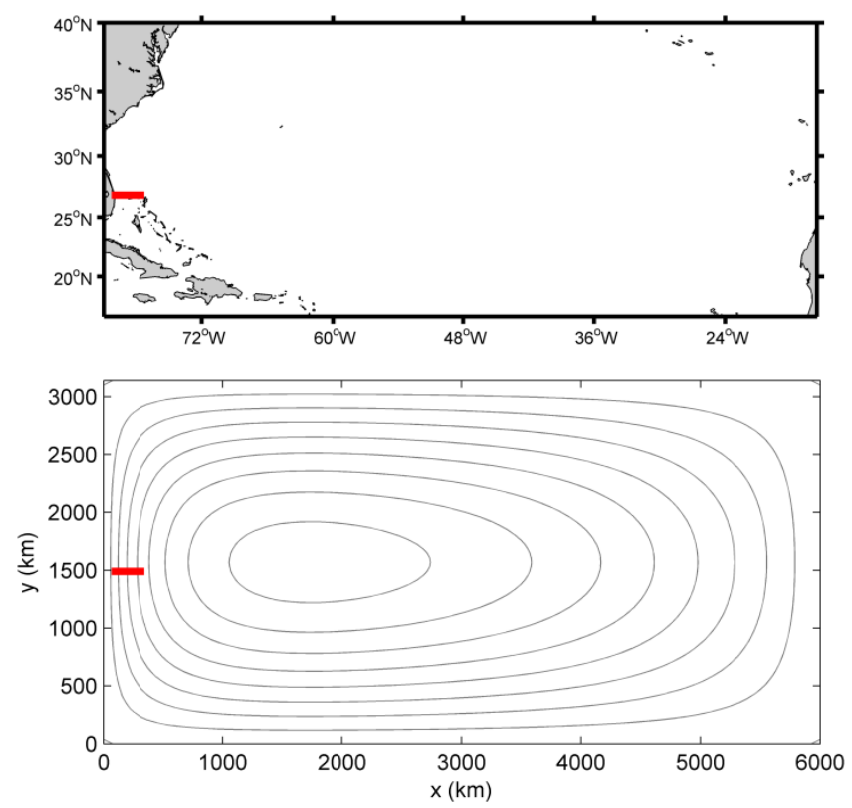

Figure 16: Location of the selected cross-section (red line) in the Gulf Stream system, through which volume flux and energy flux are calculated and compared; upper panel: the North Atlantic Basin; lower panel: the simplified basin with analytical streamlines from Equation (23).

For different combinations of basin depth $H$, maximum wind stress $\tau_{0}$, and natural drag coefficient $C_{d}$, the model produces different volume fluxes computed as

$$
Q=\int \vec{V} \cdot d \vec{A}
$$

and energy flux computed as

$$
E_{f}=\frac{1}{2} \rho \int|\vec{V}|^{2} \vec{V} \cdot d \vec{A}
$$

through the selected cross-section. The goal of calibration is to find model parameters that minimize both $\left|\frac{Q_{a}}{Q_{m}}-1\right|$ and $\left|\frac{E_{f a}}{E_{f m}}-1\right|$, where the $a$ and $m$ subscripts represent analytical and HYCOM results 
respectively. Since these quantities don't always reach minimum at the same time, a compromised strategy is to minimize a new parameter called the "Error Factor" (E.F.):

$$
E . F .=\left(\frac{Q_{a}}{Q_{m}}-1\right)^{2}+\left(\frac{E_{f a}}{E_{f m}}-1\right)^{2} .
$$

Figure 17 shows the variation of E.F. as a function of model parameters. Results show basin depth $H=140 \mathrm{~m}$, wind stress $\tau_{0}=1 \mathrm{dyn} / \mathrm{cm}^{2}$ and natural drag coefficient $C_{d}=0.021 \mathrm{~cm} / \mathrm{s}$ lead to the optimal model performance in terms of undisturbed volume and energy fluxes in the Gulf Stream crosssection.
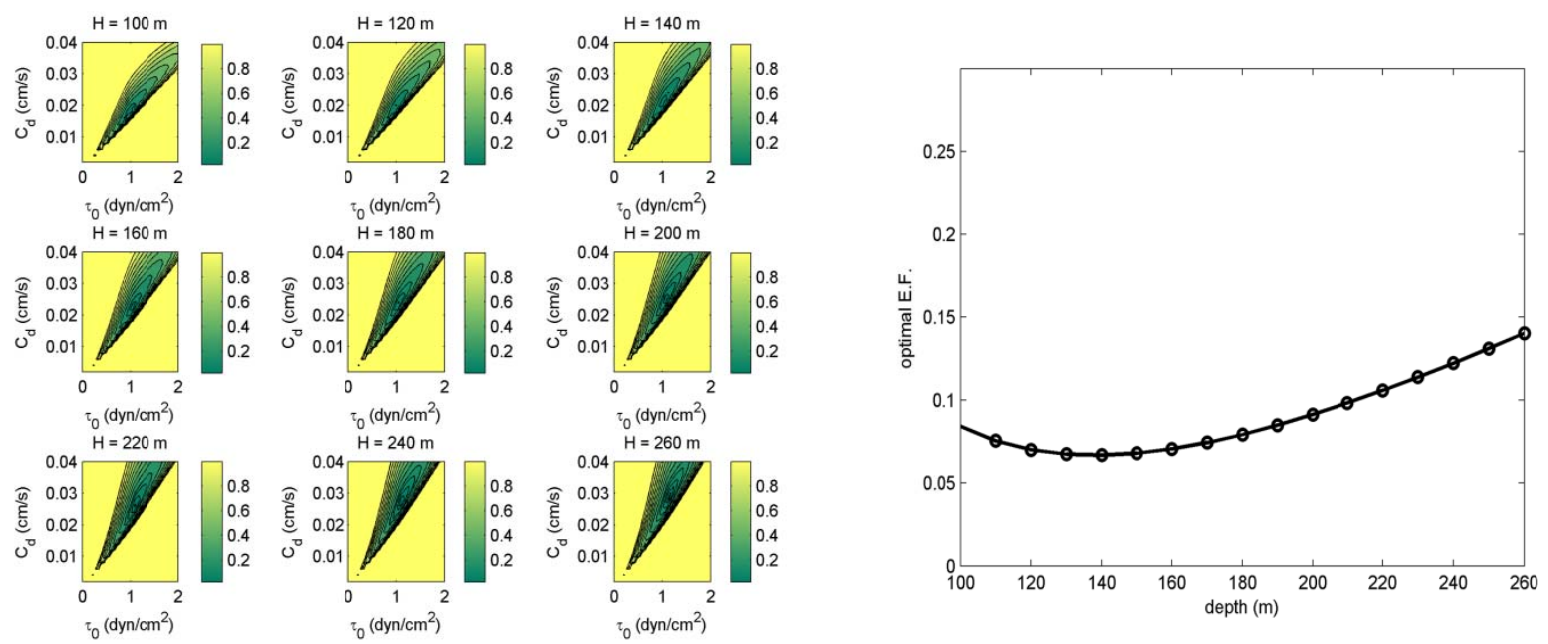

Figure 17: (left) Error Factor "E.F." as a function of varying maximum wind stress $\tau_{0}$ and natural friction coefficient $C_{d}$ for different depths, (right) "E.F." minimum as a function of depth.

\subsubsection{Uniform turbine drag}

When the turbine drag is added, energy dissipation will be comprised of natural dissipation and dissipation by turbines, a fraction of which can be collected by turbines and converted into electricity. The presence of turbines is incorporated in the model as additional turbine drag. Similar to natural drag, the additional turbine drag $\vec{T}$ is assumed linearly proportional to current velocity in the following form

$$
\vec{T}=-\frac{C_{t} \rho}{H} \vec{V}
$$

where $C_{t}$ is the turbine drag coefficient, and similar to $C_{d}$, has dimensions of velocity. The total drag force with turbines becomes $-\frac{\left(C_{t}+C_{d}\right) \rho}{H} \vec{V}$. The solution of the flow assumes the same form except that $C_{d}$ is replaced with $\left(C_{d}+C_{t}\right)$ in Equations (24) and (25).

The mechanical energy equation may be found by multiplying Equation (11) and (12) with horizontal velocity components $u$ and $v$, and adding them together, eliminating the Coriolis terms, resulting in

$$
-\frac{u}{\rho} \frac{\partial p}{\partial x}-\frac{v}{\rho} \frac{\partial p}{\partial y}+\frac{F_{x}+W_{x}}{\rho} u+\frac{F_{y}+W_{y}}{\rho} v=0
$$


Substituting Equation (21) and (22) for the wind stress and drag force into above equation and including turbine drag results in the following mechanical energy balance equation:

$$
-\left[u H \frac{\partial p}{\partial x}+v H \frac{\partial p}{\partial y}\right]-\left[\rho C_{d}\left(u^{2}+v^{2}\right)\right]-\left[\rho C_{t}\left(u^{2}+v^{2}\right)\right]-\left[\tau_{0} u \cos \left(\pi \frac{y}{b}\right)\right]=0 .
$$

The four terms in the above equation represent work done by pressure gradient $P_{\text {pres }}$, natural dissipation $D_{\text {natural }}$, energy dissipation by turbines $D_{\text {turbine }}$, and the energy production from surface wind stress $P_{\text {prod }}$, respectively. The ocean basin is considered a closed system, and Equation (31) is integrated over the entire domain. By substituting the solutions from Equation (24) and (25) into the following integration, it is found that

$$
\int_{x=0}^{a} \int_{y=0}^{b}\left[-\rho C_{d}\left(u^{2}+v^{2}\right)-\rho C_{t}\left(u^{2}+v^{2}\right)-\tau_{0} u \cos \left(\pi \frac{y}{b}\right)\right] d x d y=0 .
$$

Therefore, we also have

$$
\int_{x=0}^{a} \int_{y=0}^{b}\left[u H \frac{\partial p}{\partial x}+v H \frac{\partial p}{\partial y}\right] d x d y=0
$$

Equation (32) and (33) essentially mean in this closed circulation system, energy is solely produced from wind stress $\left(\mathrm{P}_{\text {prod }}\right)$ and dissipated from natural dissipation $\left(D_{\text {natural }}\right)$ and turbines $\left(D_{\text {turbine }}\right)$. Work by pressure gradient $\mathrm{P}_{\text {pres }}$ only serves to redistribute energy in the basin, but doesn't produce or dissipate energy.

The turbine drag coefficient $C_{t}$ is a function of the number of turbines and turbine spacing. Intuitively the greater this turbine drag coefficient, the stronger energy extraction will be. Increases in the turbine drag coefficient can be thought of as adding more turbines or increasing their size thereby further dissipating the flow field and reducing the velocity. However, at this time there is no explicit relationship between turbine properties and the turbine drag coefficient used here. The flow speed $|V|=\sqrt{u^{2}+v^{2}}$ as well as the total energy dissipation from turbines are functions of $C_{t}$ :

$$
\int D_{\text {turbine }}\left(C_{t}\right) d A=-\int C_{t} \rho\left|V\left(C_{t}\right)\right|^{2} d A
$$

Therefore the total energy balance from Equation (32) in the circulation system is rewritten as

$$
-\int \tau_{0} \cos \left(\pi \frac{y}{b}\right) u\left(C_{t}\right) \cdot \mathrm{dA}=\int C_{d} \rho\left|V\left(C_{t}\right)\right|^{2} d A+\int C_{t} \rho\left|V\left(C_{t}\right)\right|^{2} d A
$$

The left hand side represents the energy production, and the right hand side the energy dissipation. In Equation (35), as $C_{t}$ increases, current velocity in the circulation will decrease due to increased friction, which will reduce the left hand side term (i.e. energy production by wind stress), and hence the sum of two terms on the right hand side (i.e. total dissipation in the system).

Equation (11) and (12) show the momentum balance of the circulation. In the x (zonal) direction, the undisturbed circulation is under the force balance between Coriolis force $(f v)$, pressure gradient $\left(-g \frac{\partial \eta}{\partial x}\right)$, drag force $\left(-\frac{C_{d} u}{H}\right)$ and wind stress $\left(-\frac{\tau_{0}}{\rho H} \cos \left(\frac{\pi}{b} y\right)\right)$. In the y (meridional) direction, the force balance is 
between Coriolis force $(-f u)$, pressure gradient $\left(-g \frac{\partial \eta}{\partial y}\right)$, and drag $\left(-\frac{C_{d} v}{H}\right)$. Because of the western boundary intensification resulting from the Coriolis Effect, the meridional velocity component $v$ reaches its peak in the middle of the western boundary layer, leading to a peak Coriolis force in zonal direction at the same location, as seen in Figure 18. It is also seen in Figure 19 that the meridional Coriolis force is primarily balanced by pressure gradient due to spatial variation of sea surface elevation. The peak pressure gradient in $\mathrm{x}$ direction is observed on the western boundary, and therefore the steepest water surface inclination in $\mathrm{x}$ direction is expected in the same region. The drag force in $\mathrm{x}$ direction is relatively weak in the momentum balance compared to Coriolis force and pressure gradient, and so is wind stress in most of the basin except on the southern and northern boundaries where the wind stress is the strongest. In the $\mathrm{y}$ direction, the Coriolis force is relatively weaker compared to the $\mathrm{x}$ direction because of relatively weaker zonal velocity component $u$. However in most of the basin, the meridional Coriolis force is still primarily balanced by the pressure gradient except on the western boundary where the drag force is relatively strong due to fast current velocity in y direction (Figure 19).
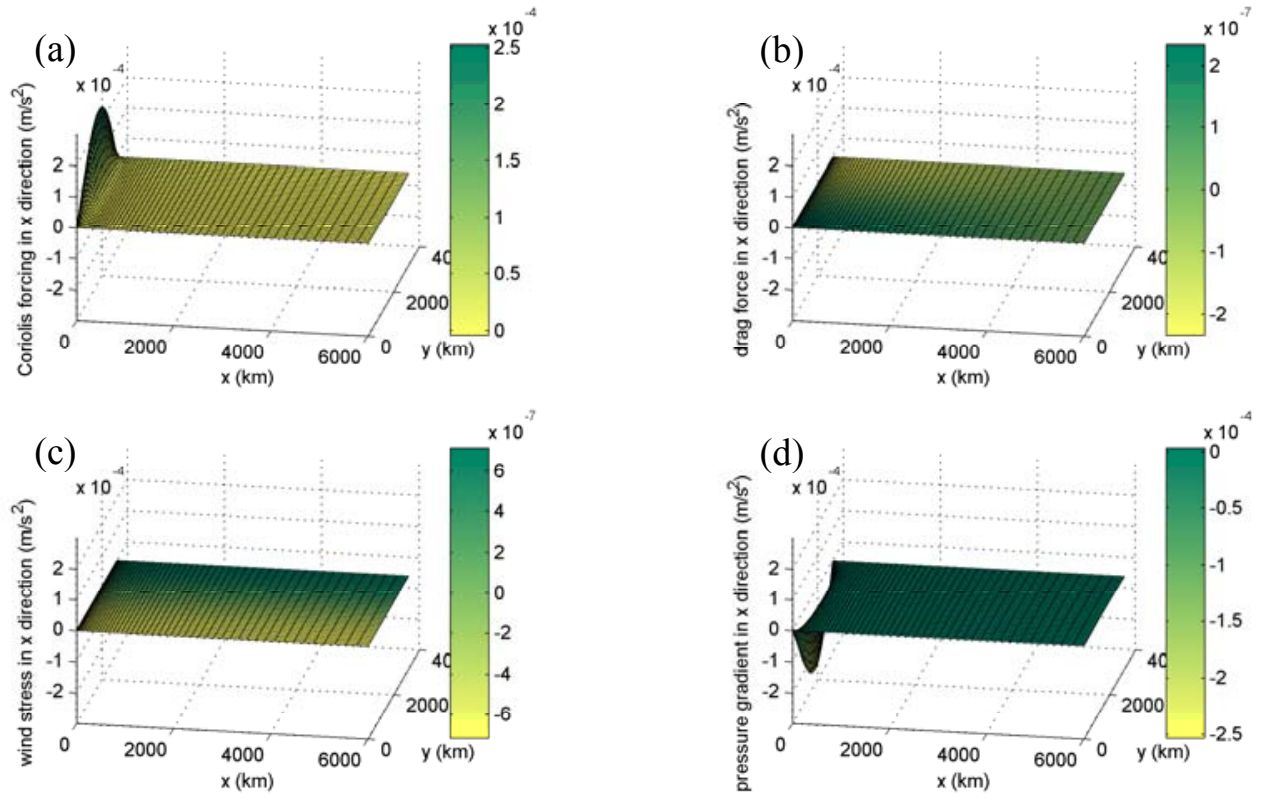

Figure 18: Spatial variation of each term in the $x$ momentum Equation 11: (a) Coriolis forcing, (b) drag force, (c) wind stress, (d) pressure gradient. 


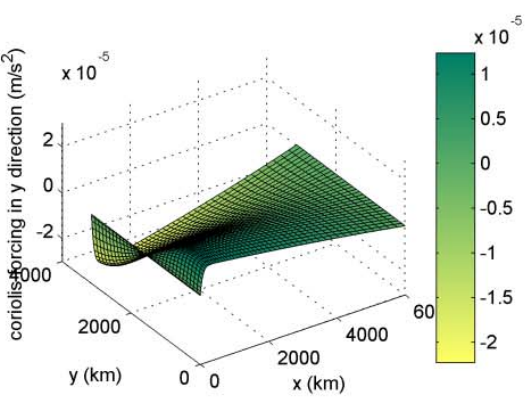

(a)

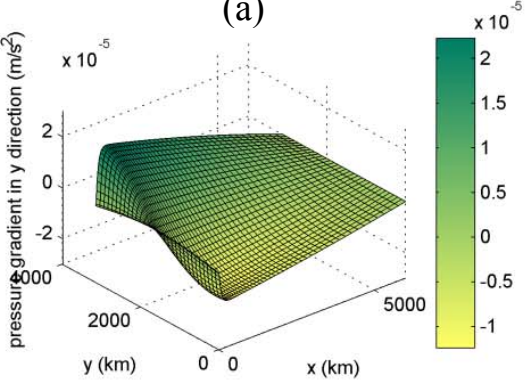

(c)

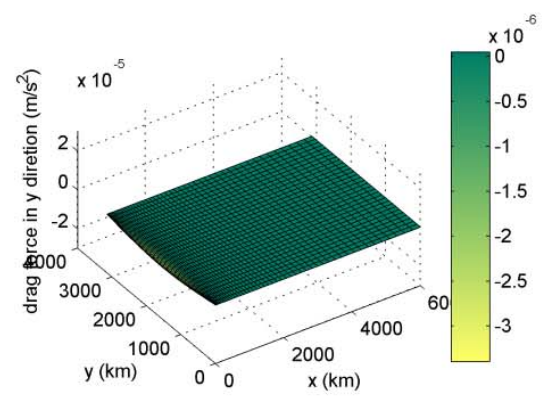

(b)

Figure 19: Spatial variation of each term in the y momentum Equation 12: (a) Coriolis forcing, (b) drag force, (c) pressure gradient.

It is seen that the primary force balance is between Coriolis force and pressure gradient in both $\mathrm{x}$ and $\mathrm{y}$ directions in the basin. Therefore the geostrophic characteristic of the circulation is still dominant in most of the basin. Areas of exception include the western, southern and northern boundaries, where external forces are strong and therefore force balance shifts away from the geostrophic balance.

The total energy dissipation by turbines is shown in Figure 20 as a function of turbine drag coefficient $C_{t}$. Once again, the flow features seasonal variation, and is found to be the strongest in summer and the weakest in winter. Figure 20 also shows three curves with markers that correspond to the minimum, mean and maximum flow conditions due to seasonal variability. The trend of energy dissipation from turbines is very obvious. When no turbines are added (i.e. turbine drag coefficient $C_{t}=0$ ), the ocean current is undisturbed and energy dissipation by turbines is zero. At the same time, the natural dissipation is at its highest $(\approx 94 G W)$. This number is not far from the estimate by Csanady (1989), which is about $70 \mathrm{GW}$. As the turbine drag coefficient $C_{t}$ increases from zero, the energy dissipation by turbines also increases till $C_{t}$ reaches about 0.04 , where energy dissipation from turbines $D_{t}$ reaches its highest $(\cong 44 G W)$. As $C_{t}$ increases to beyond $0.04, D_{t}$ starts to decrease with $C_{t}$, which means adding more turbines in this condition is not able to generate more total dissipation from turbines, but simply further blocks the current flow. Physically it means although turbine number increases, the energy dissipation from each turbine decreases. Therefore the product of those two, namely, the total dissipation from turbines, is uncertain. It is shown that maximum total energy dissipation by turbines is achieved when turbine drag coefficient is about twice of the natural drag coefficient. This means the upper limit results in about twice as much energy dissipated by turbines as is dissipated by natural friction. The natural dissipation rate decreases monotonically as turbine drag increases (blue curve in Figure 20). 


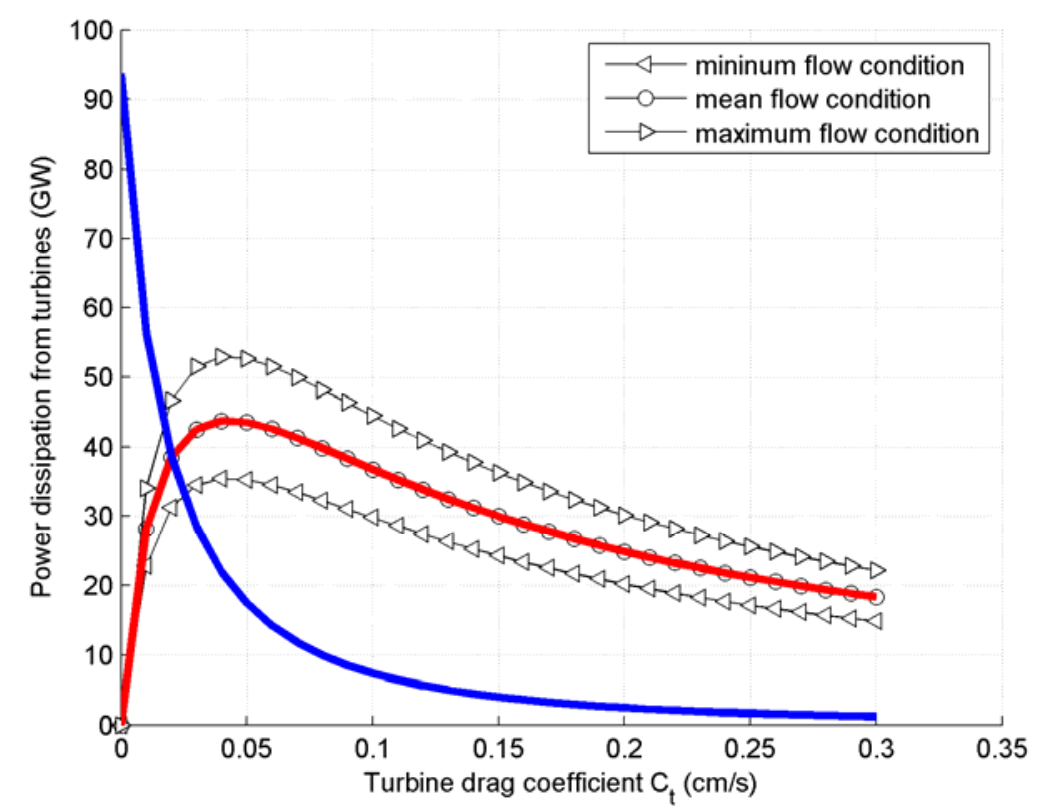

Figure 20: Power dissipation from turbines for three different flow conditions as a function of the turbine drag coefficient; energy dissipation by turbines for the mean flow condition is highlighted in red and the corresponding natural dissipation is highlighted in blue.

\subsubsection{Localized turbine drag}

The model thus far established a relationship between uniform turbine drag coefficients and the energy dissipation by turbines and determined that peak energy dissipation rates from turbines exist. However, to more realistically simulate the scenario of specifically extracting power only from the Gulf Stream area, it is necessary to modify the model to address the locally high energy dissipation in the Gulf Stream due to turbines. It is desirable to have a spatially varying turbine drag coefficient instead of a constant value. Therefore $C_{t}$ is formulated as a function of both x and y instead of a simple constant.

Differentiating $\mathrm{x}$ and $\mathrm{y}$ momentum equations with respect to $\mathrm{y}$ and $\mathrm{x}$ respectively and subtracting result in a slightly different equation

$f \frac{\partial u}{\partial x}+u \frac{\partial f}{\partial x}+\left(f \frac{\partial v}{\partial y}+v \frac{\partial f}{\partial y}\right)=\frac{1}{H}\left(u \frac{\partial C_{\text {total }}}{\partial y}+C_{\text {total }} \frac{\partial u}{\partial y}\right)-\frac{1}{H}\left(C_{\text {total }} \frac{\partial v}{\partial x}+v \frac{\partial C_{\text {total }}}{\partial x}\right)-\frac{\tau_{0}}{\rho H} \frac{\pi}{b} \sin \left(\frac{\pi}{b} y\right)$

where $C_{\text {total }}=C_{d}+C_{t}$ and represents the total of natural and turbine drag. The above equation is further simplified as

$$
\beta v=\frac{C_{\text {total }}}{H}\left(\frac{\partial u}{\partial y}-\frac{\partial v}{\partial x}\right)+\frac{1}{H}\left(u \frac{\partial C_{\text {total }}}{\partial y}-v \frac{\partial C_{\text {total }}}{\partial x}\right)-\frac{\tau_{0}}{\rho H} \frac{\pi}{b} \sin \left(\frac{\pi}{b} y\right)
$$

After introducing the streamfunction $\psi$, the governing equation becomes

$$
\left(\frac{\partial^{2} \psi}{\partial x^{2}}+\frac{\partial^{2} \psi}{\partial x^{2}}\right)+\alpha_{1}(x, y) \frac{\partial \psi}{\partial x}+\alpha_{2}(x, y) \frac{\partial \psi}{\partial y}=\frac{\tau_{0} \pi}{C_{\text {total }} \rho b} \sin \left(\frac{\pi}{b} y\right)
$$


where $\alpha_{1}(x, y)=\left(\frac{1}{C_{\text {total }}} \frac{\partial C_{\text {total }}}{\partial x}+\frac{H \beta}{C_{\text {total }}}\right)$, and $\alpha_{2}(x, y)=\left(\frac{1}{C_{\text {total }}} \frac{\partial C_{\text {total }}}{\partial y}\right)$.

To more accurately represent the scenario of extracting power from the fastest western boundary currents (i.e. the Gulf Stream), it is desirable to design a spatially varying turbine drag coefficient that peaks in the middle of the western boundary where ocean current is the strongest and declines rapidly to zero away from the Gulf Stream region. The turbine drag coefficient profile is formulated as

$$
C_{t}(x, y)=C_{t 0} e^{-\frac{\left(x^{2}+\left(y-\frac{1}{2} b\right)^{2}\right)}{\epsilon}}
$$

where $C_{t 0}$ is the peak value of the turbine drag coefficient, and $\epsilon$ is a parameter controlling the approximate area of the turbine region. An example illustrating the spatially varying $C_{t}$ is shown in Fig. 21.

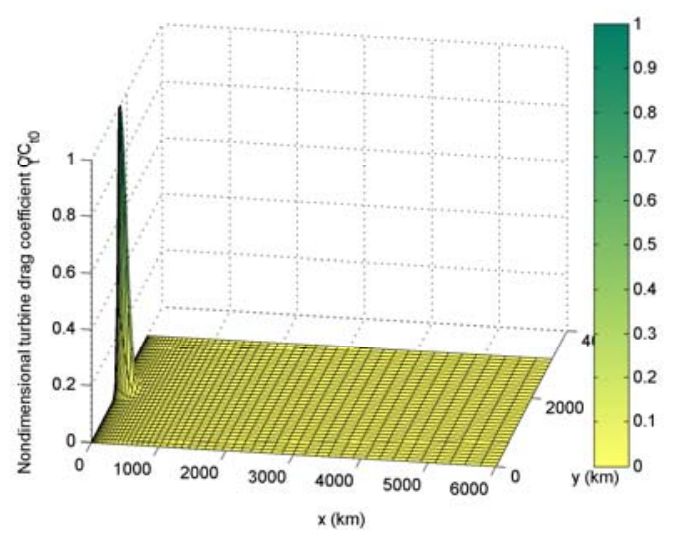

Figure 21: Distribution of the nondimensional localized turbine drag in the Gulf Stream $\left(\epsilon=10^{4} \mathrm{~km}^{2}\right)$.

Equation (38) is a second order partial differential equation with variable coefficients. Because of the spatially varying drag coefficient, analytical solutions are no longer possible and a numerical solution is obtained. Considering the simplicity of the model domain, we are using a finite difference approach to approximate the derivatives in the differential equation. The computational domain is discretized into a Cartesian mesh, and the differential equation is replaced by difference equations at each mesh point. At each mesh point $(i, j)$ the partial derivatives are replaced by central difference quotients:

$$
\begin{aligned}
& \frac{\partial \psi}{\partial x}=\frac{\psi_{i+1, j}-\psi_{i-1, j}}{x_{i+1, j}-x_{i-1, j}} \\
& \frac{\partial \psi}{\partial y}=\frac{\psi_{i, j+1}-\psi_{i, j-1}}{y_{i, j+1}-y_{i, j-1}} \\
& \frac{\partial^{2} \psi}{\partial x^{2}}=\frac{\frac{\psi_{i+1, j}-\psi_{i, j}}{x_{i+1, j}-x_{i, j}}-\frac{\psi_{i, j}-\psi_{i-1, j}}{x_{i, j}-x_{i-1, j}}}{x_{i+\frac{1}{2}, j}-x_{i-\frac{1}{2}, j}} \\
& \frac{\partial^{2} \psi}{\partial^{2} y}=\frac{\frac{\psi_{i, j+1}-\psi_{i, j}}{y_{i, j+1}-y_{i, j}}-\frac{\psi_{i, j}-\psi_{i, j-1}}{y_{i, j}-y_{i, j-1}}}{y_{i, j+\frac{1}{2}}-y_{i, j-\frac{1}{2}}}
\end{aligned}
$$


where $i$ and $j$ are indices in $\mathrm{x}$ and $\mathrm{y}$ directions. Indices $\left\{i \pm \frac{1}{2}\right\}$ and " $\left.j \pm \frac{1}{2}\right\}$ in the subscripts represent the centers of two adjacent grid points. The approximation for partial derivatives in this study is accurate to second order. Approaches to solve similar problems on a uniform grid with constant coefficients exist (e.g. Malek-Madani, 2012). A higher resolution near the western boundary is desired since the formation of a narrow western region with fast moving currents is expected. Therefore a non-uniform mesh is designed to discretize the domain such that mesh points have a higher density on the western boundary with a reduction in density to the east. In the $\mathrm{x}$ direction, a transitional uniform mesh is first defined as $z=$ $\left\{0, z_{1}, z_{2}, \ldots, z_{n}, a\right\}$, where $\Delta z=z_{i+1}-z_{i}=\frac{a}{n+1}$. Then the actual horizontal mesh is defined as

$$
x=z^{t} / a^{t-1}
$$

where $\mathrm{t}$ is a free parameter controlling the density of points on the western boundary. This maps the uniform mesh to a non-uniform mesh also defined within the same interval of $\{0, a\}$, where $x=$ $\left\{0, x_{1}, x_{2}, \ldots, x_{n}, a\right\}$. In the $\mathrm{y}$ direction, the mesh is kept uniform and $y=\left\{0, y_{1}, y_{2}, \ldots, y_{m}, b\right\}$, where $\Delta y=y_{j+1}-y_{j}=k=\frac{b}{m+1}$. Therefore the network of grid is established as $\left(x_{i, j}, y_{i, j}\right)=\left(\frac{(i \Delta z)^{t}}{a^{t-1}}, j k\right)$, where $1 \leq i \leq n, 1 \leq j \leq m$. In non-uniform grid mesh, points with " $i \pm \frac{1}{2}$ " indices will not be located at the geometrical center of two adjacent grid points, but slightly biased to the lower end according to the conversion in Equation (44). Figure 22 shows the non-uniform mesh grid with $\mathrm{t}=3, \mathrm{n}=50$ and $\mathrm{m}=30$.

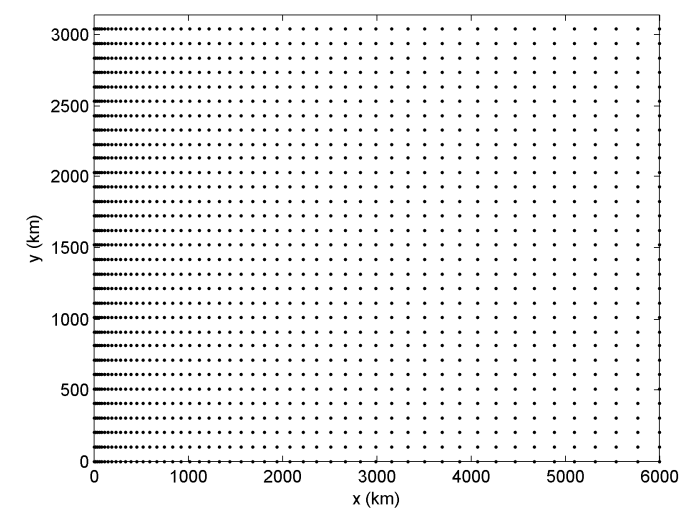

Figure 22: Non-uniform mesh grid for the domain with $t=3, n=50$, and $\mathbf{m}=\mathbf{3 0}$.

Substituting Equations (40)-(43) into the governing Equation (38), the governing equation can be rearranged to the following form

$$
\psi_{i, j}\left[A_{1}\right]+\psi_{i+1, j}\left[A_{2}\right]+\psi_{i-1, j}\left[A_{3}\right]+\psi_{i, j+1}\left[A_{4}\right]+\psi_{i, j-1}\left[A_{5}\right]=F_{i, j}
$$

where coefficients $A_{1} \sim A_{5}$ are all functions of $\mathrm{x}$ and $\mathrm{y}$ :

$$
\begin{aligned}
& A_{1}=-\frac{1}{x_{i+\frac{1}{2}, j}-x_{i-\frac{1}{2}, j}}\left(\frac{1}{x_{i+1, j}-x_{i, j}}+\frac{1}{x_{i, j}-x_{i-1, j}}\right)-\frac{1}{y_{i, j+\frac{1}{2}}-y_{i, j-\frac{1}{2}}}\left(\frac{1}{y_{i, j+1}-y_{i, j}}+\frac{1}{y_{i, j}-y_{i, j-1}}\right) \\
& A_{2}=\frac{1}{\left(x_{i+\frac{1}{2}, j}-x_{i-\frac{1}{2}, j}\right)\left(x_{i+1, j}-x_{i, j}\right)}+\frac{\alpha_{1}\left(x_{i, j}, y_{i, j}\right)}{x_{i+1, j}-x_{i-1, j}}
\end{aligned}
$$




$$
\begin{aligned}
& A_{3}=\frac{1}{\left(x_{i+\frac{1}{2}, j}-x_{i-\frac{1}{2}, j}\right)\left(x_{i, j}-x_{i-1, j}\right)}-\frac{\alpha_{1}\left(x_{i, j}, y_{i, j}\right)}{x_{i+1, j}-x_{i-1, j}} \\
& A_{4}=\frac{1}{\left(y_{i, j+\frac{1}{2}}-y_{i, j-\frac{1}{2}}\right)\left(y_{i, j+1}-y_{i, j}\right)}+\frac{\alpha_{2}\left(x_{i, j}, y_{i, j}\right)}{y_{i, j+1}-y_{i, j-1}} \\
& A_{5}=\frac{1}{\left(y_{i, j+\frac{1}{2}}-y_{i, j-\frac{1}{2}}\right)\left(y_{i, j}-y_{i, j-1}\right)}-\frac{\alpha_{2}\left(x_{i, j}, y_{i, j}\right)}{y_{i, j+1}-y_{i, j-1}}
\end{aligned}
$$

The term on the right hand side $F_{i, j}$ represents the wind forcing and is only a function of $\mathrm{y}$ or $j$ in our model. Equation (45) is series of linear algebraic equations, which can also be written in matrix form,

$$
\boldsymbol{A} \boldsymbol{\psi}=\boldsymbol{F} .
$$

The stream-function is solved by taking the inverse of the coefficient matrix:

$$
\psi=A^{-1} F
$$

Equation (52) is solved as an implicit numerical solution of the streamfunction, which can be used to calculate the flow field using Equations (17) and (18).

\subsubsection{Numerical model validation}

The basin-wide energy balance equation is given by Equation (35). The energy dissipation by turbines provides the approximate theoretical upper limit of energy extraction using turbines. When a uniform turbine drag coefficient is used in the model, the model can be solved either analytically or numerically following the method presented in the previous section. Therefore, the analytical solution can be used to validate the accuracy of the numerical solution. The error between analytical and numerical solutions is quantified by the ratios of Root Mean Square $(R M S)$ of the difference between analytical and numerical energy dissipation to the mean value of analytical energy dissipation $(M E A N)$ for 3 different grid resolutions in the $\mathrm{x}$ direction $(50 \times 30,100 \times 30,150 \times 30)$ and 3 different non-uniform grid schemes

$(\mathrm{t}=1,2,3)$. Table 5 shows $\frac{R M S}{M E A N}(\%)$ for the case with maximum uniform dissipation using different grid resolutions and schemes. It is found that denser grid points on the western boundary produces better agreement between numerical and analytical solutions, and the numerical solution converges towards the analytical solution as spatial resolution increases. The case with $\mathrm{t}=3$ and resolution of $150 \times 30$ (named case T3 hereafter) produces a numerical solution with error $\frac{R M S}{M E A N}$ less than $1 \%$. Although higher resolution might be able to produce better results, the computational expenses increases greatly for the implicit solution, while case T3 is capable of producing results with sufficient accuracy. Therefore the model settings from case T3 are used in the subsequent analysis. Figure 23a shows the comparison of analytical and numerical total energy production/dissipation for case T3. Since the energy dissipation is comprised of natural dissipation and dissipation by turbines, Figure $23 \mathrm{~b}$ shows the comparison of natural dissipation and dissipation by turbines from both analytical and numerical solutions for case T3. It is clear from these figures that the numerical model is able to reasonably reproduce the analytical results. 
Table 5: The relative error (RMS/MEAN) between analytical and numerical total energy dissipation for different spatial resolutions and different $t$ values.

\begin{tabular}{|c|c|c|c|c|}
\hline \multicolumn{2}{|c|}{ RMS/MEAN error (\%) } & $50 \times 30$ & $100 \times 30$ & $150 \times 30$ \\
\hline \multirow{2}{*}{$\begin{array}{c}\text { Total energy } \\
\text { dissipation }\end{array}$} & $\mathrm{t}=1$ & $4.24 \%$ & $3.91 \%$ & $3.64 \%$ \\
\cline { 2 - 5 } & $\mathrm{t}=2$ & $1.82 \%$ & $1.48 \%$ & $0.97 \%$ \\
\cline { 2 - 5 } & $\mathrm{t}=3$ & $1.22 \%$ & $1.16 \%$ & $0.94 \%$ \\
\hline
\end{tabular}

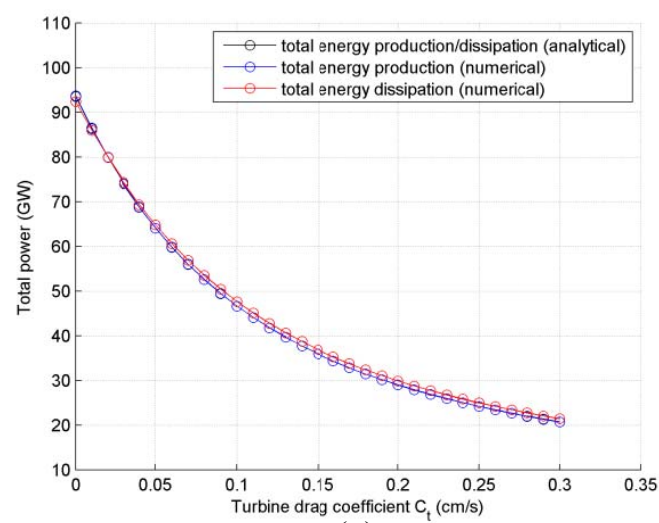

(a)

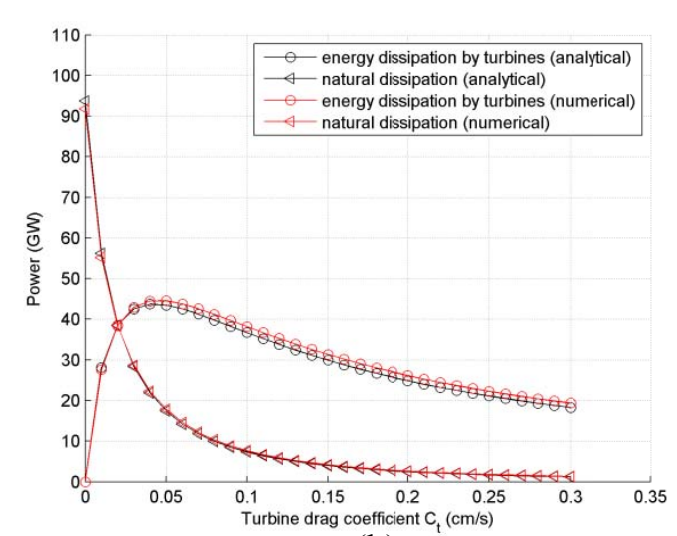

(b)

Figure 23: (a) comparing analytical and numerical total energy production/dissipation, and (b) energy dissipation by turbines and natural dissipation from both analytical and numerical solutions for case T3.

\subsubsection{Total energy dissipation by localized turbines}

The total energy dissipation from the turbine drag is evaluated by

$$
D_{\text {turbine }}=\int C_{t}\left(x, y, C_{t o}\right) \rho\left|V\left(C_{t}\left(x, y, C_{t 0}\right)\right)\right|^{2} d A
$$

which is a function of $C_{t o}$. In Equation (53), $V$ is the current speed and is equal to $\sqrt{u^{2}+v^{2}}$, and $u$ and $v$ have been numerically solved based on Equations (17) and (18). The sensitivity of energy dissipation by turbines to the peak turbine drag coefficient $C_{t 0}$ is shown in Figure $24 \mathrm{~b}$. Curves of different colors in Figure 24 correspond to different values of $\epsilon$ in Equation (39), and therefore different surface areas of turbines as summarized in Table 6. Figure 24a shows the approximate areas of localized turbine regions (boundaries defined as lines of $50 \%$ of the peak drag coefficient) for 5 different scenarios, ranging from about $0.1 \%$ (scenario A) to approximately $23 \%$ (scenario E) of the entire basin surface area. Different scenarios can be related to different realistic spatial coverage. For example, scenario A has an approximate area of $2 \times 10^{4} \mathrm{~km}^{2}$, which is similar to the actual surface area of the Florida Strait. Scenario $C$ has an area of approximately $1.7 \times 10^{5} \mathrm{~km}^{2}$, which is similar to the surface area of the Gulf Stream along the entire U.S. east coast extending from Florida to Cape Hatteras. The areas for each scenario are also tabulated in Table 6. For different scenarios, the energy dissipation from localized turbines with respect to different levels of turbine drag coefficients all share similar trends. As the turbine drag coefficient increases from zero, the energy dissipation by turbines increase until it reaches its peak. Beyond the peak, further increasing the turbine drag coefficient reduces the total energy dissipation from turbines. As the area of the turbine region increases from scenario A to scenario E, the peak energy 
dissipation by turbines increases accordingly and approaches an upper bound associated with uniform turbine drag coefficient .

Table 6: The values of approximate turbine region areas, peak turbine drag coefficient, and peak power for all scenarios.

\begin{tabular}{|c|c|c|c|c|c|}
\hline Scenario & $\begin{array}{c}\text { Area } \\
\text { percentage (\%) }\end{array}$ & Area $\left(\mathrm{km}^{2}\right)$ & $C_{t 0}(\mathrm{~cm} / \mathrm{s})$ & $\begin{array}{c}\text { Mean Peak } \\
\text { power }(\mathrm{GW})\end{array}$ & $\begin{array}{c}\text { Peak power } \\
\text { range }(\mathrm{GW})\end{array}$ \\
\hline A & $0.10 \%$ & $1.8 \mathrm{E}+04$ & 0.08 & 5.1 & $4.0-6.0$ \\
\hline B & $0.23 \%$ & $4.3 \mathrm{E}+04$ & 0.1 & 10.1 & $8.2-12.3$ \\
\hline C & $0.92 \%$ & $1.7 \mathrm{E}+05$ & 0.12 & 18.6 & $15.1-22.5$ \\
\hline D & $3.7 \%$ & $6.9 \mathrm{E}+05$ & 0.14 & 34.0 & $27.5-41.1$ \\
\hline E & $23 \%$ & $4.3 \mathrm{E}+06$ & 0.06 & 40.9 & $33.1-49.2$ \\
\hline uniform & $100 \%$ & $1.8 \mathrm{E}+07$ & 0.04 & 44.0 & $36.4-54.1$ \\
\hline
\end{tabular}

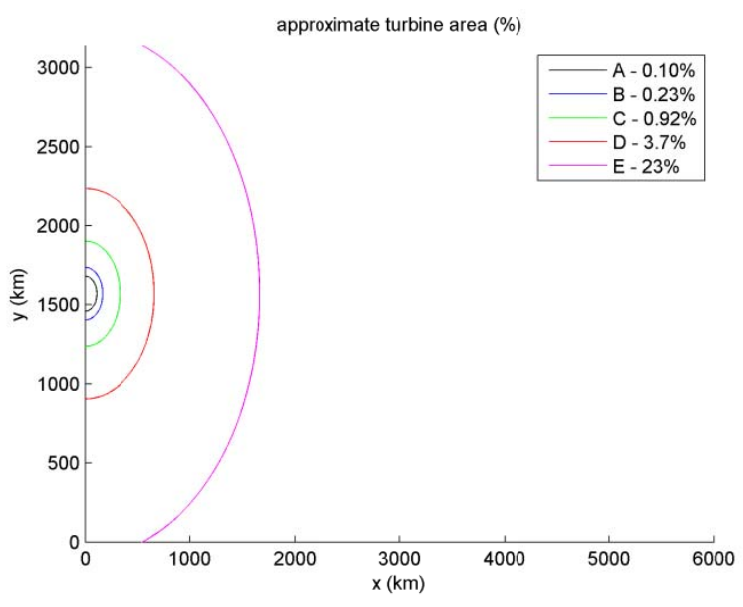

(a)

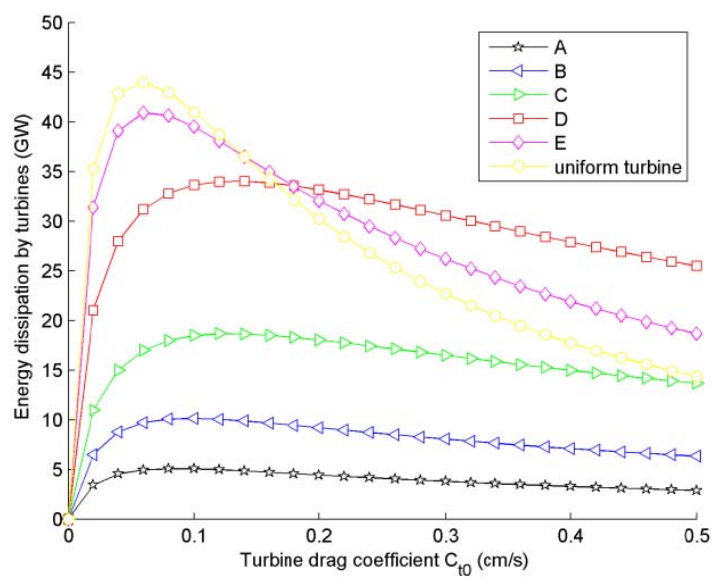

(b)

Figure 24: (a) Approximate areas of turbine regions for different scenarios, (b) energy dissipation by turbines as a function of the peak turbine drag coefficient $C_{t 0}$ for different scenarios.

As shown in Table 6, for scenario A, the peak power removal from the flow by turbines is found to be about $5.1 \mathrm{GW}$, occurring at $C_{t 0}=0.08$. The peak power removal increases to approximately $10.1 \mathrm{GW}$ in scenario $\mathrm{B}$ and $18.6 \mathrm{GW}$ in scenario $\mathrm{C}$. In scenario $\mathrm{D}$, the turbine area covers almost the entire western boundary with fast currents, and the peak power removal reaches about $34 \mathrm{GW}$ at $C_{t 0}=0.14$. In scenario $\mathrm{E}$, the turbine area covers almost the entire western quarter of the basin, and the peak energy removal rate $(40.9 \mathrm{GW})$ is very close to the case with uniform turbine drag coefficient (44 GW).

\subsubsection{Effects of localized turbine drag}

The effects on the flow field of turbine dissipation for the different scenarios for varying surface areas are found to be qualitatively similar, and only differ quantitatively for impact areas and strength. Therefore, only one scenario will be analyzed extensively and conclusions on other scenarios will be summarized in the summary section. The following analysis will be based on the turbine scenario of scenario A and the energy dissipation by turbines as a function of the turbine drag coefficient for the three different seasonal 
conditions is shown in Figure 25. The peak dissipation ranges between 4 and $6 \mathrm{GW}$ with a mean around $5 \mathrm{GW}$. The corresponding ranges of peak powers for different scenarios are shown in Table 6 .

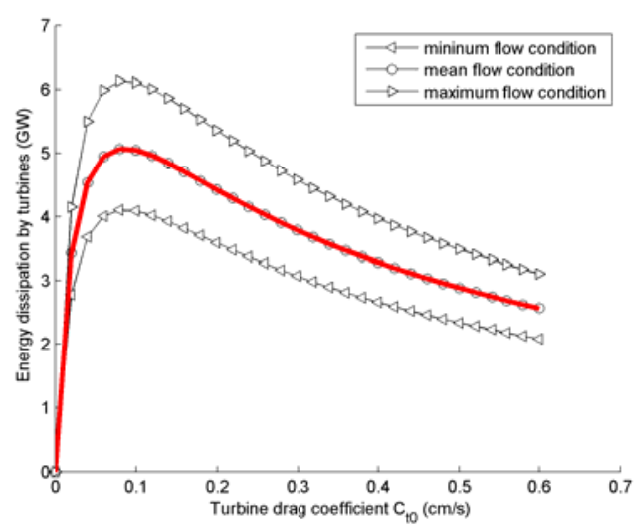

Figure 25: Energy dissipation by turbines as a function of turbine drag coefficient for three different seasonal flow conditions for scenario $A$.

Figures 26 and 27 show the detailed changes within the western boundary of the two velocity components in response to the localized turbine drag in the Gulf Stream. The meridional velocity in the turbine region decreases significantly due to the high resistance from turbines. The meridional velocity is reduced to a quarter of the original magnitude at the location with peak energy dissipation by turbines. Outside the turbine region, the meridional velocity change is negligible, therefore forming two residual meridional velocity peaks immediately up and down stream of the turbine region along the western boundary. The zonal velocity responds differently to the additional turbine drag. The zonal velocity changes direction in both the upstream and downstream of the turbine region along the western boundary. The zonal velocity magnitude increases due to the turbine presence. In the upstream, the undisturbed current flow has a westward zonal velocity component. Additional turbine drag inhibits the flow from continuing westward and guides it eastward to bypass the high resistance area. Similarly the downstream zonal velocity is redirected from the undisturbed eastward to westward with the addition of turbines.

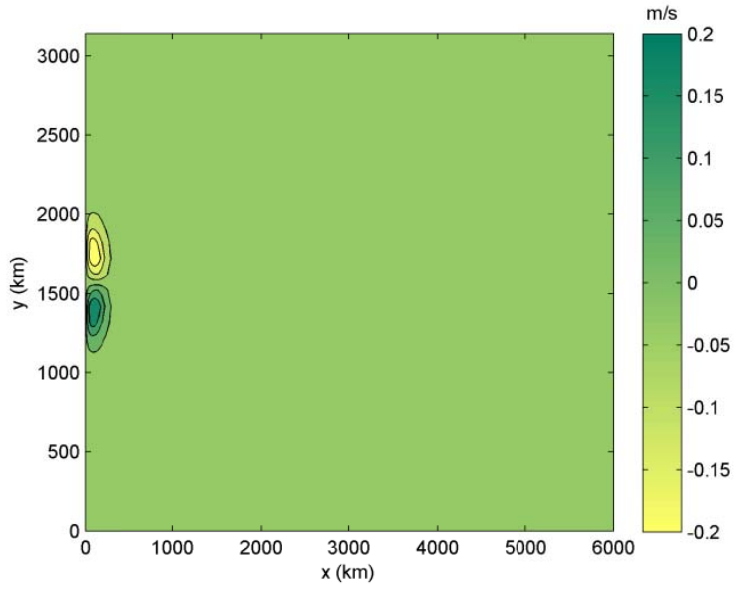

(a)

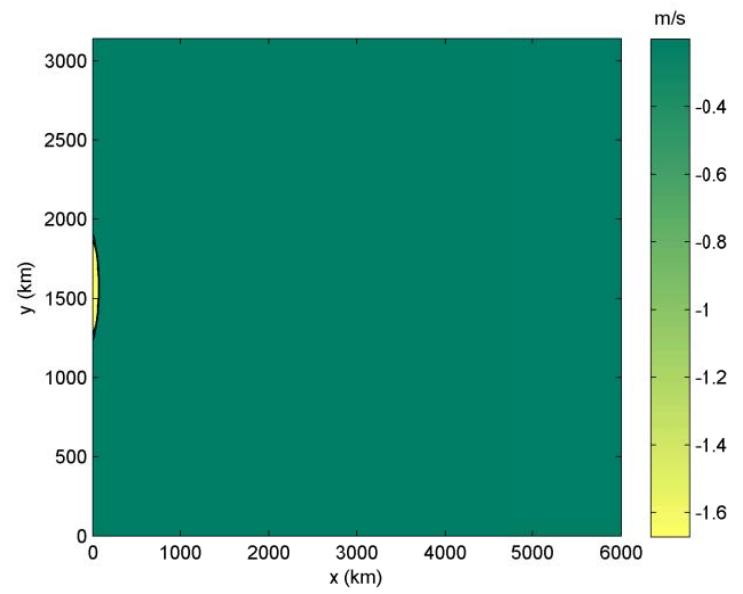

(b)

Figure 26: changes of (a) zonal velocity component, (b) meridional velocity component due to additional localized turbine drag (scenario A). 

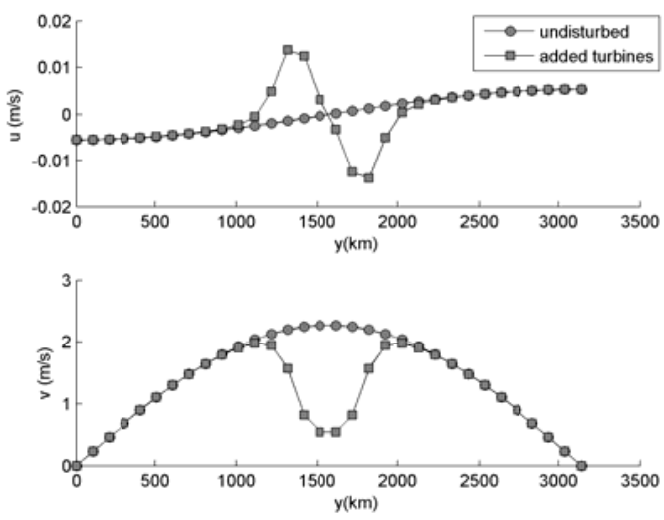

Figure 27: Comparing (a) zonal (u), and (b) meridional (v) current velocity components along the western boundary layer $(x \approx 2 \mathbf{k m})$ for undisturbed circulation and circulation with localized turbine drag (scenario $A)$.

Since the additional turbine drag significantly reduces meridional velocity in the Gulf Stream, and both Coriolis force and natural drag force are linearly related to the velocity magnitude, a corresponding reduction in Coriolis force in zonal direction and reduction in natural drag in meridional direction is seen in Figure 28. However the added turbine drag compensates for some of the reduction in natural drag without a significant change in total drag. It is observed from Figure 28 that addition of turbine drag reduces the pressure gradient in the middle of the western boundary, which consequently modifies the sea surface level. Once integrated, the pressure gradient can provide the sea surface elevation with the addition of the turbine drag. The effects of additional turbine drag on the sea surface are shown in Figure 29. In the region with additional turbine drag, a significant drop $(>0.5 \mathrm{~m})$ in the sea surface level is observed. The sea surface level elsewhere sees a negligible rise to maintain the basin-wide water mass balance.
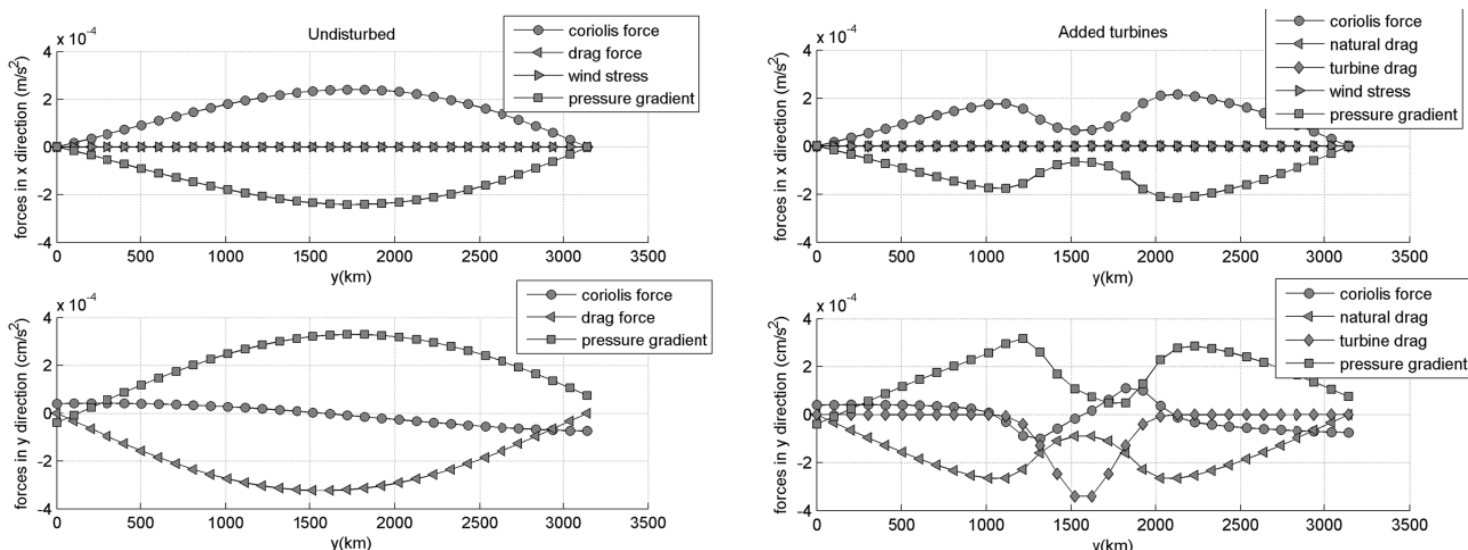

(a)

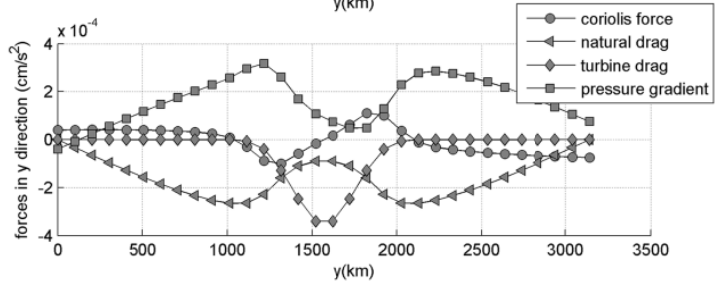

(b)

Figure 28: Force balance along the western boundary layer $(x \approx 2 \mathrm{~km})$ for $(a)$ undisturbed case and $(b)$ the case with localized turbine drag (scenario A). 

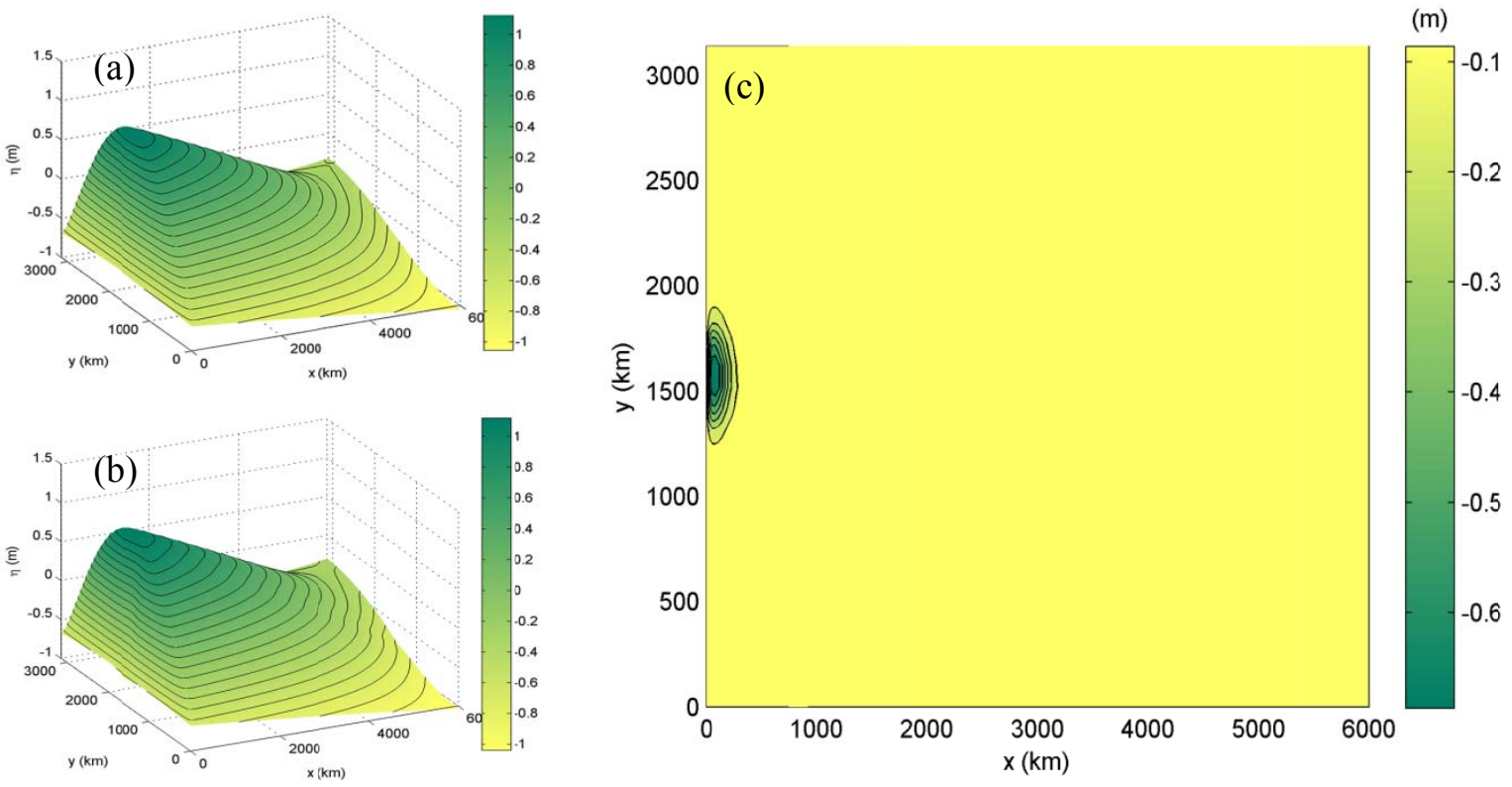

Figure 29: ocean surface elevation with lines of constant pressure for (a) undisturbed case, (b) case with additional turbines (scenario $\mathrm{A}$ ), and (c) the sea surface change after additional turbine drag is added.

The changes in zonal and meridional velocities along the western boundary are also inferred from the streamline patterns, which highlight the redirection of the Gulf Stream due to the additional turbine drag (Figure 30). The streamlines in the vicinity of the turbine region are affected by the turbine drag. The meridional velocity component decreases and the relatively weaker zonal component changes direction, resulting in bending of the streamlines within the turbine region. Current flow redirects eastward instead of going straight north to avoid the high drag region. In a physical interpretation, the Gulf Stream flow could ultimately avoid flowing through the Florida Strait by rerouting flow along the east of the Bahamas if the drag force in the Florida Strait significantly increases due to turbines.

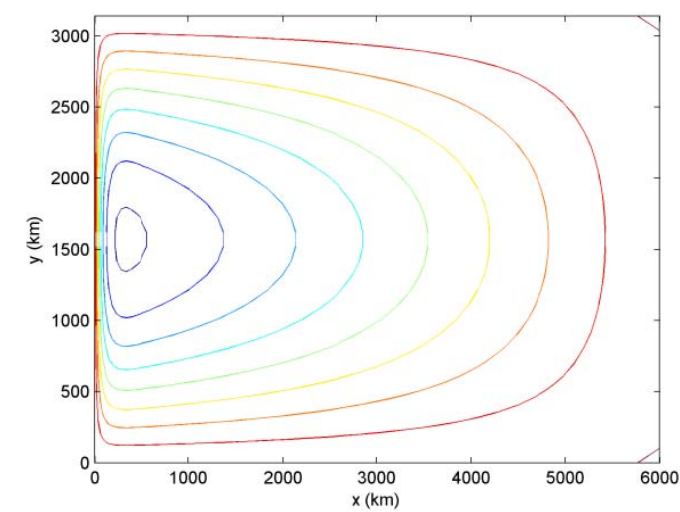

(a)

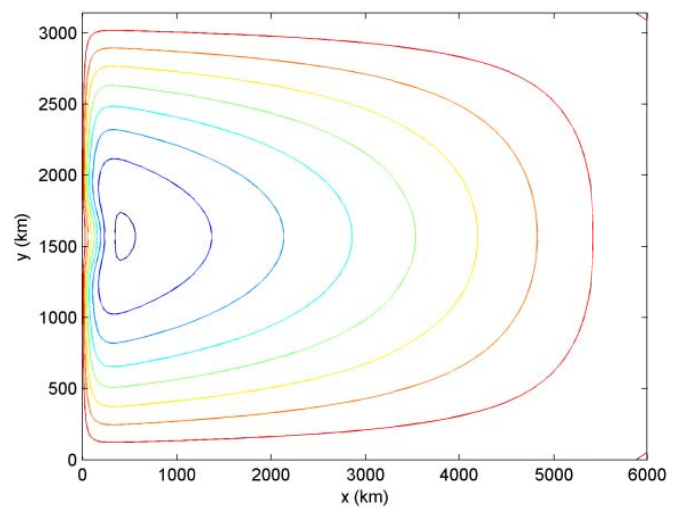

(b)

Figure 30: Comparing streamlines for (a) undisturbed circulation, (b) circulation with localized turbine drag.

The local energy balance equation (Equation 31) is shown in Figure 31 for each term with localized turbine drag applied for Scenario A. Extremely high energy dissipation by turbines in the middle of the western boundary is observed, as expected. The highest natural dissipation occurs at the immediate up 
and down streams of the turbine region along the western boundary. Presence of localized turbine drag has negligible impact on the energy balance outside of the turbine region. Near the southern and northern boundaries, the energy is balance is similar to the undisturbed case, primarily between energy production by wind stress and energy adjustment by the pressure gradient with natural dissipation playing a minor role. Overall the energy production by the wind stress is very similar to the undisturbed case except for two regions approximately $100 \mathrm{~km}$ eastward of the center of the turbine region. Because of the extra resistance from turbine drag, the zonal component of the current flow velocity in those two regions changes direction from westward to eastward. Therefore currents in that particular region change from moving with the wind to against the wind, resulting in negative energy production by wind stress in those two particular regions, effectively slowing down the currents in those two small areas. Away from the southern and northern boundaries, the energy production by wind stress reduces due to decreased wind stress. Close to the western boundary, the natural dissipation rate grows significantly in response to increased current velocity. Within the western boundary dissipation from natural friction and turbines takes more weight in the energy balance while energy production by wind stress becomes less important. As a result, the pressure gradient adjusts accordingly to keep the local energy balance by adjusting sea surface level, resulting in a local sea surface elevation drop shown in Figure 29. Local energy production by wind stress and local energy dissipation remain imbalanced. The pressure gradient functions to redistribute energy so that energy remains locally balanced. The peaks of work done by pressure gradient occur at the same locations where natural dissipation is the highest.
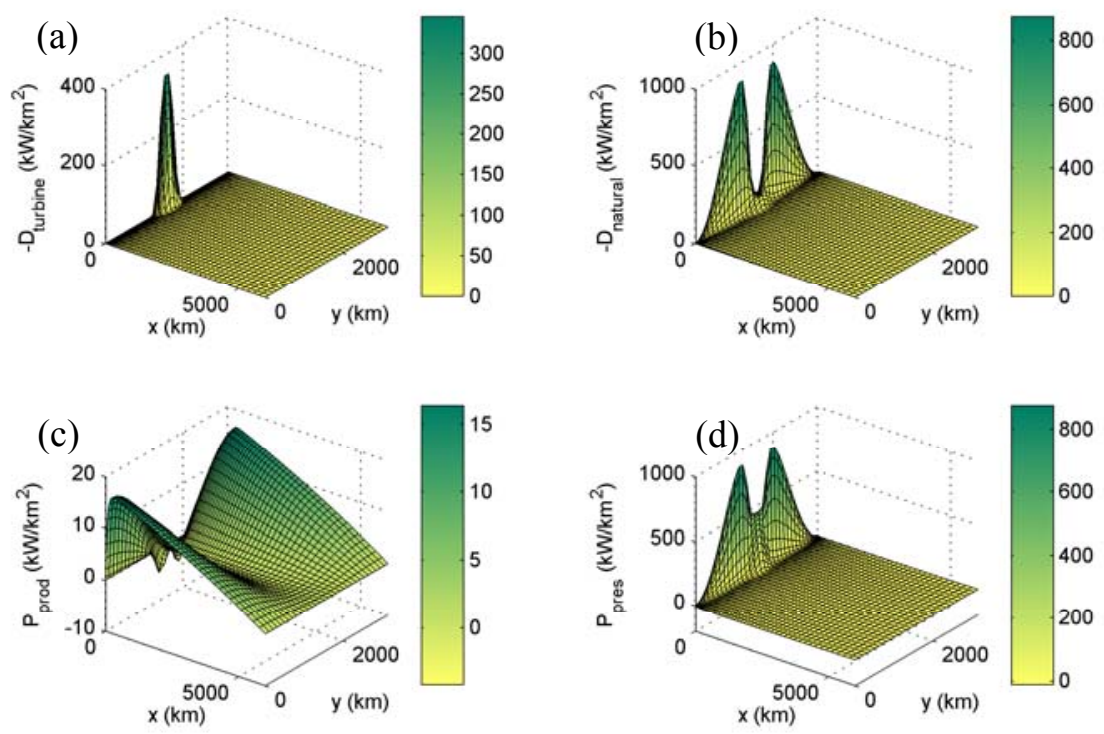

Figure 31: Spatial variation of each term from Equation 31 with localized turbine drag (scenario A): (a) density of energy dissipation by turbines; (b) density of natural energy dissipation; (c) density of energy production by wind; (d) work done by pressure gradient.

The addition of localized turbine drag significantly affects the residual energy fluxes in the circulation. This effect is evaluated by looking at the changes of residual energy fluxes through different crosssections of the circulation with different levels of energy dissipation. Figure 32a shows the undisturbed streamlines with multiple cross-sections and Figure $33 \mathrm{~b}$ shows the residual kinetic energy flux through individual cross-section. The residual energy flux drops significantly in the western boundary as turbine 
drag coefficient increases. As the turbine drag coefficient gradually increases, the peak residual energy flux shifts from the middle of the boundary (zero degrees) toward approximately 40-60 degrees, corresponding to the locations with the strongest residual current speed shown in Figure 27.

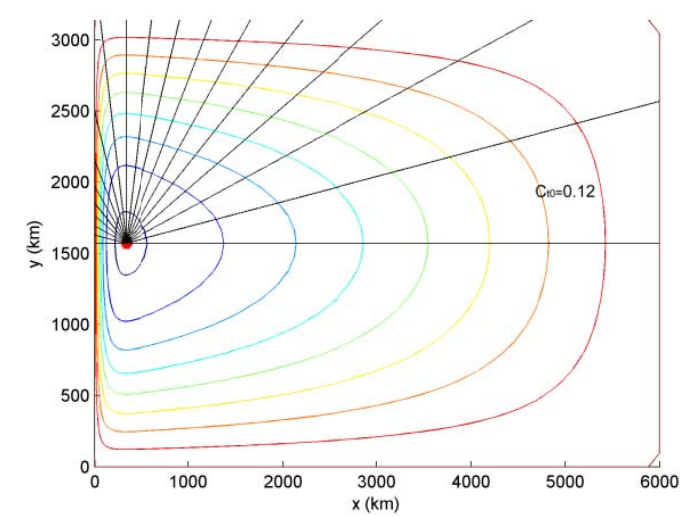

(a)

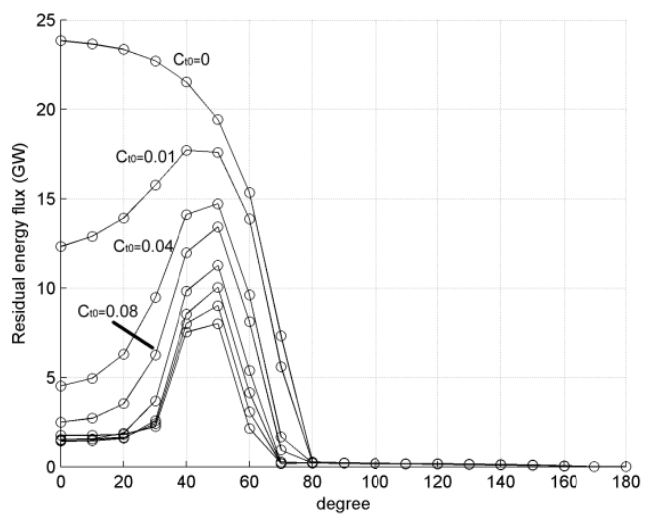

(b)

Figure 32: (a) Undisturbed streamlines with multiple cross-sections every 10 degrees, (b) residual energy flux for each cross-section on left with different level of localized energy dissipation from the Gulf Stream by turbines.

The effects of localized turbines in different scenarios share obvious similarities, but they are also physically distinct in several aspects. Due to conservation of mass, the volume flux through each crosssection stays constant for each particular case. Figure 33 shows the residual volume flux with different turbine drag coefficients for scenarios A-E and the case with uniform drag coefficient. When the turbine region is relatively small (e.g. scenarios A and B), the residual volume flux is mostly sustained even if turbine drag coefficient increases significantly. However, when the turbine region becomes much larger, a noticeable drop in residual volume flux is observed, and the residual volume flux curve is approaching the curve associated with uniform turbine drag coefficient, in which case a significant decrease in residual volume flux occurs with increased turbine drag coefficient.

Figure 34a shows the energy input in the system and Figure 34b shows the natural dissipation for different scenarios. For scenarios with small turbine region (e.g. scenarios A and B), the energy input remains almost constant, similar to the residual volume flux. The natural dissipation drops slightly with increased turbine drag coefficient. As the turbine region increases, the energy input starts to drop more rapidly with the turbine drag coefficient and approaches the case associated with uniform turbine drag coefficient. A similar trend is observed for natural dissipation.

It is noted from the previous discussion that the energy input from the wind stress is predominantly on the southern and northern boundaries where the wind is the strongest. The impact of turbines is primarily confined in the turbine regions with negligible far field effect. For cases with relatively small turbine regions, the additional turbine drag does not extend far into the southern/northern boundaries so that no significant flow reduction occurs in the areas with the primary energy production. Therefore the energy input does not change significantly, nor does the residual flow rate. As the turbine region grows much larger, the region with reduced flow also grows accordingly and extends further both to the south and north, causing energy production from wind stress to decrease. Therefore, a significant drop in energy input, as well as natural dissipation is observed. This also leads to considerably reduced flow rate. The extreme case with uniform turbine drag coefficient slows the flow universally across the entire basin 
resulting in a significant reduction in energy production rate. The residual flow rate is consequently reduced accordingly.

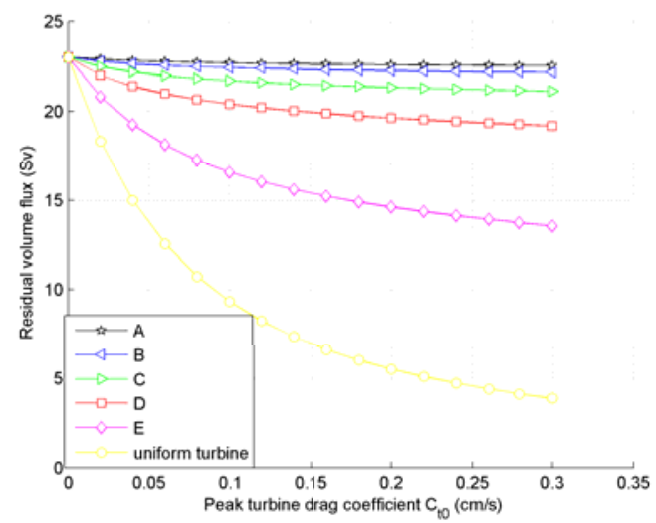

Figure 33: Residual volume flux as a function of peak turbine drag coefficient $C_{t 0}$ for different scenarios.

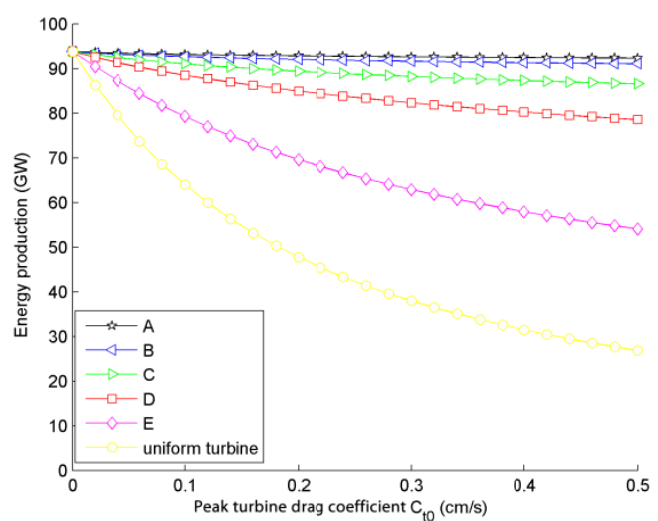

(a)

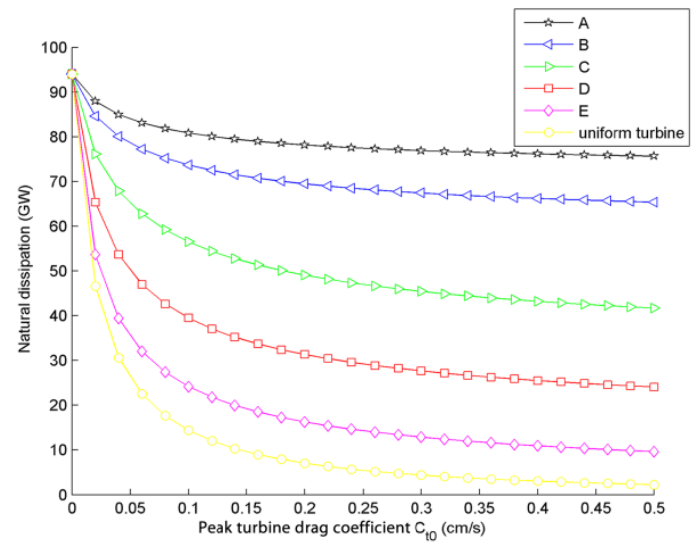

(b)

Figure 34: changes of (a) energy production, and (b) natural energy dissipation in the circulation with turbine drag coefficient for different scenarios.

\subsubsection{Total available power from undisturbed power density}

The previous power estimates provide the theoretical upper limit for recoverable energy resource from the Gulf Stream system for various scenarios. From a practical point of view, it is helpful to quantify the undisturbed kinetic power from hypothetical turbine arrays deployed in similar areas to determine the validity of the theoretical approach. Although this approach is neglecting the effects of extraction, this will help to determine the approximate size and capacity of arrays necessary to extract the maximum theoretical power. To examine the undisturbed kinetic power from hypothetical turbine arrays, it is assumed that turbines are uniformly deployed $50 \mathrm{~m}$ below the sea surface in the Gulf Stream and current velocities from the database is used to calculate the power. The principle velocity component in the Florida Current is northward along the channel, the undisturbed kinetic power $\left(P_{k}\right)$ from this turbine array is estimated using

$$
P_{k}=\Sigma \frac{1}{2} \rho|V|^{3} E_{f} A_{s} A_{c} N
$$


where $\mathrm{V}$ is the velocity at the assumed turbine depth, $\rho$ is the water density $\left(1025 \mathrm{~kg} / \mathrm{m}^{3}\right), \mathrm{E}_{\mathrm{f}}$ is the Efficiency $(40 \%), \quad A_{s}$ is the swept area of device $\left(400 \mathrm{~m}^{2}\right), A_{c}$ is the surface area of computation cell $\left(\sim 16 \mathrm{~km}^{2}\right)$ and $\mathrm{N}$ is the number of devices per unit surface area $\left(1 / 1 \mathrm{~km}^{2}\right)$ corresponding to one $\mathrm{km}$ spacing between devices. Open ocean turbine technology is not yet fully developed and tested; therefore it is not possible to obtain all the technological details of turbines to be used for the Florida Current. Estimates are based on assumed turbine parameters, which are subject to change but any modification would produce a corresponding linear change in the total power estimate.

In the first case, the turbine region is selected within a box area spanning from Florida to the Bahamas (Figure 35). Assuming turbines are uniformly deployed in this area with the assumed parameters, the mean annual kinetic power from this hypothetical turbine array is $5.6 \mathrm{GW}$ with the number of devices on the order of 35,000 in place, making the mean power per device approximately $0.16 \mathrm{MW}$.

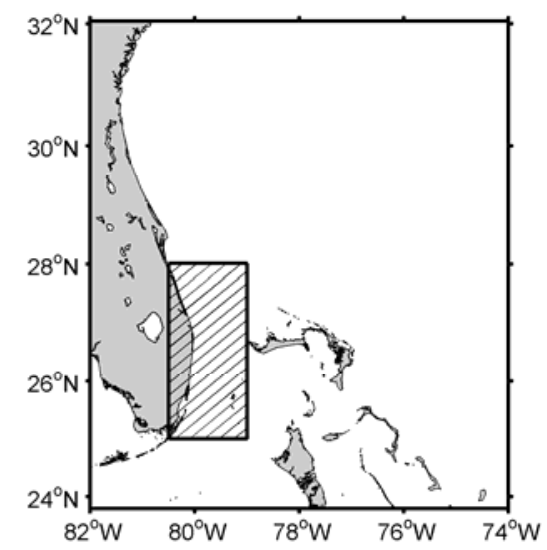

Figure 35: The area in the Florida Current where the hypothetical turbine array will be deployed.

The Florida Current's very strong monthly variability is reflected in the total kinetic power from the hypothetical turbine array as shown in Figure 36a. The peak power occurs in July and reaches more than $7 \mathrm{GW}$, and its lowest power occurs in November and is about $4.6 \mathrm{GW}$. That results in maximum power per device of about $0.2 \mathrm{MW}$ in July and minimum power per device of about $0.13 \mathrm{MW}$ in November.

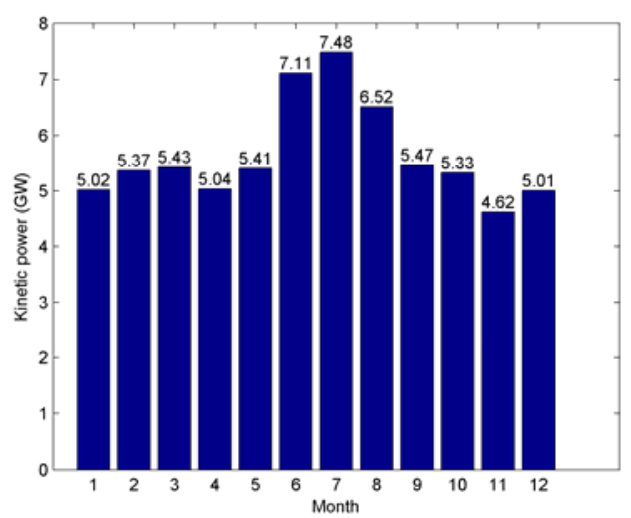

(a)

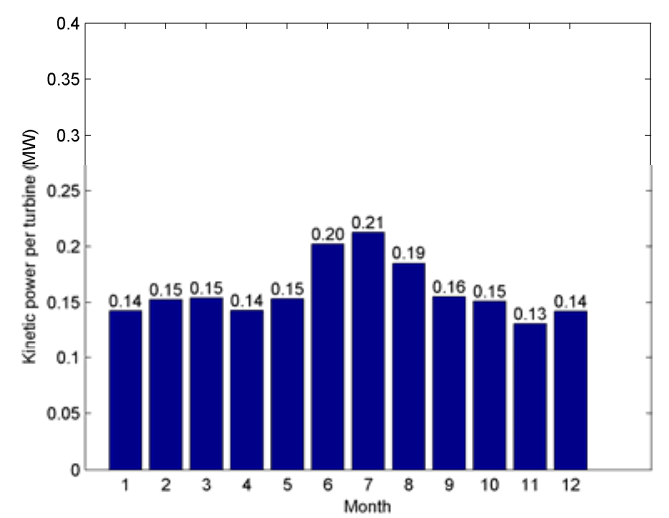

(b)

Figure 36: Monthly variation of (a) total kinetic power and (b) power per device from the hypothetical turbine array. 
To make the estimate more realistic, it is reasonable to assume the devices are only deployed in areas with high current velocity. From a technological point of view, most devices require a minimum "cut-in" flow speed at which devices will start producing power. Therefore devices should only be deployed in areas where the mean speed exceeds a certain threshold. For this analysis this threshold is set to $1 \mathrm{~m} / \mathrm{s}$ which results in turbines being deployed in the areas with black dots in Figure 37. The approximate surface area of the turbine region in this case is $2.0 \times 10^{4} \mathrm{~km}^{2}$ matching scenario A.

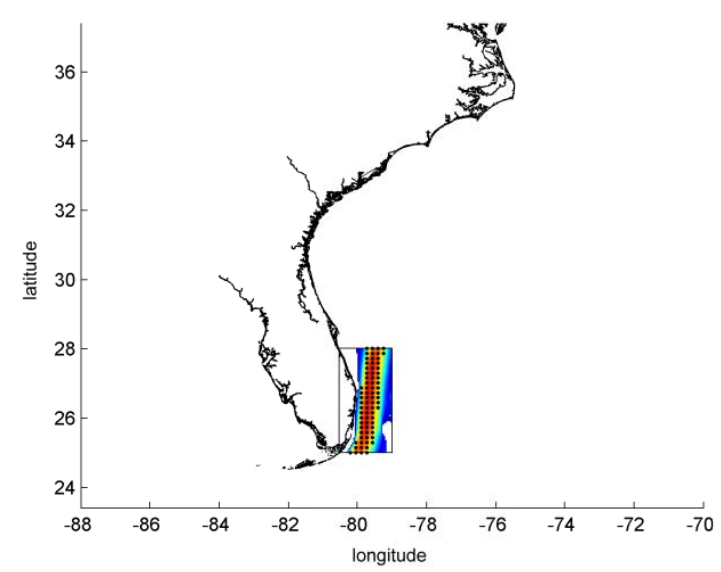

Figure 37: area with black dots representing the area with mean current speed exceeding $1 \mathrm{~m} / \mathrm{s}$.

Applying the threshold for minimum current speed, the mean kinetic power slightly drops to about 5.2 GW corresponding to a decrease around 7\% (Figure 38a). However, the number of devices is reduced by nearly half from roughly 35,000 to 18,000 , thereby increasing the mean power per device to about 0.28 MW (Figure 38b). This represents nearly a 70\% increase in power per device from the original scenario. The maximum power per device increases to $0.37 \mathrm{MW}$ in July and the minimum increases to about 0.23 MW in November. Therefore this is a much more cost effective and thus realistic deployment scheme resulting in much higher per device power without significantly reducing the total power.

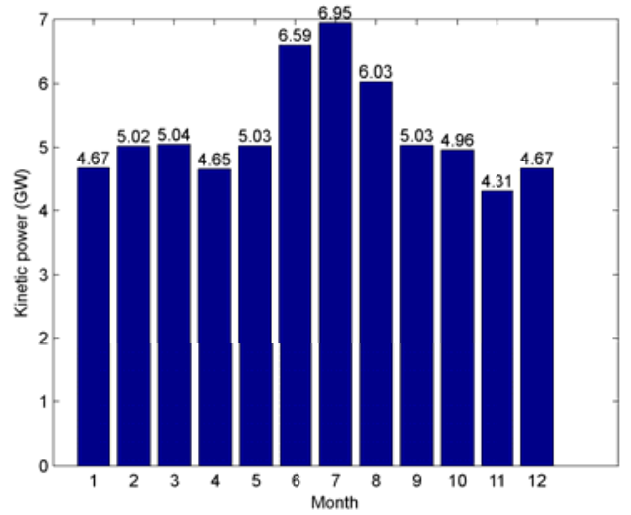

(a)

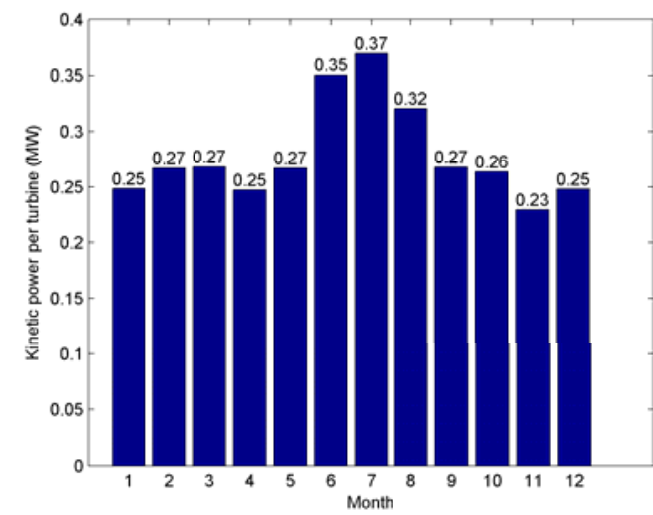

(b)

Figure 38: Monthly variation of (a) total kinetic power and (b) power per device with devices only deployed in areas with mean speed exceeding $1 \mathrm{~m} / \mathrm{s}$.

We further extend the turbine region beyond the box limit to a larger area $\left(\approx 4.5 \times 10^{4} \mathrm{~km}^{2}\right)$ with the turbines still only deployed in areas with mean speeds greater than $1 \mathrm{~m} / \mathrm{s}$ (Figure 39a). In this case the 
average total kinetic power from the turbines increases to approximately $8.0 \mathrm{GW}$ (Figure 39b), and the turbine number increases to roughly 30,000 and the average power per device decreases to about 0.26 MW. If the turbine region is expanded to include the offshore area of Cape Hatteras (Figure 40a), the surface area of the turbine region increases to about $1.4 \times 10^{5} \mathrm{~km}^{2}$, and the total kinetic power goes up to about 15.4 GW (Figure 41). In this case, the number of turbines goes up to the order of 88,000 and the average power per devices drops to about $0.17 \mathrm{MW}$.

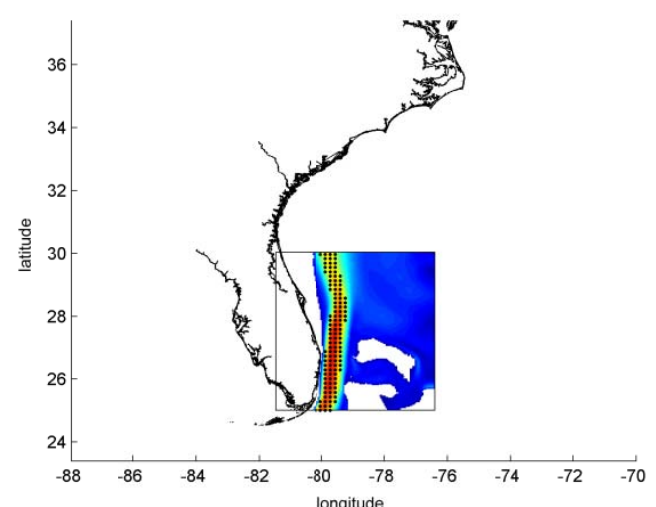

(a)

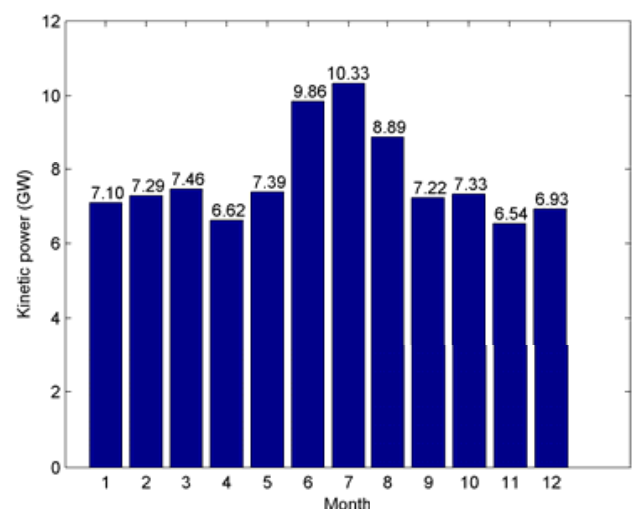

(b)

Figure 39: (a) The turbine region including sections up and down streams of the Florida Current, and (b) the monthly variation of total kinetic power.

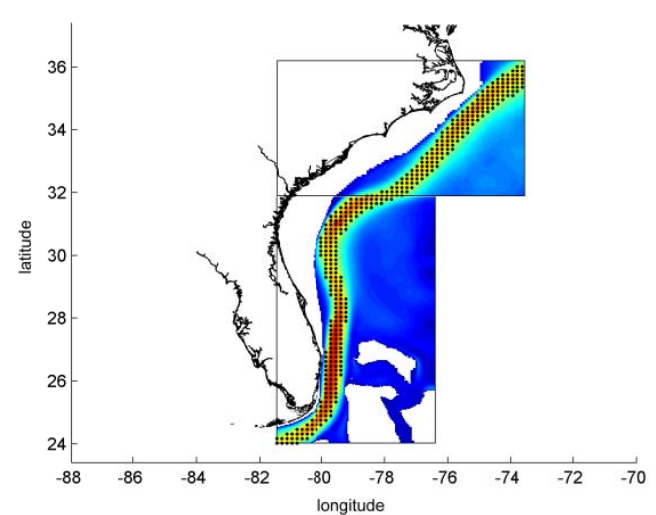

(a)

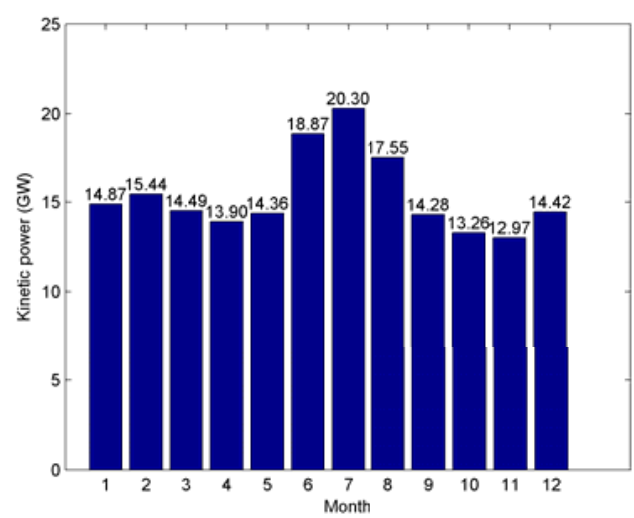

(b)

Figure 40: (a) The turbine area including offshore of Cape Hatteras, and (b) the monthly variation of total kinetic power.

Table 7 compares the power estimates from the previous subsection with the power estimate based on undisturbed kinetic power for three different scenarios with similar surface areas of the turbine region. Scenario A in the previous subsection has a similar area of turbines with the first case here, and the estimated power is also very similar. Scenario B and C from the previous subsection are comparable to the second and third cases here regarding the area of the turbine region. The comparison shows that the theoretical power limit is achievable by the commonly used approach based on undisturbed power density when typical but still hypothetical turbine parameters are used. However, the estimate of $P_{k}$ carries uncertainty and could vary significantly by adjusting the turbine parameters. In addition, the estimate of $P_{k}$ based on undisturbed power density is only meaningful when the number of turbines and the back effects on the existing flow are small. The velocity will be reduced when large amount of energy is extracted and larger number of turbines will be needed to extract the same amount of power. Therefore 
the estimate of $P_{k}$ based on undisturbed velocity field is only useful for providing an order of magnitude of the number of devices and should not be used solely for determining the maximum available power.

Table 7: Comparing power estimate in theory with the estimate based on undisturbed kinetic power.

\begin{tabular}{|c|c|c|c|c|}
\hline & \multicolumn{2}{|c|}{$\begin{array}{c}\text { Approx. surface area of turbine region } \\
\left(\mathrm{km}^{2}\right)\end{array}$} & \multicolumn{2}{c|}{ Estimated Power (GW) } \\
\hline & Theoretical model & $\begin{array}{c}\text { Undisturbed } \\
\text { kinetic power } \\
\text { estimate }\end{array}$ & Theoretical model & $\begin{array}{c}\text { Undisturbed } \\
\text { kinetic power } \\
\text { estimate }\end{array}$ \\
\hline Scenario A & $1.8 \times 10^{4}$ & $2.0 \times 10^{4}$ & 5.1 & 5.2 \\
\hline Scenario B & $4.3 \times 10^{4}$ & $4.5 \times 10^{4}$ & 10.1 & 8.0 \\
\hline Scenario C & $1.7 \times 10^{5}$ & $1.4 \times 10^{5}$ & 18.6 & 15.4 \\
\hline
\end{tabular}

\subsubsection{Total power summary}

The ocean current energy potential from the Gulf Stream system has been estimated by investigating the theoretical energy balance of a simplified quasi-geostrophic ocean circulation model, and the theoretical upper limit of recoverable energy resource is evaluated as the energy dissipation from additional turbine drag. The analysis has shown that considering extraction over a region comprised of the entire Florida Current portion of the Gulf Stream system, the average power dissipated ranges between 4-6 GW with a mean around $5.1 \mathrm{GW}$. This corresponds to an average of approximately $45 \mathrm{TWh} / \mathrm{yr}$. However, if the extraction area comprises the entire portion of the Gulf Stream within 200 miles of the US coastline between Florida and North Carolina, the average power dissipated becomes $18.6 \mathrm{GW}$ or $163 \mathrm{TWh} / \mathrm{yr}$.

As defined by the National Research Council (NRC, 2013), the theoretical resource is the amount of power contained in the natural system. The values provided here may be regarded as the theoretical resource. However, the technically recoverable resource is defined as the resource extraction realizable within the limitations of presently available devices and site-specific resource intensities, and should be significantly below the theoretical estimate provided here. Such limitations include wake losses, turbine and transmission efficiencies, and other engineering and technological constraints. The exact percentage of the theoretical resource that can be converted into electricity considering turbine related efficiencies needs more research to determine. Assuming a typical value of the overall power efficiency is suggested to be around 30\% (Bahaj and Myers, 2003). However, providing an estimate by assuming a 30\% conversion efficiency for energy removal from the flow to electrical power yields an average potential for electricity production of about 1.5 GW from the Florida Current and 5.6 GW from the entire US portion of the Gulf Stream system or 13 and $49 \mathrm{TWh} / \mathrm{yr}$, respectively.

However, the theoretical estimate of maximum power using depth averaged 2D equations has its shortcomings. Although it is able to solve the bulk flow, it's insufficient in resolving the vertical structure and temporal variability of the current flow. The simplification of the ocean model also makes it impossible to include the impact of actual coastline and bottom topography on the currents. In the future, full numerical modeling can be performed to gain a more realistic representation of the ocean circulation and a more reasonable evaluation of the energy extraction potential from ocean currents. 


\subsection{Dissemination of Data}

An interactive, web-based GIS system has been developed to facilitate dissemination of the ocean current data to interested users, including electric power utilities, policy makers, regulators and turbine manufacturers. The webpage can be accessed at: http://www.oceancurrentpower.gatech.edu/. The GIS tools allow the user to interact with the ocean current database. Ocean current project data is stored in a geodatabase that enables the search query function via a rich internet application (RIA) supported by ArcGIS server. Users can interact with the map using the pull down menus or widgets on the right of the screen. Besides the map navigation functions, the RIA also enables the users to identify the source data to retrieve the ocean current information for the given location and export the selected data specified by the user. This system provides the following capabilities:

- GIS layers and map displays of the monthly and yearly mean currents and power densities.

- Provide the velocity probability distributions along the U.S. coastline at different depths.

- Download monthly and yearly mean surface current velocity and power density for particular regions.

This website is functionally designed similarly to the tidal energy website (http://www.tidalstreampower.gatech.edu/) documented by Defne et al. (2012). However, based on the experience learned from operating that website, key components were modified as described below to enhance the technical capabilities.

\subsubsection{Design and highlights of data dissemination}

\section{Data layers}

The web page consists of multiple layers (a data points layer and a set of color mapped raster layers) that can be turned on and off with the data layers widget. The color mapped raster layers include the water depth, the mean current speed for each month and the total and the mean kinetic power density. These layers are generated by interpolating the model results from computational grids onto an ArcGIS raster grid and are useful for a quick visual examination. On the other hand, the data point layer contains more detailed information that corresponds to actual model grid points and can be queried through the interactive tools, and is therefore more suited for in-depth analyses.

Figure 41 shows the screenshot of the GIS map of mean surface current speed. One the top of the screen, it has four pull down menus: "Map", "Navigation", "Tools" and "Help". A pull down menu will appear once the mouse pointer stays on the icon. The content of each menu is also shown in Figure 41. On the right of the screen is the area of interactive widgets. Corresponding widget windows will show in this area upon activation of different functions. Figure 42 displays the map with three different widgets windows: "Overview map", "Data layers", and "Show legend". "Overview map" widget shows the location of the location of the current map view in the context of the larger geographical area. "Data layers" widget toggles between 17 different data layers on the map to display. "Show legend" widget shows the legend for data from all different layers. 


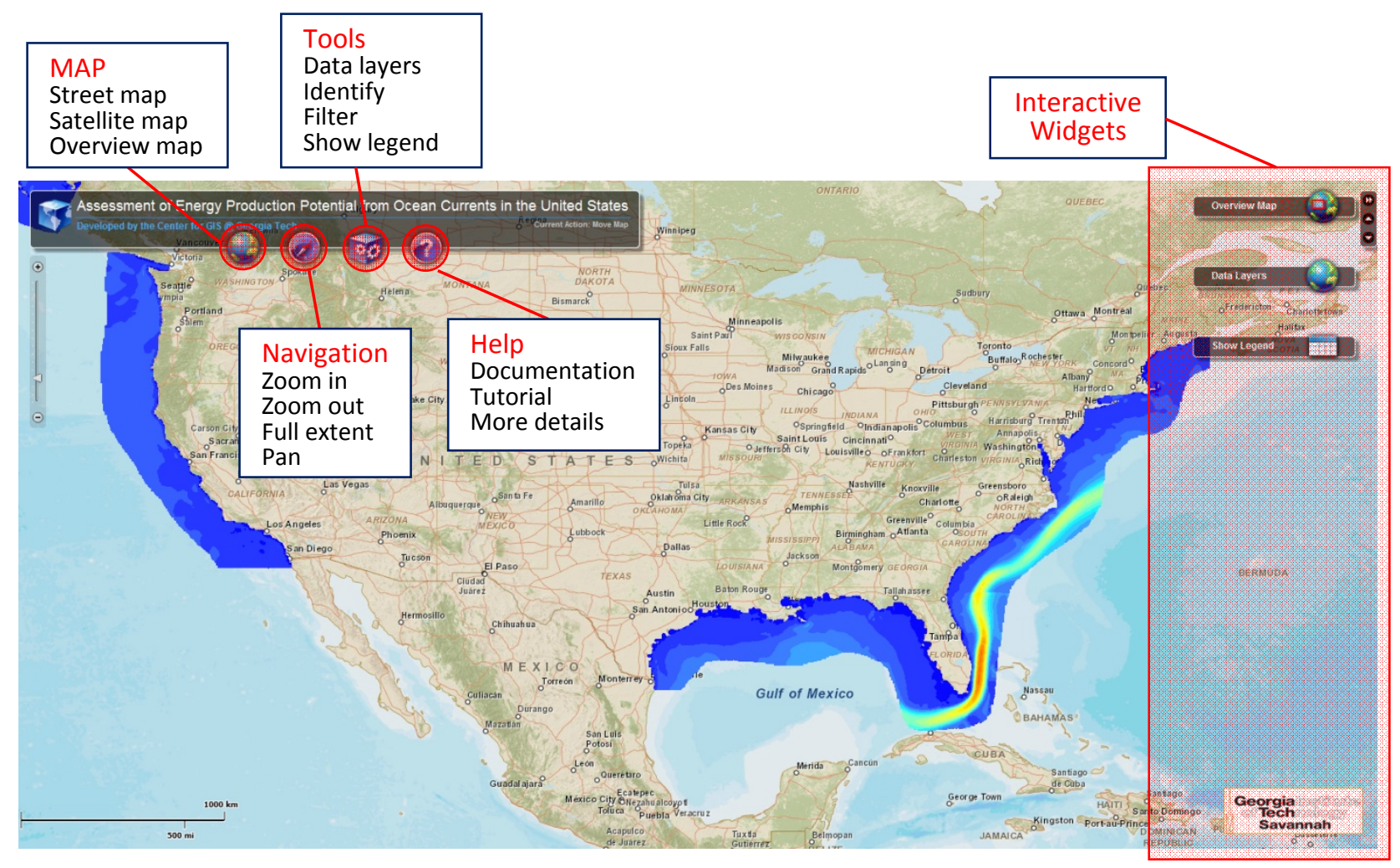

Figure 41: GIS map of mean surface ocean current speed with pull down menus on the top and interactive widgets on the right.

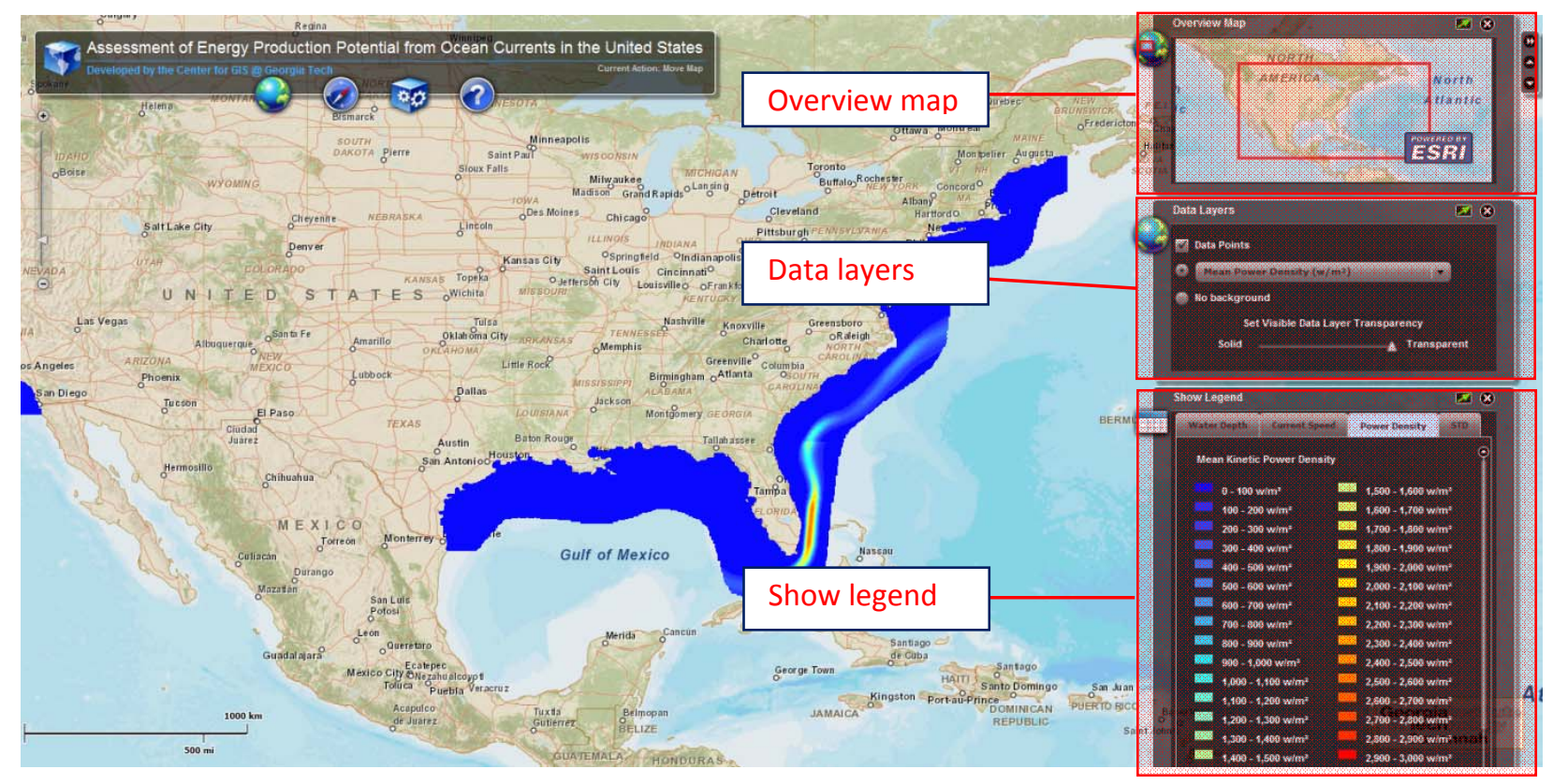

Figure 42: Map of mean surface power density with display of "overview map", "data layers", and "show legend" widgets.

\section{Identify tool}

This tool is used to identify a single data point either by clicking on the map or by specifying a longitude and latitude. The identify tool returns the model water depth, mean current speed, mean kinetic power density and the exact longitude, latitude of the selected point. Both joint and marginal histograms for ocean current velocity at a selected point can be plotted for any specific month or the entire year using the identify tool. These histograms facilitate an overview of the probabilistic nature of the ocean current resource at a location. Similarly, vertical current speed profiles at selected locations can also be plotted 
with the identify tool. Figure 43 shows the screenshot of an example of the "Identify" function. Once a data point is identified, the point will be highlighted in green, and information including longitude, latitude, water depth, mean current speed, mean power density and speed standard deviation will show in the widget window. Further instructions will also be given in the widget window to show plots of "Vertical speed profile", "Joint probability histogram", "Marginal probability histogram" or "Download spreadsheet". For example, Figure 44 shows the vertical current speed profiles of location (26.912N, $79.680 \mathrm{~W}$ ) generated by the interface and Figure 45 shows the joint and marginal probabilities of surface current velocity.

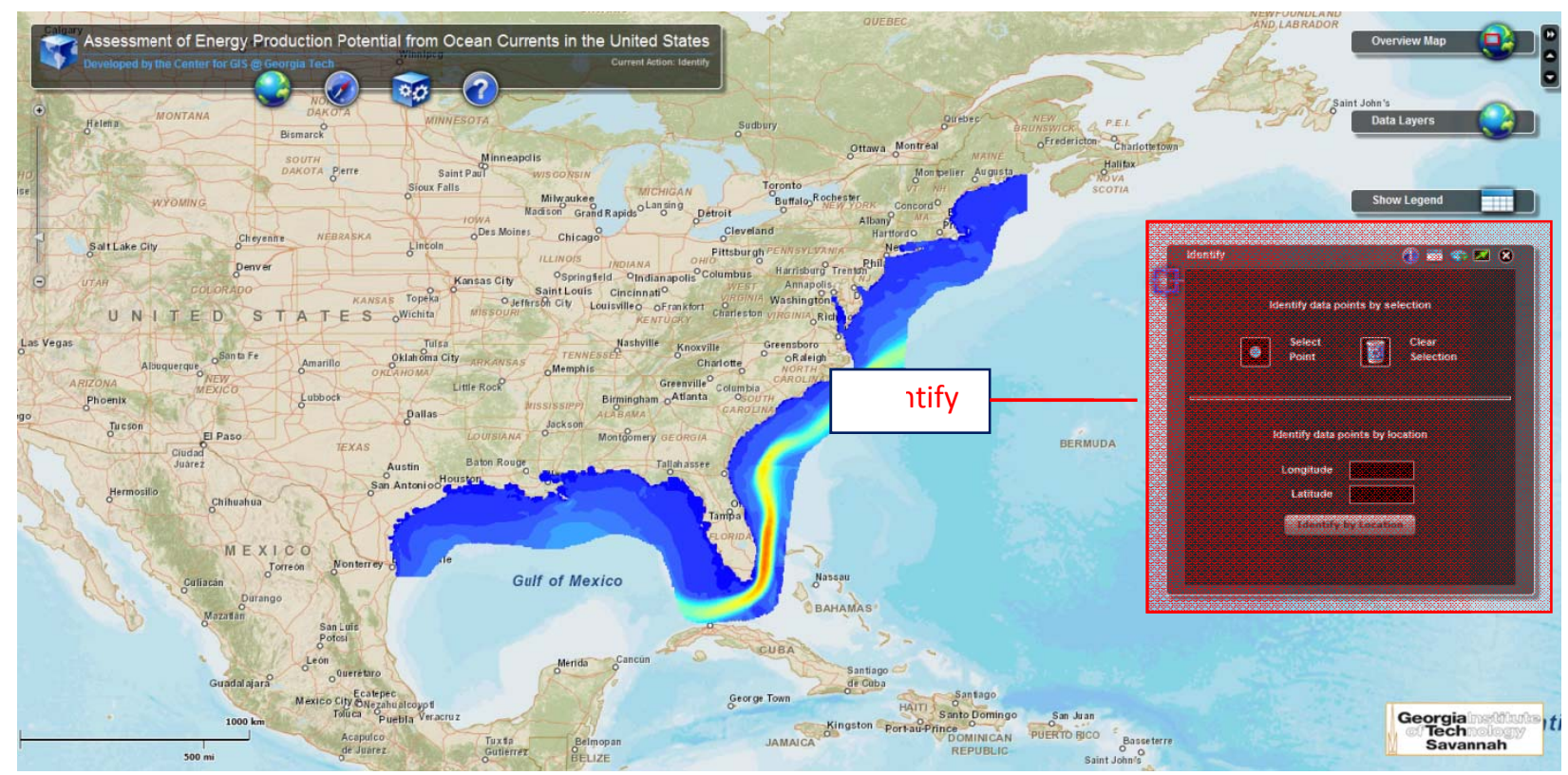

Figure 43: Demonstration of the "Identify" widget.

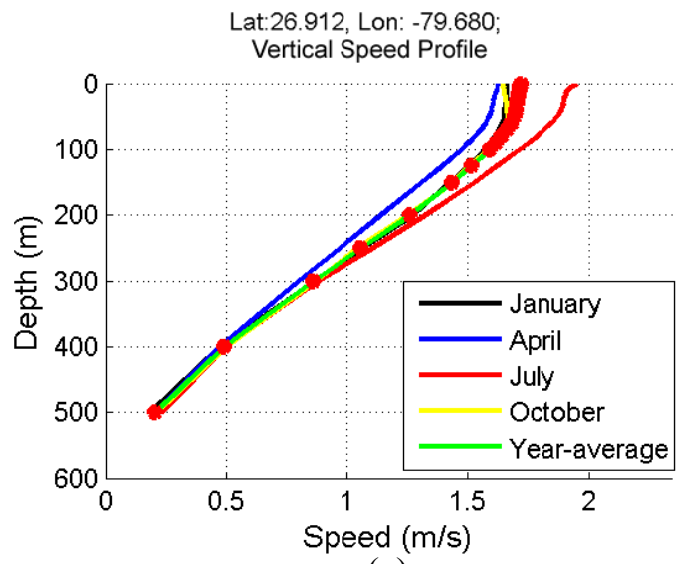

(a)

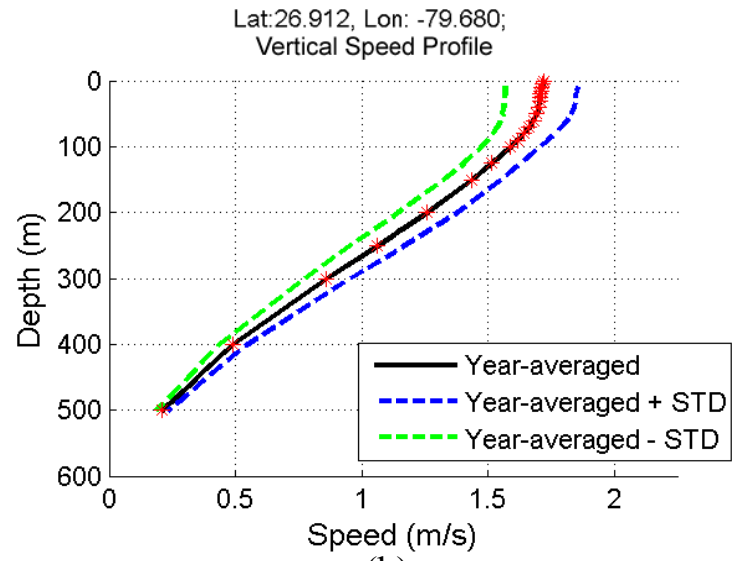

(b)

Figure 44: Vertical current speed profiles for (26.912N, 79.680W): (a) monthly variation and (b) standard deviation. 


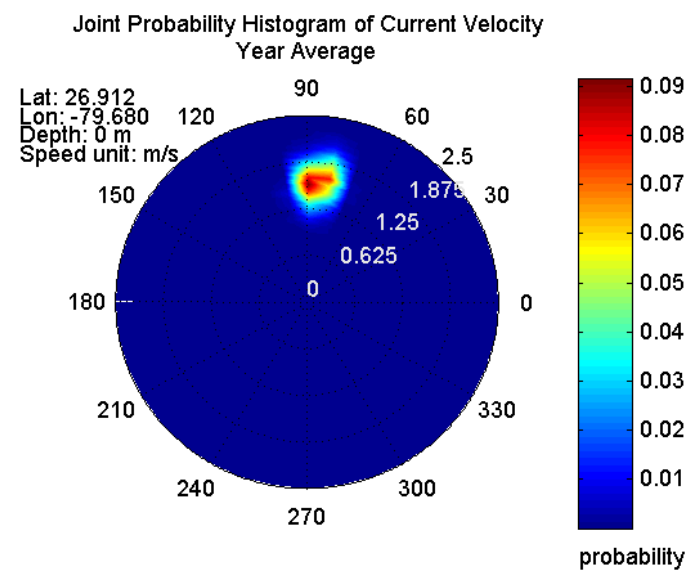

(a)
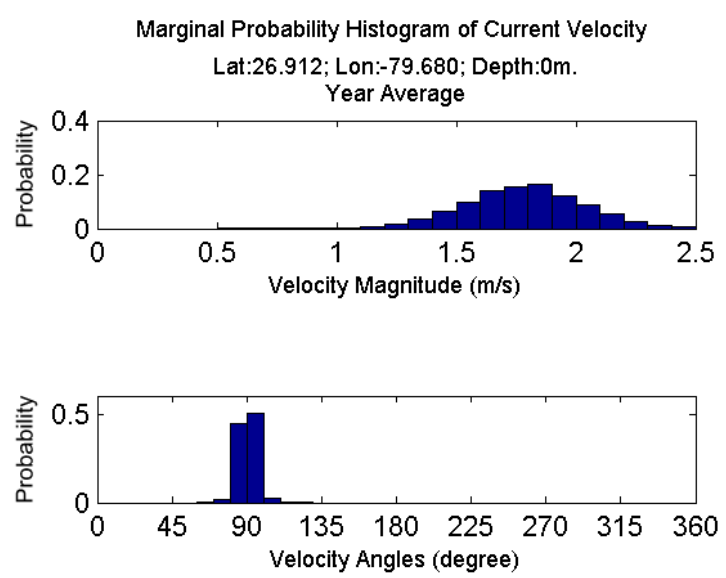

(b)

Figure 45: (a) Joint and (b) marginal probability distributions of surface current velocity for (26.912N, 79.680W).

\section{Filter tool}

The filter tool is used to download data at selected grid points. A single point or multiple points can be selected using the filter tool by dragging a window or selecting by polygon. The selected data can be filtered based on the water depth, mean current magnitude or mean power density or a combination of them prior to downloading. This provides the user with the option to only include the areas that meet certain criteria, such as a minimum depth or a minimum speed. The selected data is exported to a spreadsheet and for each point it includes display geographical coordinates, the modeled depth, monthly and annual mean surface current speed, current speed standard deviation and mean power density.

Based on the users' experience and reflection on the previous tidal stream project, there was a bottleneck when exporting the data selected by the users. The solution in tidal stream project was based on ArcGIS server search query function. When a large volume of data is queried, it has to loop through each feature to retrieve the individual values and re-format the data into a tabular format downloadable as a spreadsheet. To improve the performance of the export function, a SQL Server database was created that stores a copy of the non-spatial tabular data in the geodatabase. A REST Web service was developed through Visual Studio .NET that executes a SQL transaction to implement the search query over the SQL Server database to generate the output spreadsheet. The response time is significantly reduced in this approach.

An example of the "Filter" tool is shown in Figure 46. Once an area is selected, a button will appear to prompt users to download a spreadsheet as shown in Figure 47. The spreadsheet includes geographical coordinates, the modeled depth, mean surface current speed for each month and one entire year, the current speed standard deviation, the mean power density and the name of the region for each grid point in the selected region. 


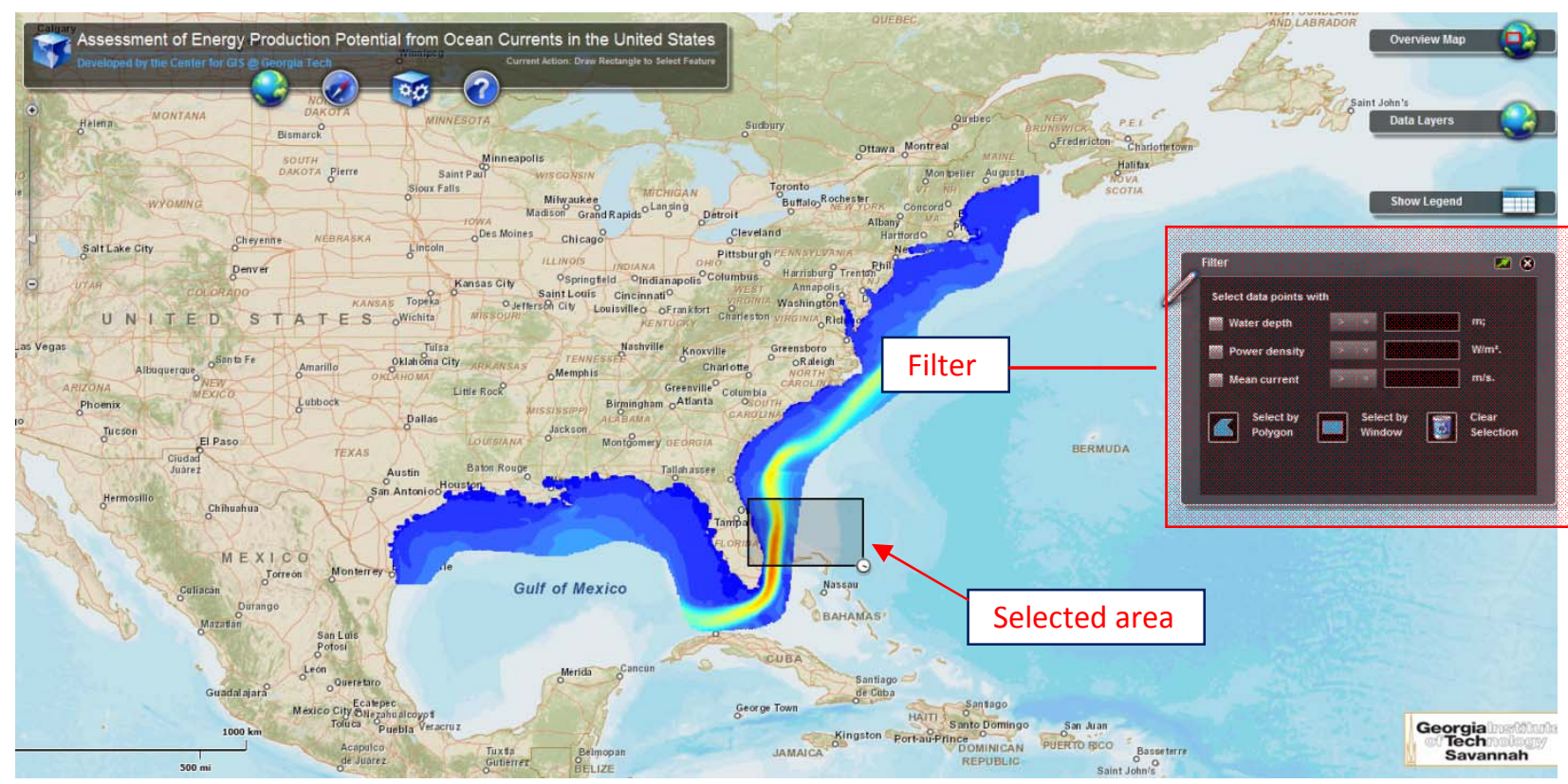

Figure 46: Demonstration of "Filter" function by using "selection by window" option.

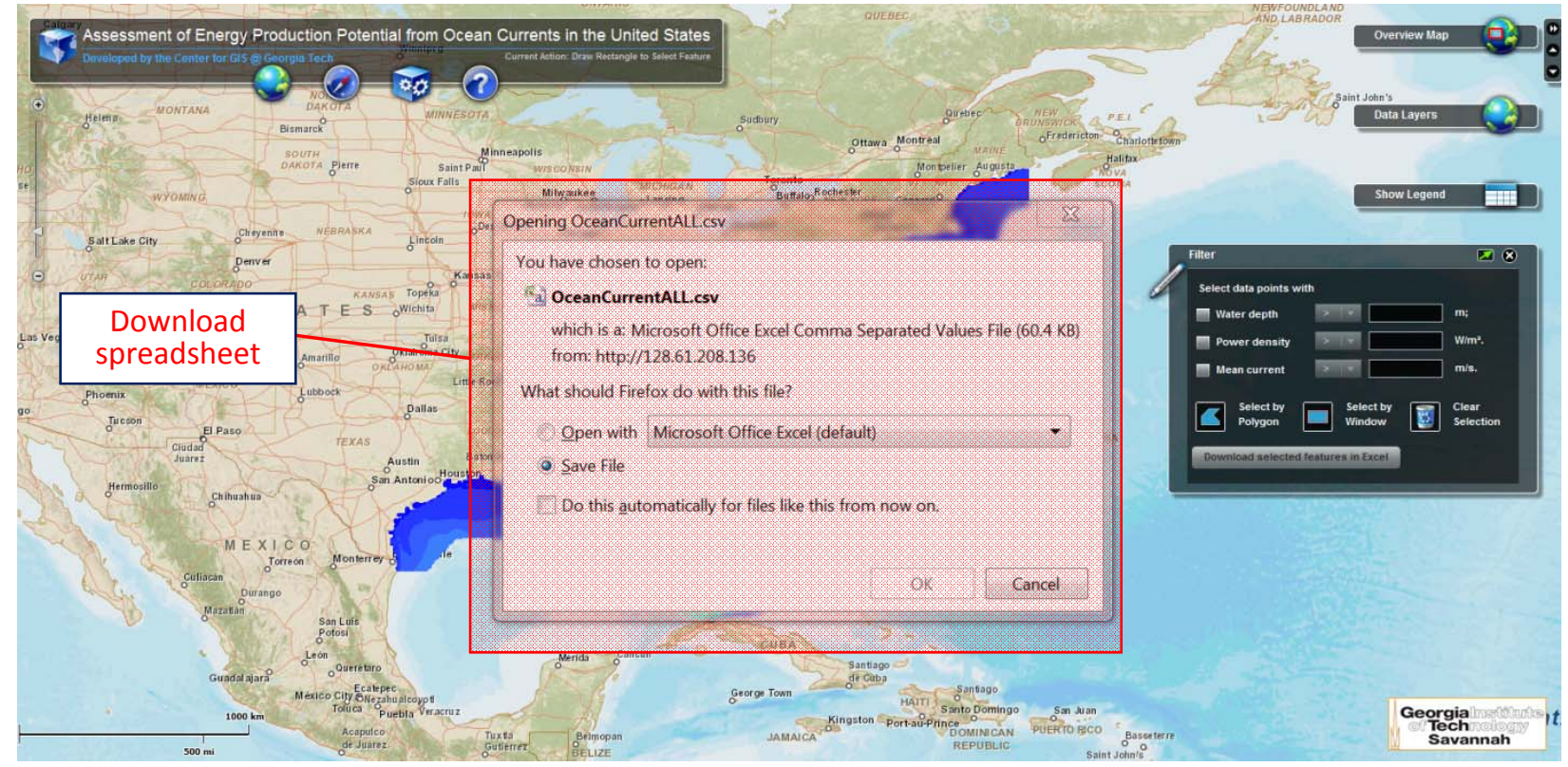

Figure 47: Demonstration of downloading spreadsheet of data for the selected area by "Filter" function.

\subsubsection{Probability uncertainty}

The GIS website developed in this project enables the user to select their interested location and provides the probability distribution of current velocity and direction from the database. However the distributions are calculated based on 7 years of daily snapshot data, and therefore contains uncertainty that needs to be addressed with a certain level of confidence interval. 
The probability distribution of current speed shows the chances of current speed resting in corresponding intervals. In general, the estimator of proportion in each interval $\hat{p}$ is given by

$$
\hat{p}=\frac{X}{n}
$$

where $\mathrm{X}$ is the number of elements in the interval, and $\mathrm{n}$ is the total number of elements. When $\mathrm{n}$ is large, the sample proportion $\hat{p}$ is well approximated as normal with mean $\hat{p}$ and standard deviation $\sqrt{\frac{\hat{p}(1-\hat{p})}{n}}$ (Johnson, 2005). Therefore a confidence interval for $\hat{p}$ is given by

$$
\left(\hat{p}-Z_{\frac{\alpha}{2}} \sqrt{\frac{\hat{p}(1-\hat{p})}{n}}, \hat{p}+Z_{\frac{\alpha}{2}} \sqrt{\frac{\hat{p}(1-\hat{p})}{n}}\right)
$$

where $Z_{\frac{\alpha}{2}}$ denotes the upper $\frac{\alpha}{2}$ point of the standard normal distribution. For a $95 \%$ confidence interval, $\alpha=0.05, z_{\frac{\alpha}{2}}=1.96$ and using 7 years of daily data, $n \approx 7 \times 365=2555$. Defining $\gamma=z_{\frac{\alpha}{2}} \sqrt{\frac{\hat{p}(1-\hat{p})}{n}}, \gamma$ can be computed as a function of probability $\hat{p}$, as shown in Figure 48a. For example, Figure 49a shows the probability of ocean current speed at $(26.912 \mathrm{E}, 79.600 \mathrm{~W})$. For a certain speed value (e.g. $\sim 1.52 \mathrm{~m} / \mathrm{s})$, there is a corresponding probability $p^{\prime}(0.06)$ as marked by the green dash line in Figure 49a. In Figure $48 \mathrm{a}, p^{\prime}=0.06$ corresponds to a value of $\gamma^{\prime} \approx 0.0095$. Therefore the confidence interval for $p^{\prime}=0.06$ is approximately $\left(p^{\prime}-\gamma^{\prime}, p^{\prime}+\gamma^{\prime}\right)$ or $p^{\prime}(1.52 \mathrm{~m} / \mathrm{s})=0.06 \pm 0.0095$. The red dashed lines in Figure $49 \mathrm{a}$ shows the $95 \%$ confidence interval for the probability distribution of the current speed. Similarly, for the monthly probability histograms estimated from 7 years of data, the total number of elements $n \approx 7 \times$ $30=210$. The procedure to otain $95 \%$ confidence interval of the probability is the same, but a different curve for the confidence interval shown in Figure $48 \mathrm{~b}$ needs to be used as illustrated by the example provided in Figure 49b. Clearly the uncertainty for the monthly distributions is much higher due to the reduction in data.

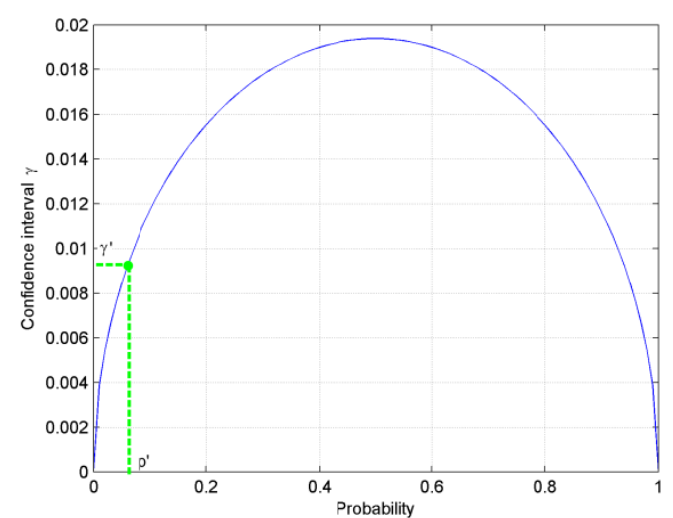

(a)

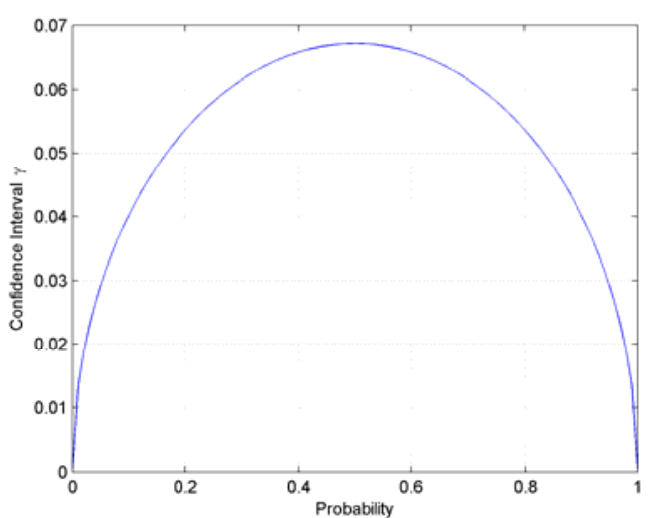

(b)

Figure 48: Confidence interval profiles for probability estimation based on (a) daily data of 7 years, and (b) daily data for an individual month of 7 years. 


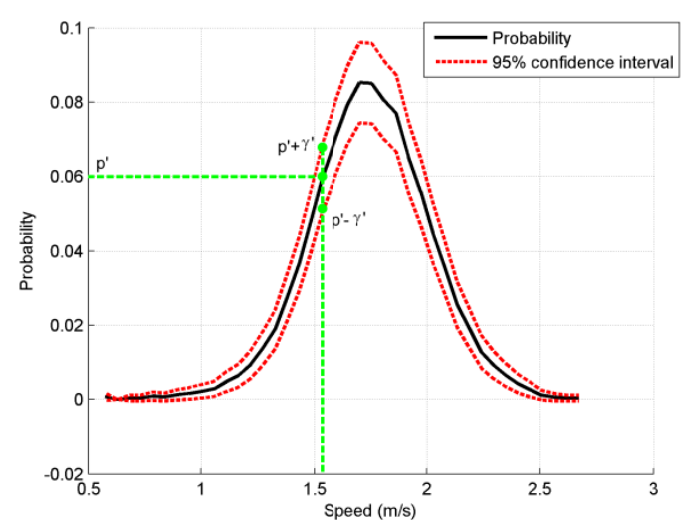

(a)

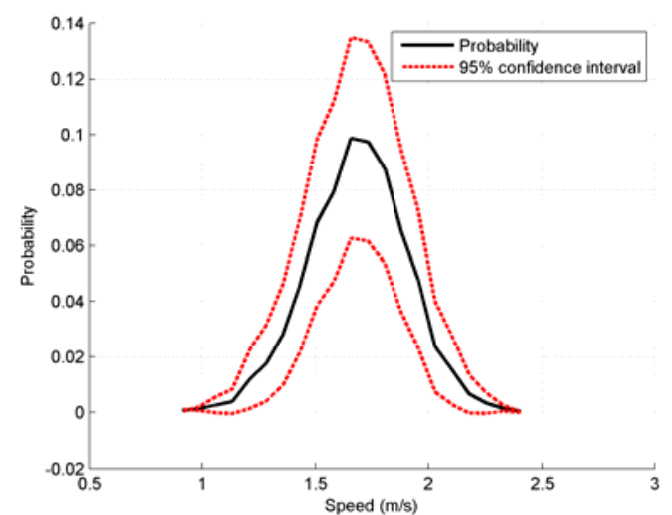

(b)

Figure 49: An example of the probability distribution and 95\% confidence interval of surface current speed at (26.912E, $79.600 \mathrm{~W}$ ) estimated from (a) daily data of 7 years, (b) daily data of only December.

\section{Products}

\section{Publications}

Yang, X., Haas, K. and Fritz, H. (2013) Theoretical Assessment of Ocean Current Energy Potential for the Gulf Stream System. Submitted to Marine Technology Society Journal.

Yang, X., Haas, K. and Fritz, H. (2013) The Potential for Energy Extraction from the Gulf Stream System. Submitted to Renewable Energy.

\section{Presentations}

Haas, K. (2013) Invited speaker, University of Georgia, Marine Science seminar series, "Assessing the Viability of Ocean Energy" April 2013.

Yang, X., Haas, K. and Fritz, H. (2013) Prospect of Recovering Renewable Energy from the Gulf Stream System. Presented at the Georgia Tech Research and Innovation Conference, Atlanta, GA.

Yang, X., Haas, K. and Fritz, H. (2013) Ocean Current energy Assessment for the Gulf Stream. Presented at the $4^{\text {th }}$ Annual Marine Renewable Energy Technical Conference, Warwick, Rhode Island.

Haas, K. (2012) Tidal Stream Energy Resource Assessments. Invited presentation at the 5th Annual Global Marine Renewable Energy Conference, Washington, DC.

Haas, K. (2012) Invited speaker for Standards and Resource Assessment panel in the Ocean/Tidal/Stream Power track at the 2012 Hydro Vision International Conference, Aug. 2012.

\section{Website/Databases}

The data is stored in a GIS database accessible via the website http://www.oceancurrentpower.gatech.edu 


\section{Collaborations/Networks}

Kevin Haas is an expert member for the U.S. on IEC TC-114, and the chair for the U.S. Shadow committee working on the specification 62600-201 "Tidal Energy Resource Characterization and Assessment."

Kevin Haas was an invited participant and Breakout Session Chair for the NSF sponsored Marine/Hydrokinetic Energy and the Environment Workshop, St. Anthony Falls Laboratory, University of Minnesota, Minneapolis, MN. October 2011.

\section{Student Education}

Ph.D. Student

Xiufeng Yang

Adviser: Kevin Haas

Graduation: Fall 2013

Topic: Ocean Current Energy Resource Assessment for the United States

\section{References}

Barron, C. N., Kara, A. B., Martin, P. J., Rhodes, R. C., and Smedstad, L. F. (2006). Formulation, implementation and examination of vertical coordinate choices in the global navy coastal ocean model (NCOM). Ocean Modelling, 11(34):347- 375.

Bleck, R. (2002). An oceanic general circulation model framed in hybrid isopycnic-cartesian coordinates. Ocean Modelling, 4(1):55-88.

Csanady, G. T. (1989). Energy dissipation and upwelling in a western boundary current. Journal of Physical Oceanography, 19(4):462-473.

Defne, Z., Haas, K., Fritz, H., Jiang, L., French, S., Shi, X., Smith, B., Neary, V. and Stewart, K. (2012). National geodatabase of tidal stream power resource in USA. Renewable and Sustainable Energy Reviews 16 (2012). 3326-3338.

Duran, D. (1999). Numerical methods for wave equations in geophysical fluid dynamics. Springer, New York, 532pp.

Fratantoni, D. M. (2001). North Atlantic surface circulation during the 1990's observed with satellitetracked drifters. Journal of Geophysical Research, 106(C10):22,067-22,093.

Garrett, C. and Cummins, P. (2005). The power potential of tidal currents in channels. Proceedings of the Royal Society A-Mathematical Physical and Engineering Sciences, 461(2060):2563-2572.

Haidvogel, D. B., Arango, H., Budgell, W. P., Cornuelle, B. D., Curchitser, E., Di Lorenzo, E., Fennel, K., Geyer, W. R., Hermann, A. J., Lanerolle, L., Levin, J., McWilliams, J. C., Miller, A. J., Moore, A. M., 
Powell, T. M., Shchepetkin, A. F., Sherwood, C. R., Signell, R. P., Warner, J. C., and Wilkin, J. (2008). Ocean forecasting in terrain-following coordinates: Formulation and skill assessment of the regional ocean modeling system. Journal of Computational Physics, 227(7):3595-3624.

Halliwell, G. R. (2004). Evaluation of vertical coordinate and vertical mixing algorithms in the hybridcoordinate ocean model (HYCOM). Ocean Modelling, 7(3-4):285-322.

Hogg, N.G. and W.E. Johns, (1995). Western boundary currents. U.S. National Report to International Union of Geodesy and Geophysics 1991-1994, Supplement to Reviews of Geophysics, 33:1311-1334.

Johnson, R.A. (2006). Statistics: Principles and Methods 5th Edition. Wiley \& Sons. 671 pp.

Larsen, J. C. and Sanford, T. B. (1985). Florida current volume transports from voltage measurements. Science, 227(4684):302-304.

Melek-Madani, R. (2012). Physical oceanography: a mathematical introduction with MATLAB. Capman and Hall/CRC. 456 pp.

Miller, L. M., Gans, F., and Kleidon, A. (2011). Jet stream wind power as a renewable energy resource: little power, big impacts. Earth System Dynamics, 2:201-212.

National Research Council of the National Academies (NRC). (2013). An evaluation of the U.S. Department of Energy's marine and hydrokinetic resource assessments. The National Academies Press. $154 \mathrm{pp}$.

Neary, V.S., Gunawan, B. and Ryou, A. (2012). Performance evaluation of HYCOM-GOM for hydrokinetic resource assessment in the Florida Strait. U.S. DOE report.

Kelly, K.A., and Gille, S.T. (1990). Gulf Stream surface transport and statistics at $69^{\circ} \mathrm{W}$ from the Geosat altimeter. Journal of Geophysical Research, 95:3149-3161.

Rhodes, R. C., Hurlburt, H. E., Wallcraft, A. J., Barron, C. N., Martin, P. J., Metzger, E. J., Shriver, J. F., Ko, D. S., Smedstad, O. M., Cross, S. L., and Kara, A. B. (2002). Navy real-time global modeling systems. Oceanography, 15(1):29-43.

Richardson, P.L., (1985). Average velocity and transport of the Gulf Stream near $55^{\circ}$ W. Journal of Marine Research, 42:83-111.

Stewart, R. (2008). Introduction to physical oceanography. Open source textbook at http://oceanworld.tamu.edu/. 353pp. (accessed in 2012).

Stommel, H. (1948). The westward intensification of wind-driven ocean currents. Trans. AGU, 29:202206. 
Stommel, H., (1965). The Gulf Stream: A physical and dynamical description. Second edition, University of California Press, Berkeley, and Cambridge University Press, London, 248 pp.

Vallis, G. (2006). Atmospheric and oceanic fluid dynamics : fundamentals and large-scale circulation, Cambridge University Press. 745pp.

Venkatesh, S., Sanderson, B., and El-Tahan, M. (1990). Optimum deployment of satellite-tracked drifters to support iceberg drift forecasting. Cold Regions Science and Technology, 18(2):117-131.

Zlotnicki, V. (1991). Sea level differences across the Gulf Stream and Kuroshio Extension. Journal of Physical Oceanography, 21:599-609. 


\section{Appendix A}

This appendix includes figures showing the direct comparison of different ocean model data with the drifter measurement data for each sub-region of the east coast shown in Figure 2.

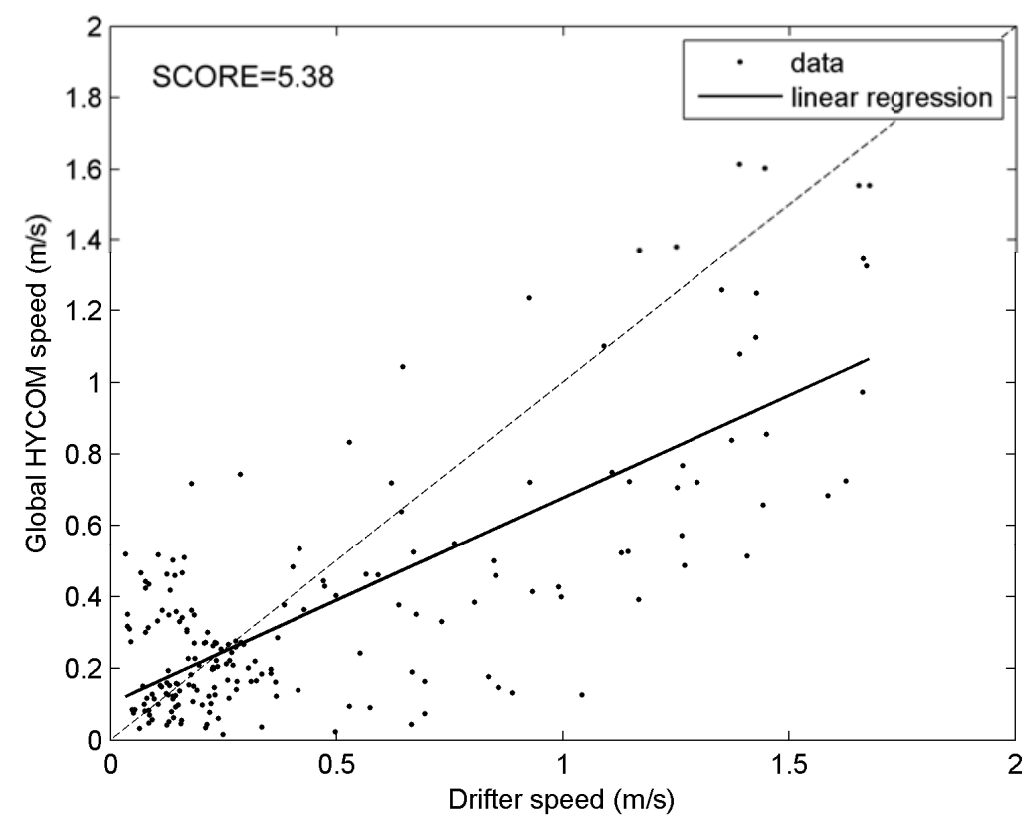

Figure A1: comparison of Global HYCOM data with measurement data for E1 region.

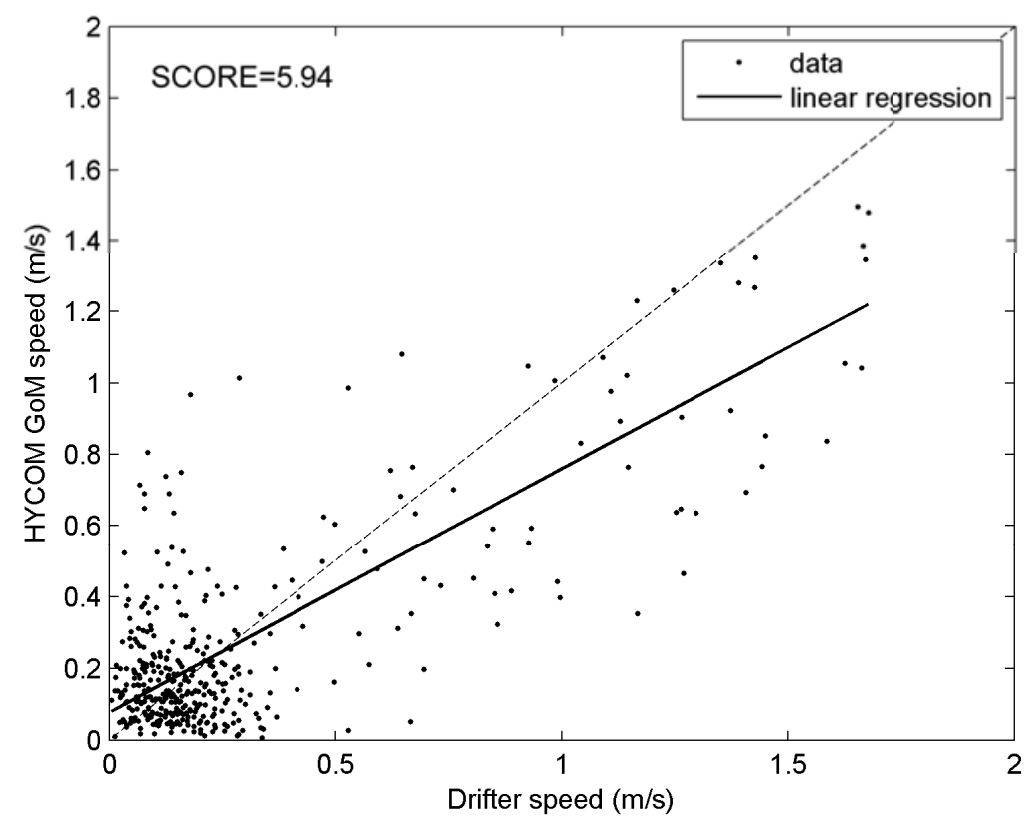

Figure A2: comparison of HYCOM GoM data with measurement data for E1 region. 


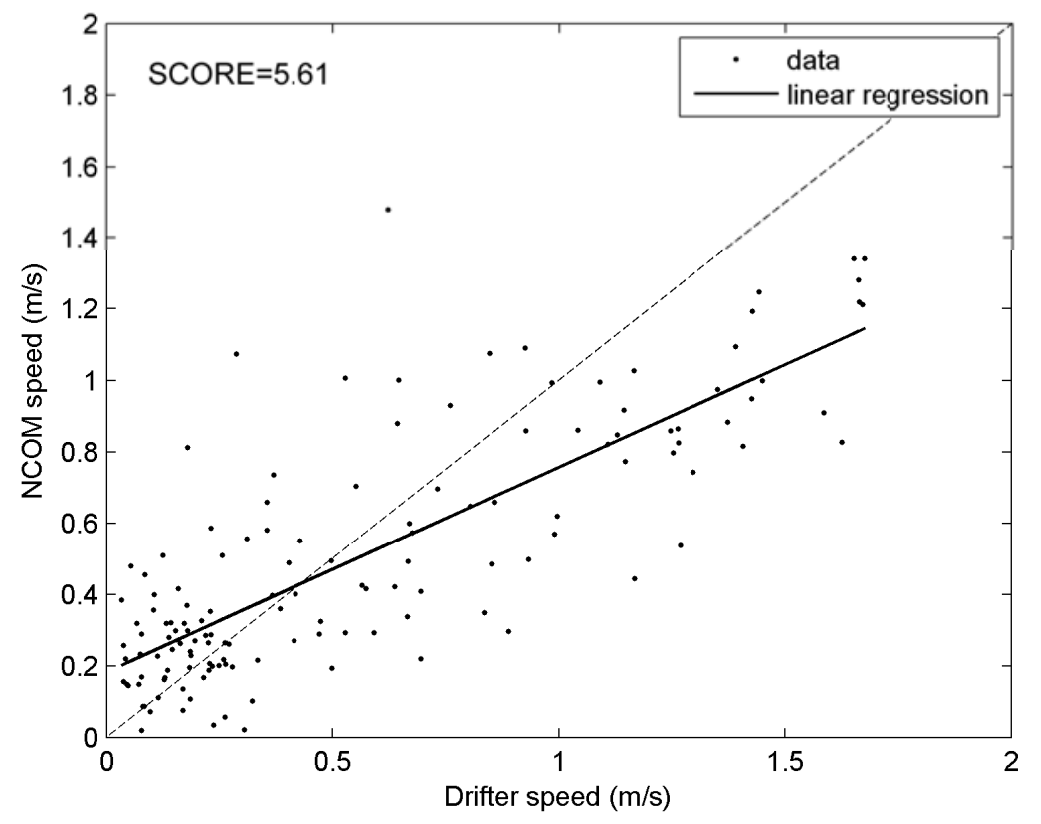

Figure A3: comparison of NCOM data with measurement data for E1 region.

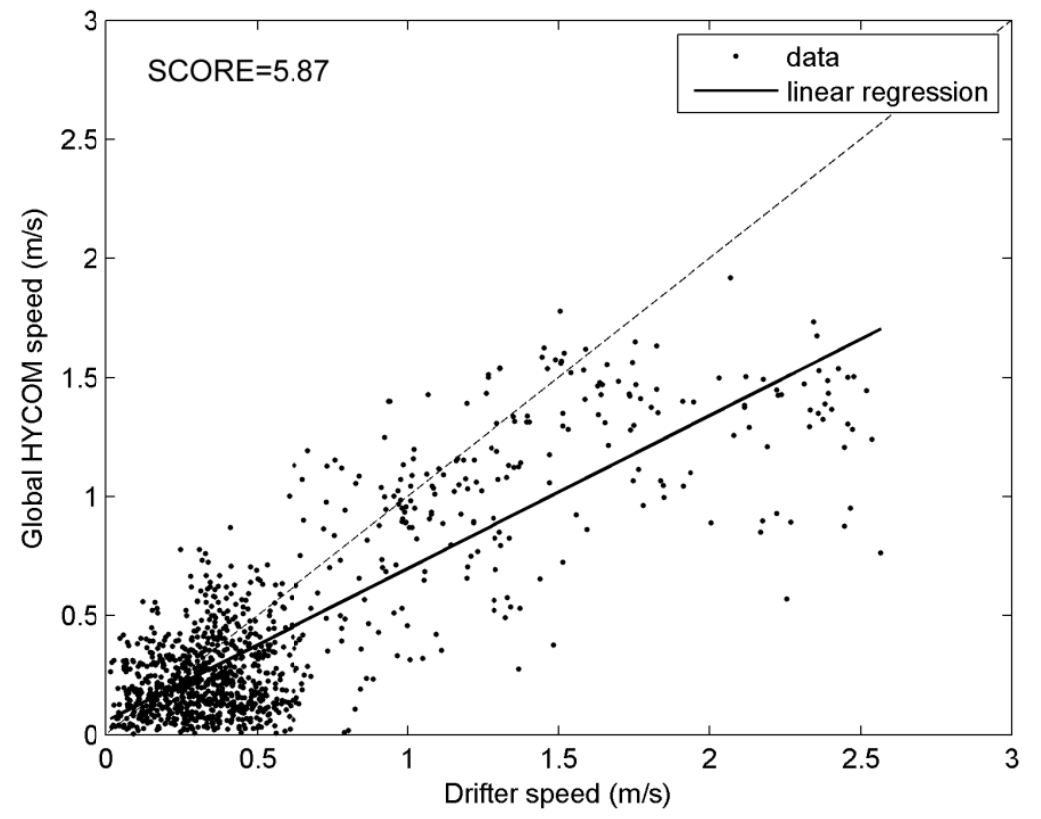

Figure A4: comparison of Global HYCOM data with measurement data for E2 region. 


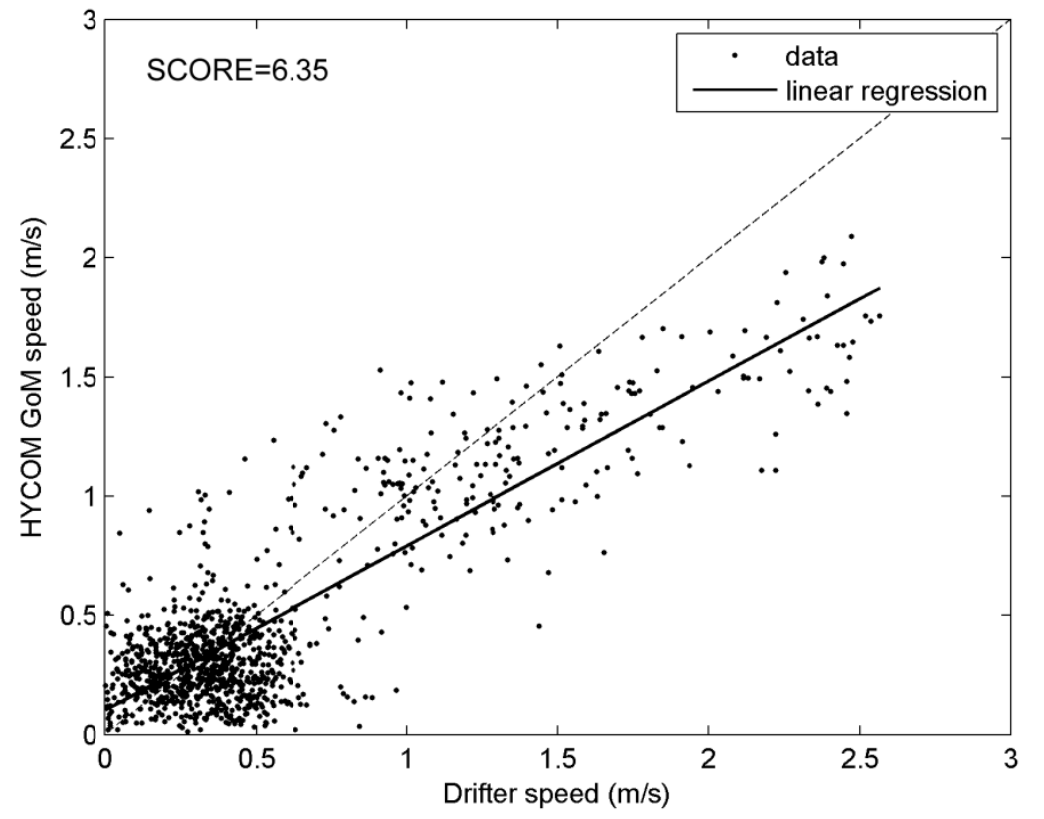

Figure A5: comparison of HYCOM GoM data with measurement data for E2 region.

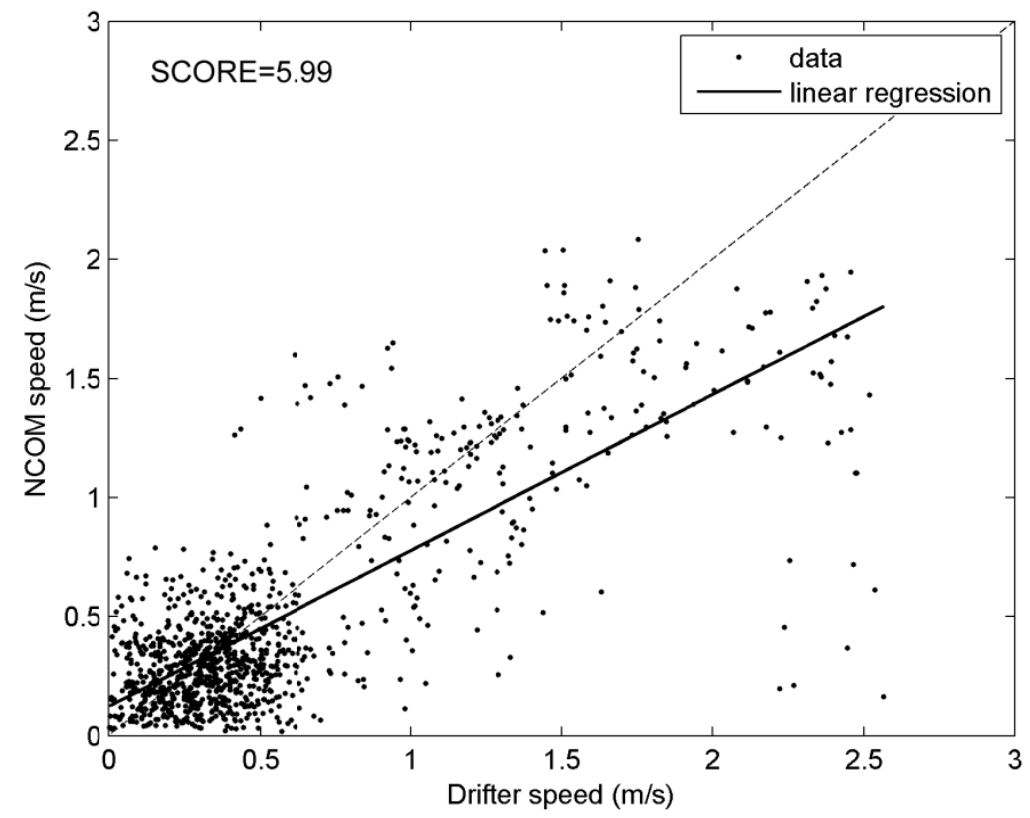

Figure A6: comparison of NCOM data with measurement data for E2 region. 


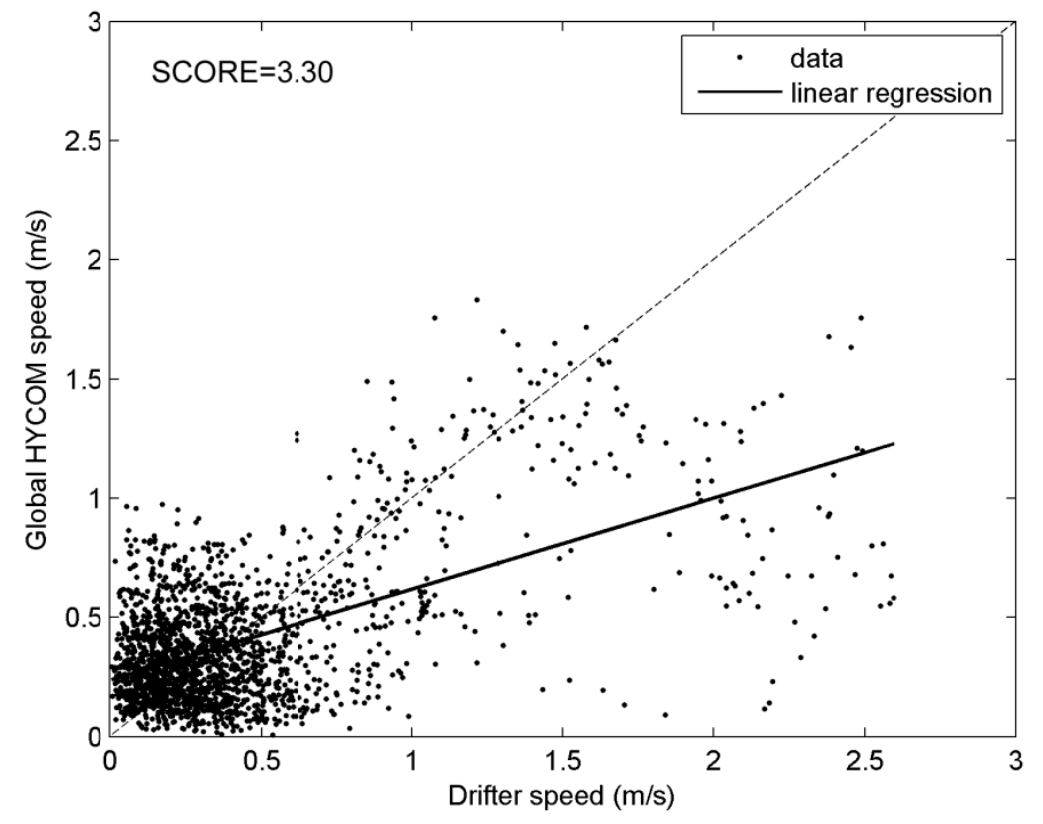

Figure A7: comparison of Global HYCOM data with measurement data for E3 region.

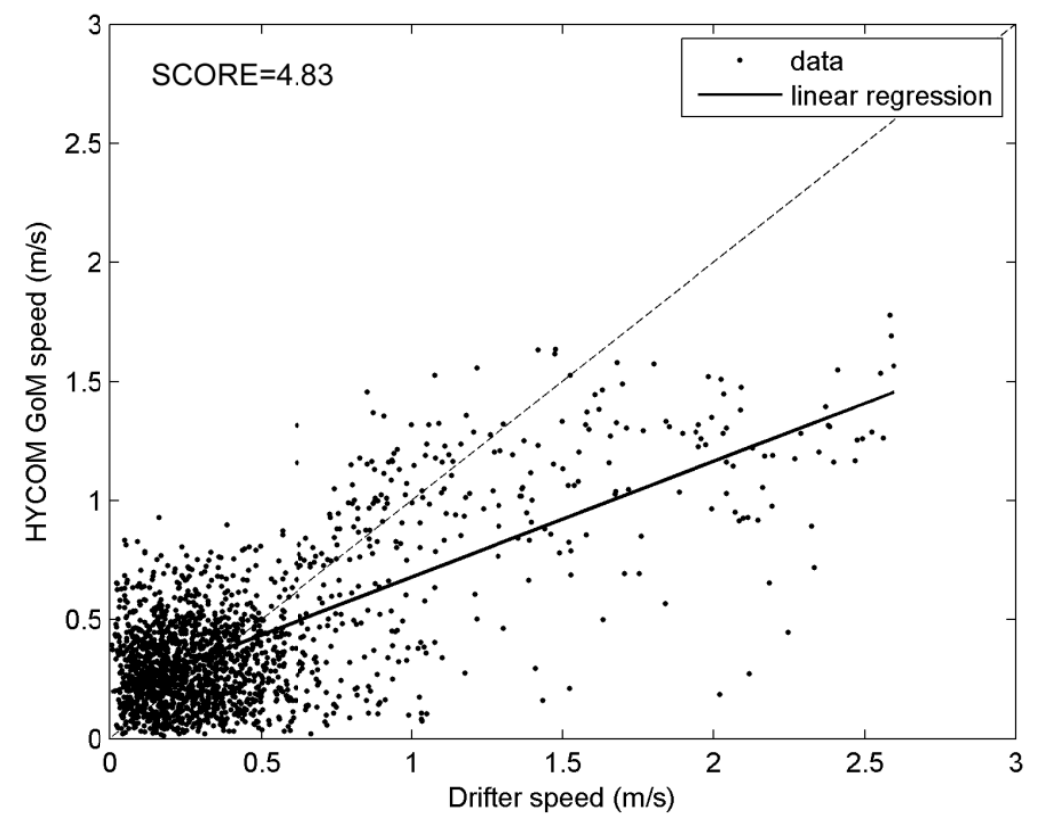

Figure A8: comparison of HYCOM GoM data with measurement data for E3 region. 


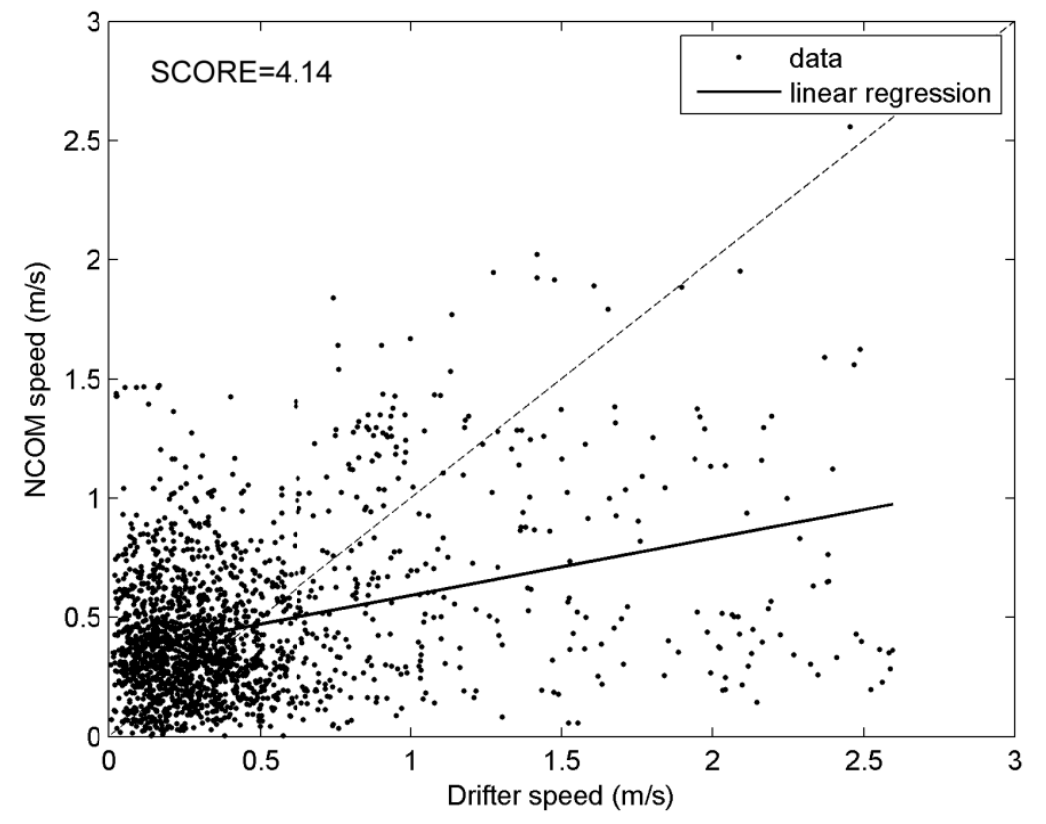

Figure A9: comparison of NCOM data with measurement data for E3 region.

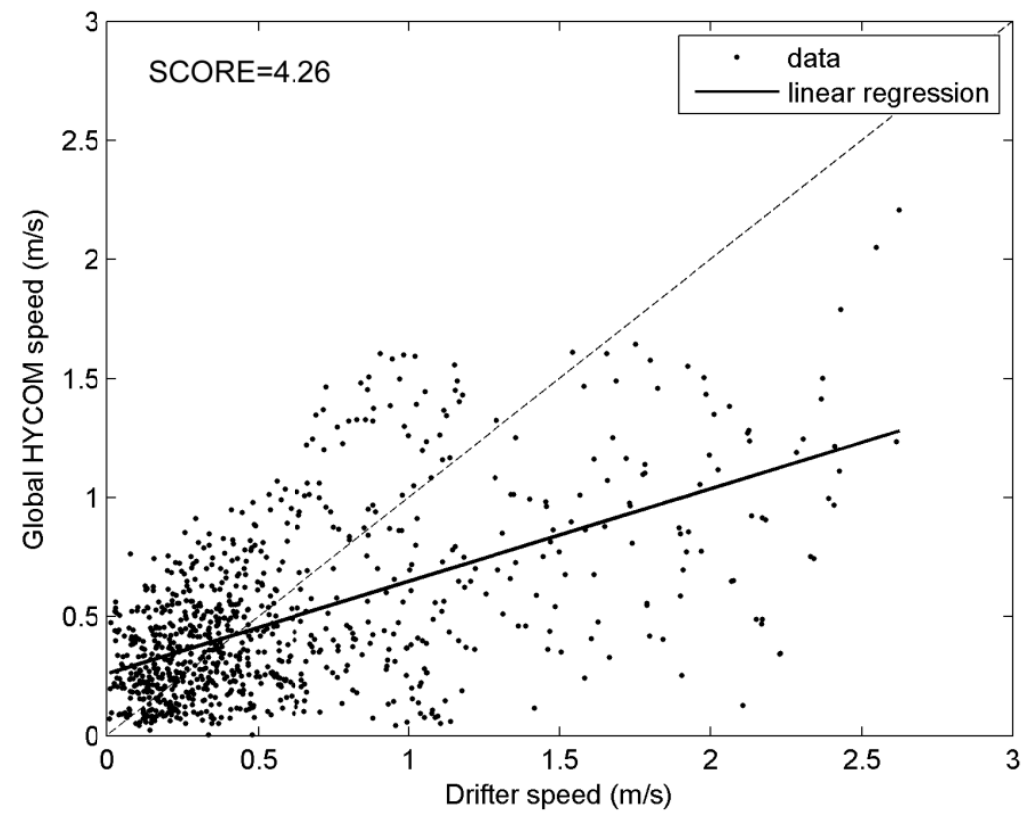

Figure A10: comparison of Global HYCOM data with measurement data for E4 region. 


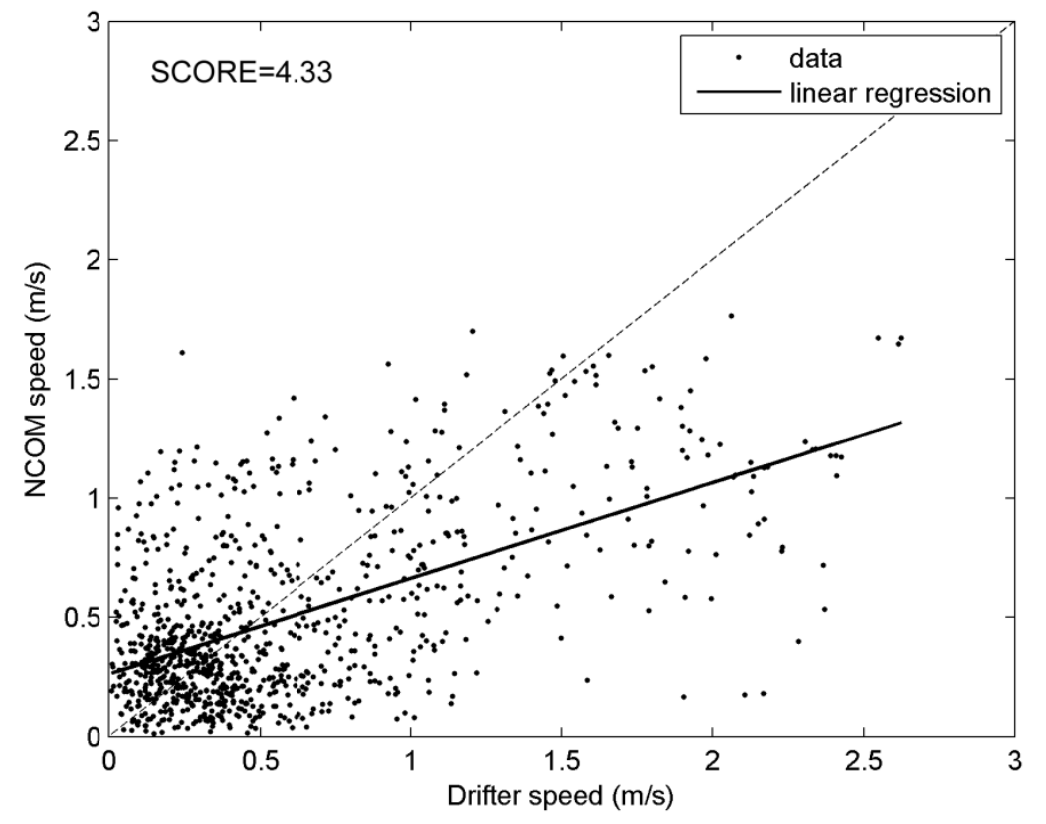

Figure A11: comparison of NCOM data with measurement data for E4 region.

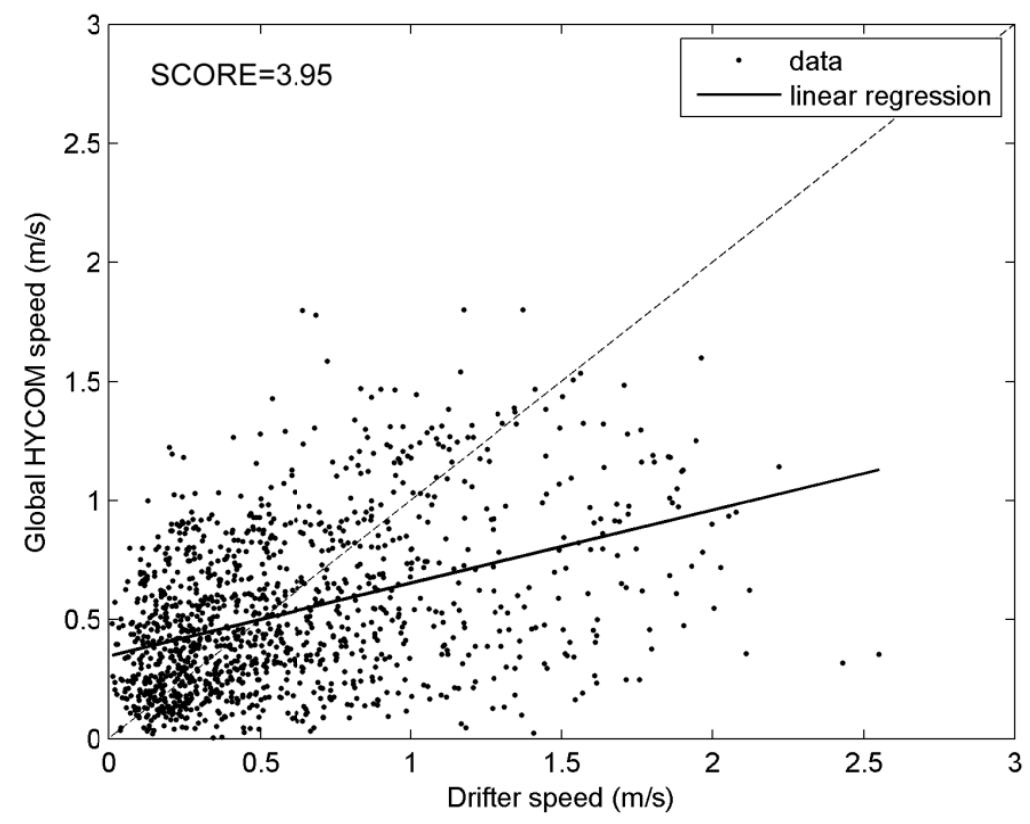

Figure A12: comparison of Global HYCOM data with measurement data for E5 region. 


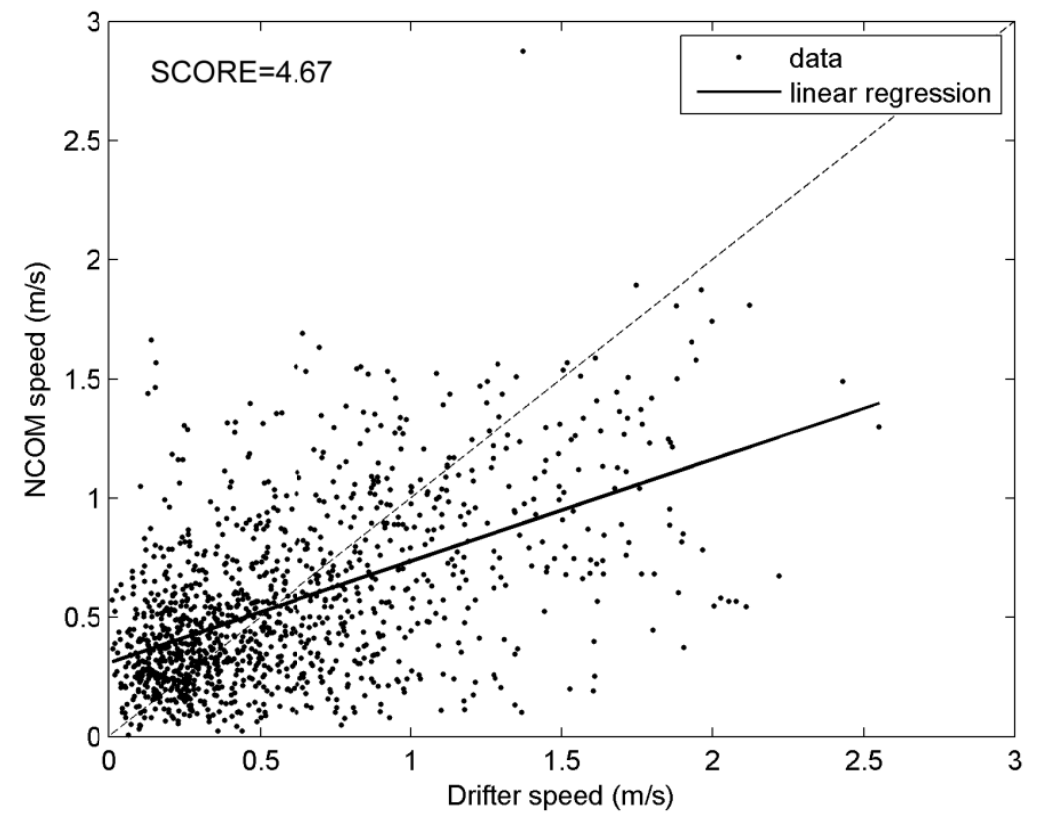

Figure A13: comparison of NCOM data with measurement data for E5 region.

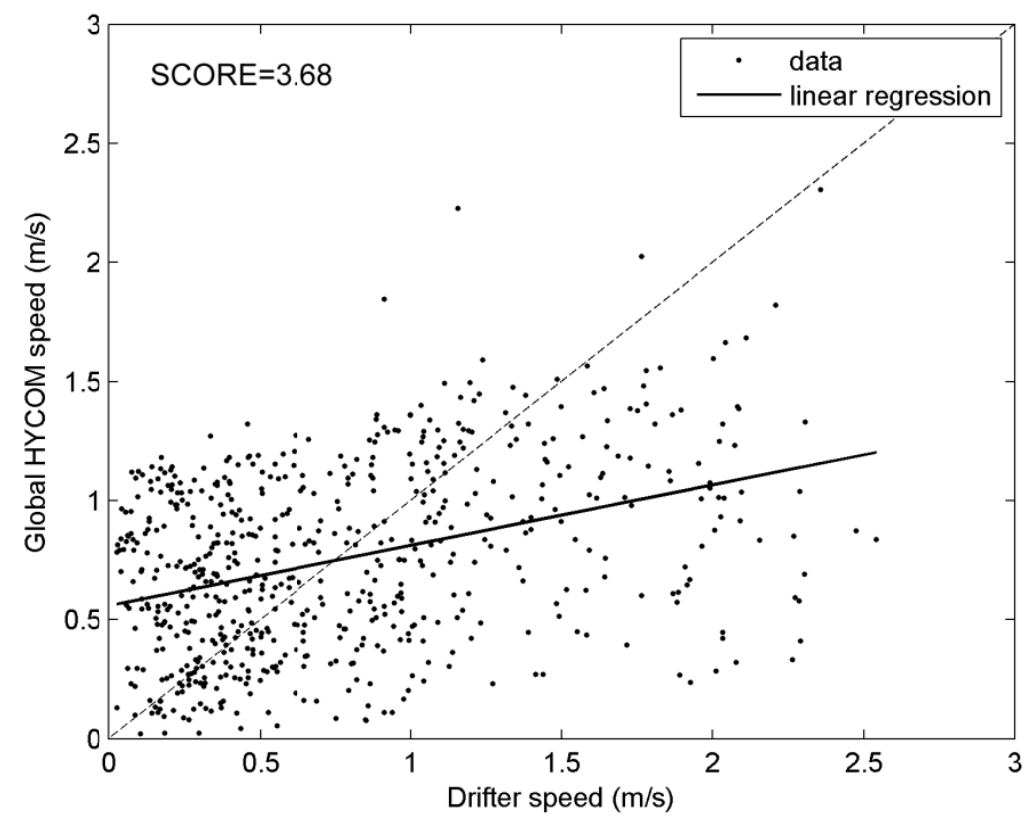

Figure A14: comparison of Global HYCOM data with measurement data for E6 region. 


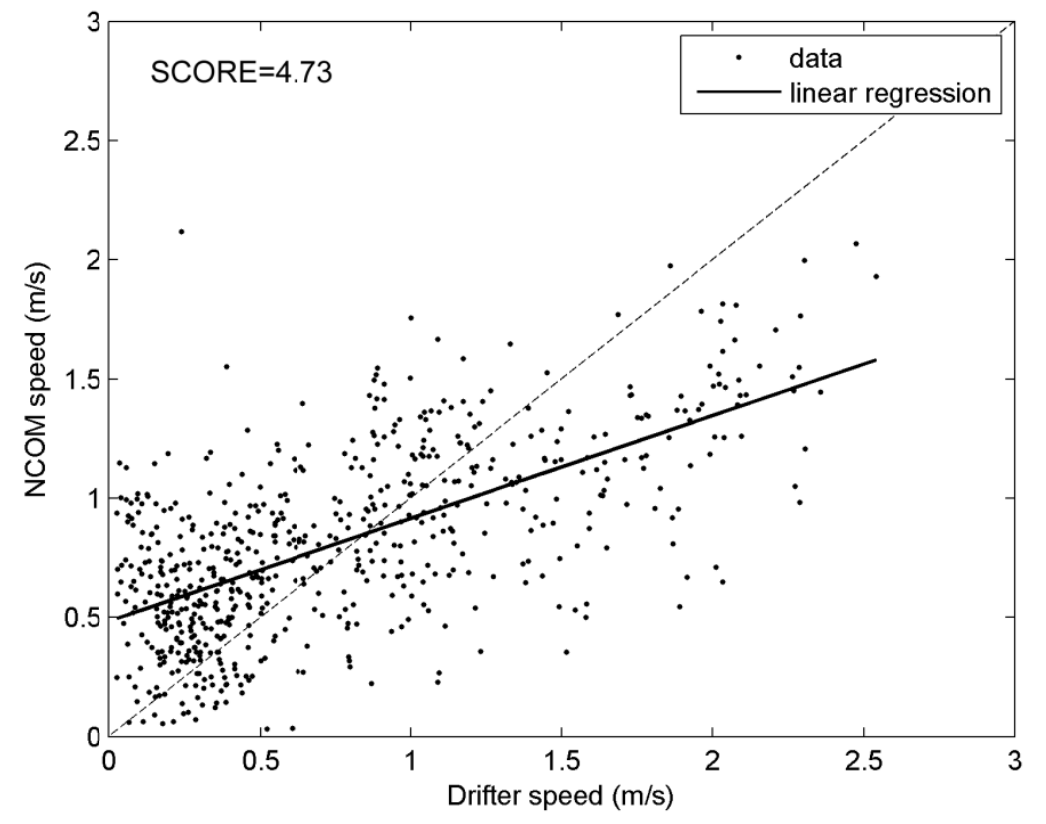

Figure A15: comparison of NCOM data with measurement data for E6 region.

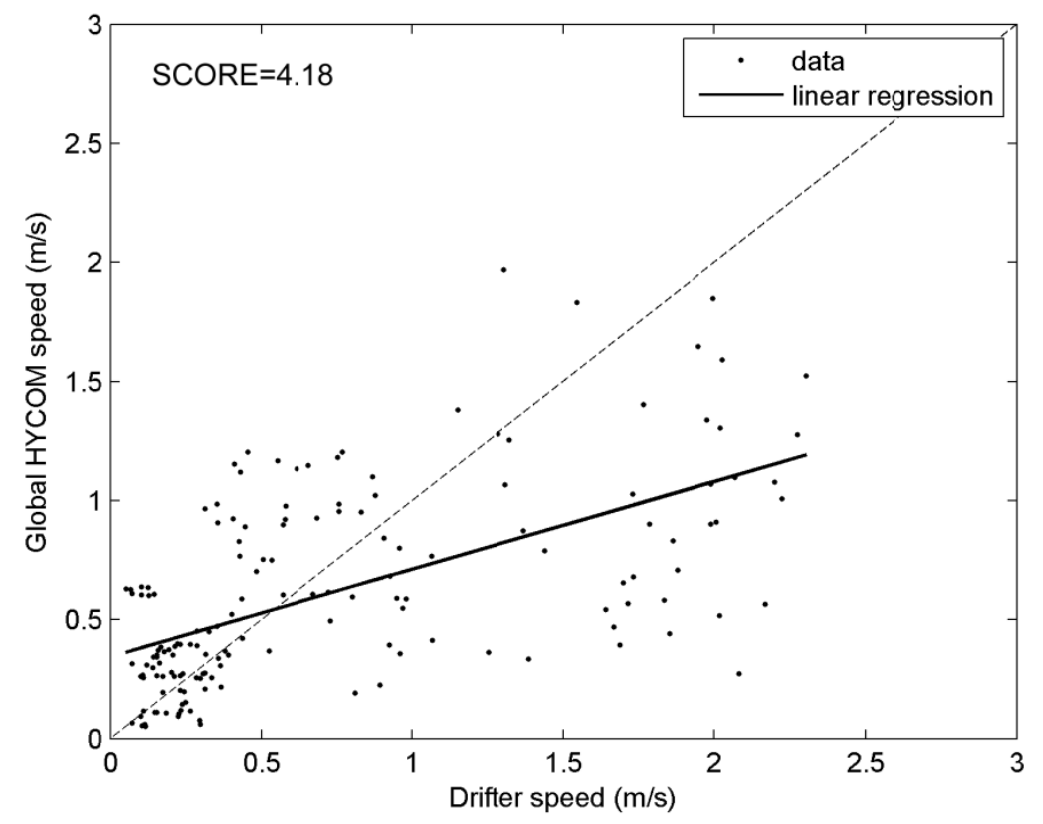

Figure A16: comparison of Global HYCOM data with measurement data for E7 region. 


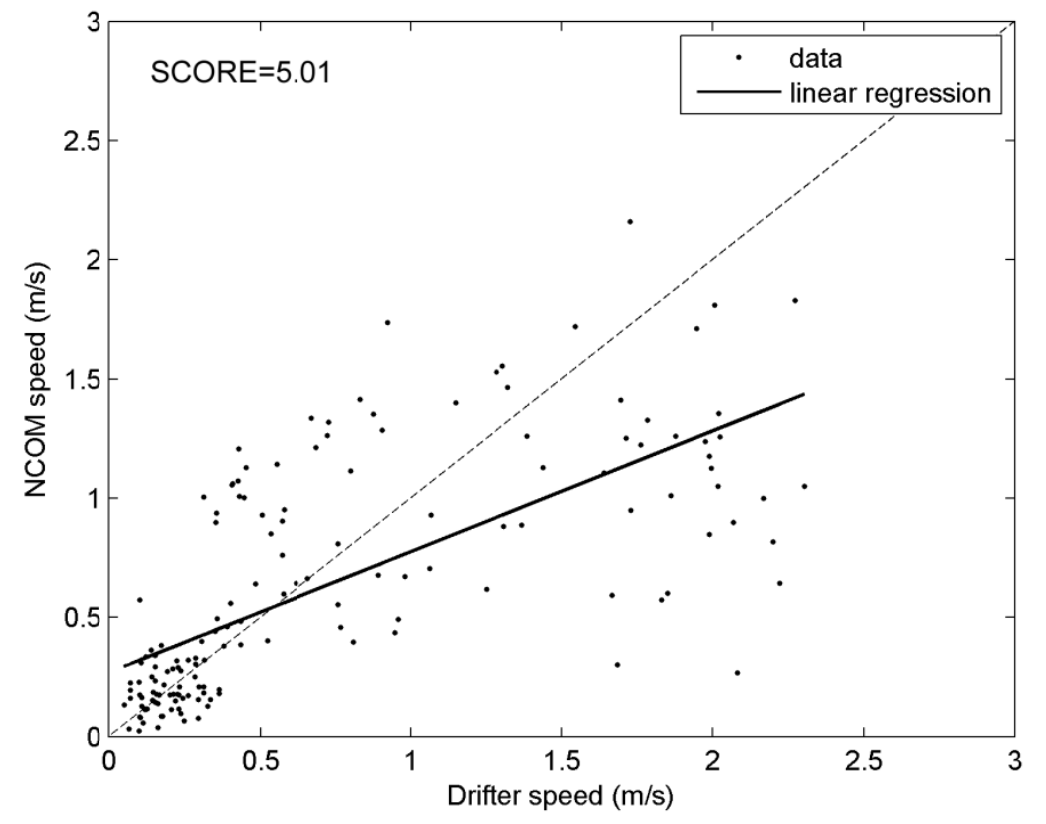

Figure A17: comparison of NCOM data with measurement data for E7 region.

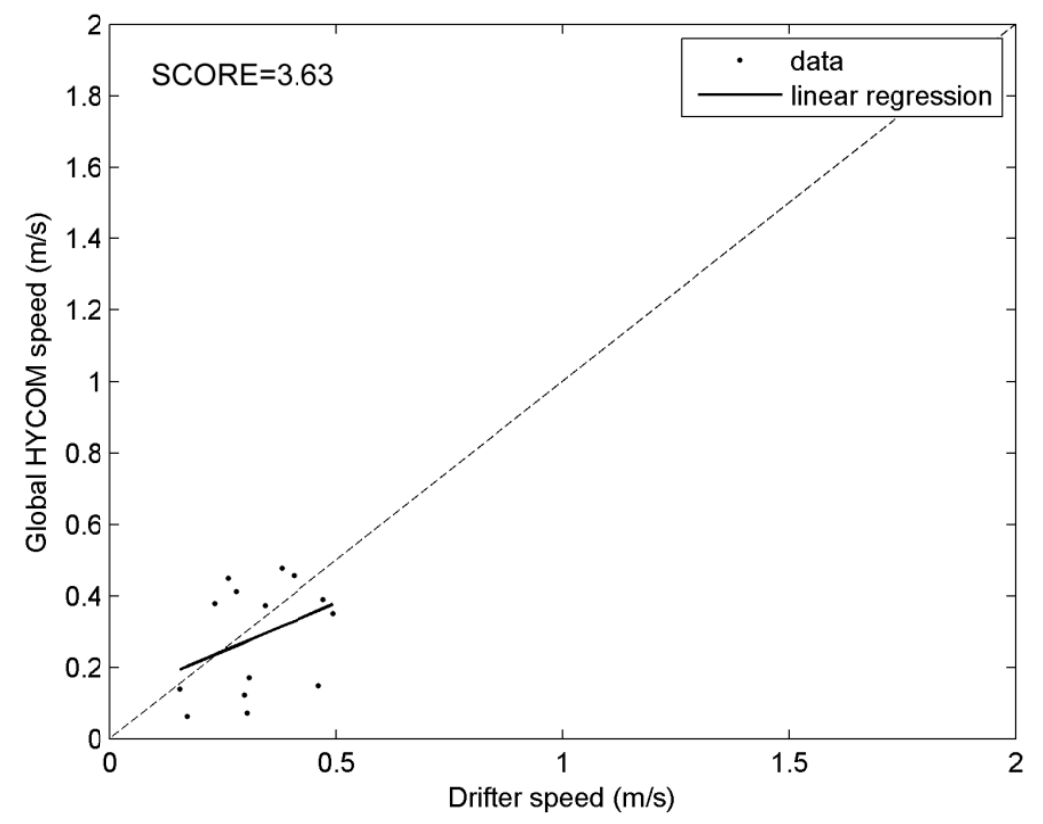

Figure A18: comparison of Global HYCOM data with measurement data for E8 region. 


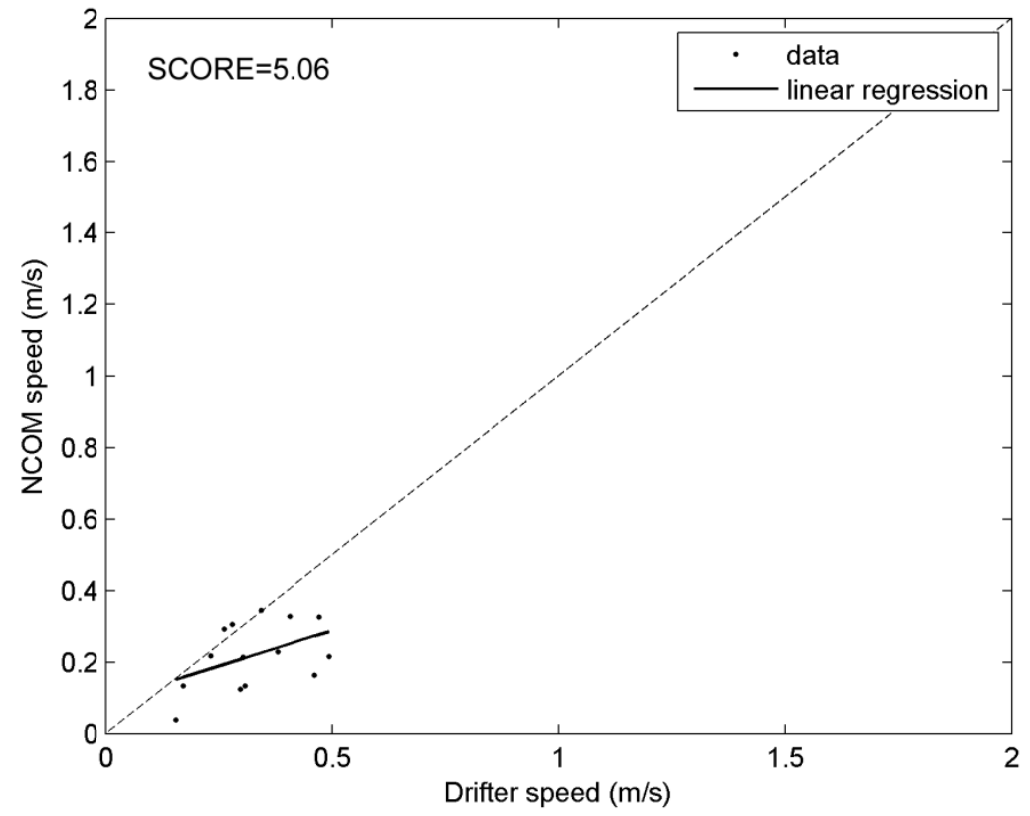

Figure A19: comparison of NCOM data with measurement data for E8 region.

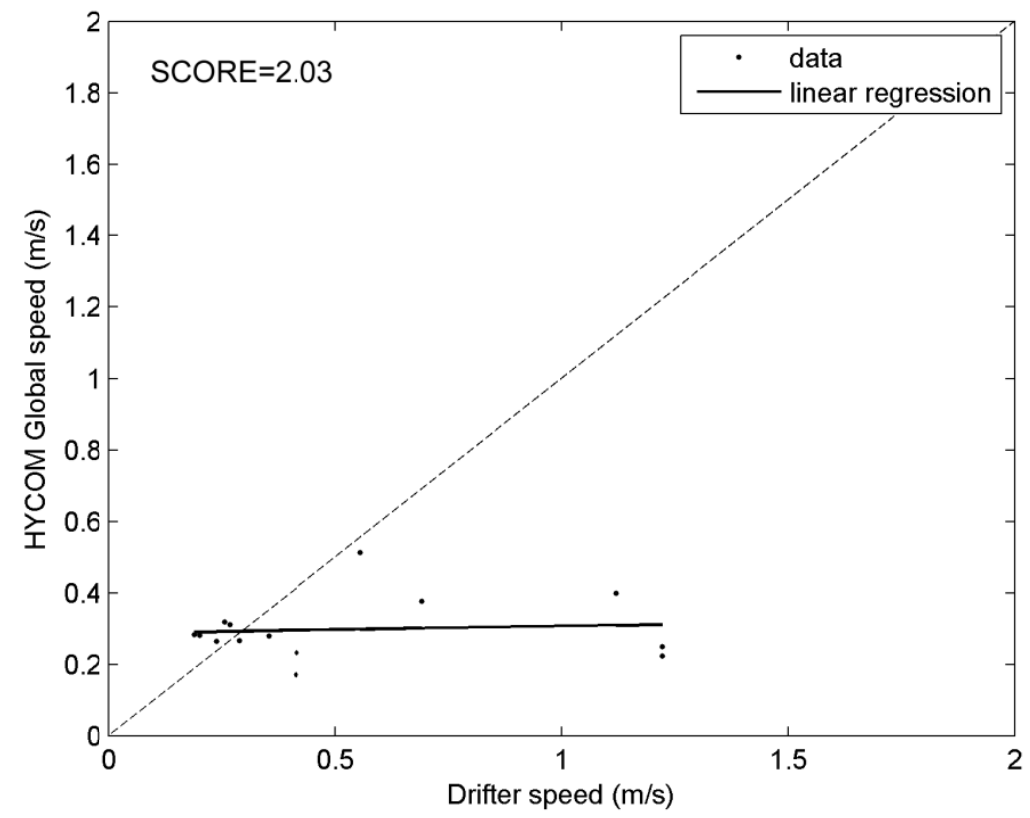

Figure A20: comparison of Global HYCOM data with measurement data for E9 region. 


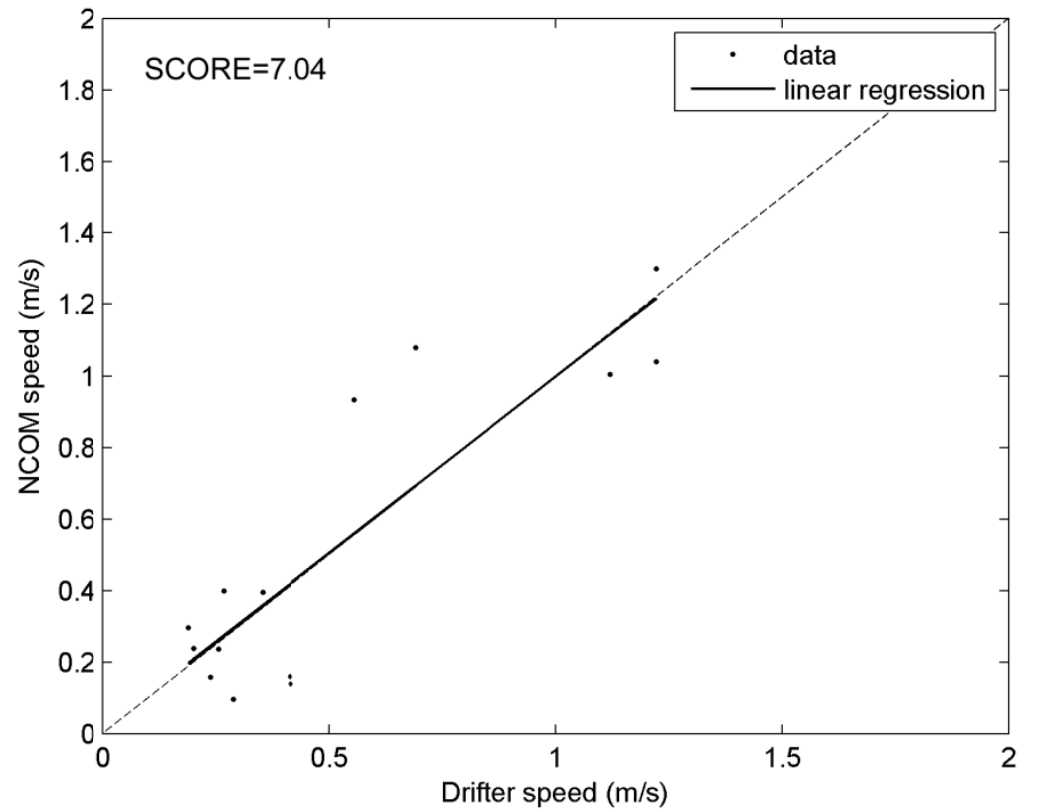

Figure A21: comparison of NCOM data with measurement data for E9 region. 